\title{
Testing grain-surface chemistry in massive hot-core regions ${ }^{\star}$
}

\author{
S. E. Bisschop ${ }^{1}$, J. K. Jørgensen ${ }^{2}$, E. F. van Dishoeck ${ }^{1}$, and E. B. M. de Wachter ${ }^{1}$ \\ 1 Leiden Observatory, Leiden University, PO Box 9513, 2300 RA Leiden, The Netherlands \\ e-mail: bisschop@strw.leidenuniv.nl \\ 2 Harvard-Smithsonian Center for Astrophysics, 60 Garden Street MS42, MA 02138, USA
}

Received 4 July 2006 / Accepted 29 January 2007

ABSTRACT

\begin{abstract}
Aims. We study the chemical origin of a set of complex organic molecules thought to be produced by grain surface chemistry in high mass young stellar objects (YSOs).

Methods. A partial submillimeter line-survey was performed toward 7 high-mass YSOs aimed at detecting $\mathrm{H}_{2} \mathrm{CO}, \mathrm{CH}_{3} \mathrm{OH}, \mathrm{CH}_{2} \mathrm{CO}$, $\mathrm{CH}_{3} \mathrm{CHO}, \mathrm{C}_{2} \mathrm{H}_{5} \mathrm{OH}, \mathrm{HCOOH}, \mathrm{HNCO}$ and $\mathrm{NH}_{2} \mathrm{CHO}$. In addition, lines of $\mathrm{CH}_{3} \mathrm{CN}, \mathrm{C}_{2} \mathrm{H}_{5} \mathrm{CN}, \mathrm{CH}_{3} \mathrm{CCH}, \mathrm{HCOOCH}_{3}$, and $\mathrm{CH}_{3} \mathrm{OCH}_{3}$ were observed. Rotation temperatures and beam-averaged column densities are determined. To correct for beam dilution and determine abundances for hot gas, the radius and $\mathrm{H}_{2}$ column densities of gas at temperatures $>100 \mathrm{~K}$ are computed using $850 \mu \mathrm{m}$ dust continuum data and source luminosity.

Results. Based on their rotation diagrams, molecules can be classified as either cold $(<100 \mathrm{~K})$ or hot $(>100 \mathrm{~K})$. This implies that complex organics are present in at least two distinct regions. Furthermore, the abundances of the hot oxygen-bearing species are correlated, as are those of $\mathrm{HNCO}$ and $\mathrm{NH}_{2} \mathrm{CHO}$. This is suggestive of chemical relationships within, but not between, those two groups of molecules.

Conclusions. The most likely explanation for the observed correlations of the various hot molecules is that they are "first generation" species that originate from solid-state chemistry. This includes $\mathrm{H}_{2} \mathrm{CO}, \mathrm{CH}_{3} \mathrm{OH}, \mathrm{C}_{2} \mathrm{H}_{5} \mathrm{OH}, \mathrm{HCOOCH}, \mathrm{CH}_{3} \mathrm{OCH}_{3}, \mathrm{HNCO}, \mathrm{NH}_{2} \mathrm{CHO}$, and possibly $\mathrm{CH}_{3} \mathrm{CN}$, and $\mathrm{C}_{2} \mathrm{H}_{5} \mathrm{CN}$. The correlations between sources implies very similar conditions during their formation or very similar doses of energetic processing. Cold species such as $\mathrm{CH}_{2} \mathrm{CO}, \mathrm{CH}_{3} \mathrm{CHO}$, and $\mathrm{HCOOH}$, some of which are seen as ices along the same lines of sight, are probably formed in the solid state as well, but appear to be destroyed at higher temperatures. A low level of non-thermal desorption by cosmic rays can explain their low rotation temperatures and relatively low abundances in the gas phase compared to the solid state. The $\mathrm{CH}_{3} \mathrm{CCH}$ abundances can be fully explained by low temperature gas phase chemistry. No cold $\mathrm{N}$-containing molecules are found.
\end{abstract}

Key words. astrochemistry - line: identification - methods: observational - stars: formation - ISM: abundances - ISM: molecules

\section{Introduction}

A characteristic stage of high-mass star formation is the hot core phase where high abundances of complex molecules are found in the gas-phase and in the ice mantles around the dust grains in the cold extended envelope (e.g., Millar 1996; Ikeda et al. 2001; Boogert \& Ehrenfreund 2004). The existence of both ices and gas-phase molecules around the same high-mass protostars suggests that the envelopes have temperatures that range from $>200 \mathrm{~K}$ in the inner region to as low as $10 \mathrm{~K}$ in the cold outer part (e.g., van der Tak et al. 2000; Gibb et al. 2000b; Ikeda et al. 2001). Together the submillimeter and infrared data indicate that there is a rich chemistry which involves interactions between gas and grain-surface species. The precise origin of complex molecules is still heavily debated: are they "first generation" species formed on the grains during the cold collapse phase (e.g., Tielens \& Charnley 1997), or "second generation" species produced by high-temperature gas phase reactions following ice evaporation (e.g., Millar et al. 1991; Charnley et al. 1992; Charnley 1995)? The aim of this work is to test the formation schemes of key complex organic molecules by presenting submillimeter observations of a sample of high-mass cores using the same instrument and frequency settings.

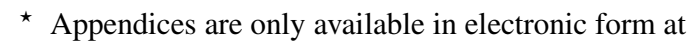
http://www . aanda.org
High column densities of the organic molecules $\mathrm{CH}_{3} \mathrm{OH}$, $\mathrm{CH}_{4}, \mathrm{HCOOH}, \mathrm{OCN}^{-}$and potentially $\mathrm{H}_{2} \mathrm{CO}$ have been detected in ice mantles in the cold outer envelopes of high-mass young stellar objects (YSOs) (Gibb et al. 2004). Abundances for some ice species such as $\mathrm{CH}_{3} \mathrm{OH}$ and $\mathrm{OCN}^{-}$are large, up to $30 \%$ with respect to $\mathrm{H}_{2} \mathrm{O}$ ice or $3 \times 10^{-5}$ with respect to $\mathrm{H}_{2}$ (Brooke et al. 1999; Dartois et al. 1999; Pontoppidan et al. 2003; van Broekhuizen et al. 2005). Information on minor species such as $\mathrm{CH}_{4}, \mathrm{HCOOH}, \mathrm{H}_{2} \mathrm{CO}$ and $\mathrm{CH}_{3} \mathrm{CHO}$ is more limited, but they appear to have constant abundances at the level of a few \% with respect to $\mathrm{H}_{2} \mathrm{O}$ ice (Schutte et al. 1999; Keane et al. 2001; Gibb et al. 2004). More complex species with abundances lower than $0.1 \%$ cannot be detected by infrared observations because of their small optical depth. Moreover, features of the same functional groups such as $\mathrm{C}-\mathrm{H}$ and $\mathrm{O}-\mathrm{H}$ groups overlap, so that they can only be assigned to a class of molecules rather than to a specific species. Deep submillimeter surveys in the gas phase are more sensitive to detect these minor species.

The abundances of the detected ice species are so large that they cannot be produced by pure gas-phase processes but must be formed on the grains. A proposed scheme for the formation of various "first generation" molecules on grains (based on Tielens \& Charnley 1997) is shown in Fig. 1. Through successive addition of $\mathrm{H}, \mathrm{C}, \mathrm{O}$, and $\mathrm{N}$ to $\mathrm{CO}$, many complex organic species are formed. The outcome depends on the relative gas-phase 


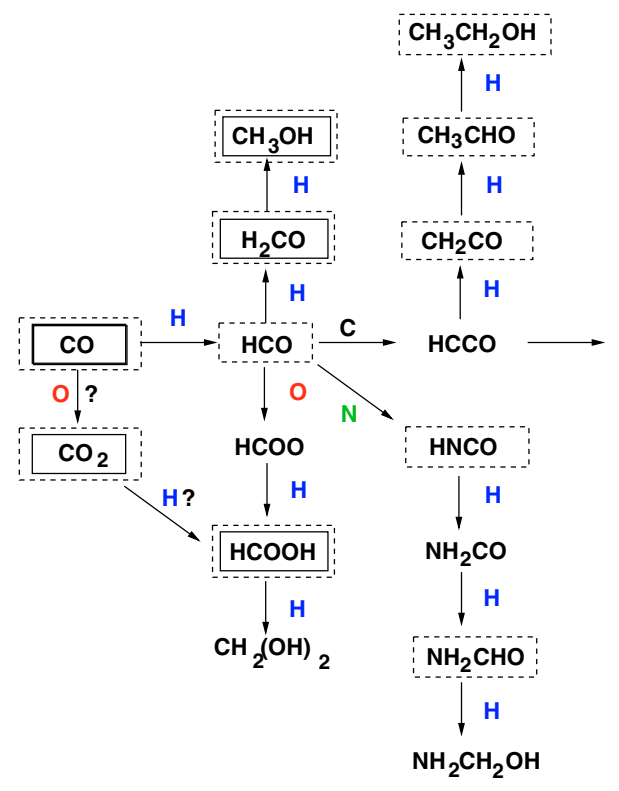

Fig. 1. Grain-surface chemistry routes involving hydrogenation of CO. Solid rectangular boxes contain molecules which have been detected in interstellar ices, whereas dashed boxes indicate molecules that have been detected in the gas phase (based on Tielens \& Charnley 1997).

abundances of the atoms, their mobility on the grains, and the $\mathrm{CO}$ abundance. If the formation routes depicted in Fig. 1 are indeed valid and proceed under similar initial conditions, this would imply that the molecules in this scheme are related and that they will have correlated abundance ratios upon evaporation. For different initial conditions, the relative abundances will vary from source to source; the $\mathrm{H}_{2} \mathrm{CO} / \mathrm{CH}_{3} \mathrm{OH}$ ratio depends for example on ice temperature, and the $\mathrm{C}_{2} \mathrm{H}_{5} \mathrm{OH} / \mathrm{CH}_{3} \mathrm{OH}$ ratio on the atomic carbon abundance. In contrast, gas phase formation of second generation species is expected to cause time-dependent abundance variations where "first" and "second generation" as well as non-related "first generation" species are uncorrelated. A combination of rotation temperatures and relative abundances between species can determine which species are part of the same chemical group. To test the basic grain surface chemistry scheme, our survey has targeted emission lines of all species depicted in Fig. 1. Only $\mathrm{CO}_{2}$, the unstable species $\mathrm{HCOO}, \mathrm{HCCO}$, and $\mathrm{NH}_{2} \mathrm{CO}$, as well as $\mathrm{CH}_{2}(\mathrm{OH})_{2}$ and $\mathrm{NH}_{2} \mathrm{CH}_{2} \mathrm{OH}$ for which no laboratory frequencies are available, are lacking.

Many line surveys have been performed to study the molecular composition of high mass star forming regions (e.g., Blake et al. 1987; Sutton et al. 1995; Helmich \& van Dishoeck 1997; Schilke et al. 1997; Nummelin et al. 2000; Gibb et al. 2000a; Schilke et al. 2001). However, they often cover a single atmospheric window, each at a different telescope. These data thus probe a variety of excitation conditions with different beamsizes, which complicates the comparison of column densities and abundances between different sources. Our observing strategy employs deep, partial line surveys in multiple atmospheric windows rather than complete, unbiased line surveys. Partial line surveys exist, but are usually targeted at a few specific molecules such as $\mathrm{CH}_{3} \mathrm{OH}$ (van der Tak et al. 2000) and HNCO (Zinchenko et al. 2000). The advantage of our survey is that it efficiently covers lines with a large range of excitation temperatures and that the settings and telescopes are the same for all sources. The lines of the molecules targeted in this work are sufficiently strong so that no complete line survey is needed for their identification. Compared with previous studies such as those by
Table 1. Positions, luminosities, distances and typical line width of selected sources.

\begin{tabular}{lcclll}
\hline \hline Sources & $\alpha(2000)$ & $\delta(2000)$ & $\begin{array}{l}L^{a} \\
{\left[10^{5} L_{\odot}\right]}\end{array}$ & $\begin{array}{l}d^{b} \\
{[\mathrm{kpc}]}\end{array}$ & $\begin{array}{l}\Delta V \\
\mathrm{~km} \mathrm{~s}^{-1}\end{array}$ \\
\hline AFGL 2591 & $20: 29: 24.6$ & $+40: 11: 19$ & 0.2 & 1.0 & 3 \\
G24.78 & $18: 36: 12.6$ & $-07: 12: 11$ & 7.9 & 7.7 & 6 \\
G75.78 & $20: 21: 44.1$ & $+37: 26: 40$ & 1.9 & 4.1 & 4 \\
NGC 6334 IRS1 & $17: 20: 53.0$ & $-35: 47: 02$ & 1.1 & 1.7 & 5 \\
NGC 7538 IRS1 & $23: 13: 45.4$ & $+61: 28: 12$ & 1.3 & 2.8 & 4 \\
W 3(H 2 O) & $02: 27: 04.6$ & $+61: 52: 26$ & 0.2 & 2.0 & 6 \\
W 33A & $18: 14: 38.9$ & $-17: 52: 04$ & 1.0 & 4.0 & 5 \\
\hline
\end{tabular}

${ }^{a} \overline{\text { From van der Tak et al. (2000), except for G24.78 and G75.78 where }}$ the luminosities are from Zhang (2005) and Churchwell et al. (1990) respectively. ${ }^{b}$ From van der Tak et al. (2000), except for G24.78 and G75.78 which are based on Forster \& Caswell (1989) and Churchwell et al. (1990) respectively.

Ikeda et al. (2001) and Zinchenko et al. (2000) our observations cover higher frequencies, which implies smaller beams and, for some species, lines from higher energy levels.

This paper is organized as follows: Sect. 2 presents the selection of sources plus frequencies, and the observational techniques, Sect. 3 presents the data reduction techniques, Sect. 4 the results on the derived rotation temperatures plus column densities and compares those to other high mass YSOs. In Sect. 5 the correlations of the abundances between different molecular species are determined. Section 6 discusses the origin of the constant abundance ratios and compares these to astrochemical models, and finally in Sect. 7 the main conclusions are summarized.

\section{Observations}

\subsection{Source sample}

The basis for this survey is formed by a sample of 7 high-mass young stellar objects summarized in Table 1. The sources are known to have hot gas in their inner envelope where ices have evaporated and they either show complex organic molecules due to hot core chemistry or are on the verge of reaching that stage (e.g., Boonman et al. 2001). Most of the sources were selected from the sample of high mass YSOs studied in detail by van der Tak et al. (2000) based on the following criteria: (i) narrow line widths $\left(\lesssim 6 \mathrm{~km} \mathrm{~s}^{-1}\right)$ to minimize line confusion; (ii) detection of $\mathrm{CH}_{3} \mathrm{OH}$ lines, where the strongest lines in the $7_{K}-6_{K} 338 \mathrm{GHz}$ band should have main-beam temperatures of $\geq 1 \mathrm{~K}$; (iii) distances $<5 \mathrm{kpc}$ and (iv) visible from the James Clerk Maxwell Telescope (JCMT) ${ }^{1}$. Preference was also given to sources for which infrared absorption line data of ices are available. The source list additionally includes G75.78 and G24.78. G75.78 has been previously observed by Hatchell et al. (1998) and obeys all previously mentioned selection criteria. G24.78 has a distance $>5 \mathrm{kpc}$, but was selected based on the large line intensities of $\mathrm{CH}_{3} \mathrm{CN}$ detected by Beltrán et al. (2005). Trial JCMT observations of the $7_{K}-6_{K} 338 \mathrm{GHz} \mathrm{CH}_{3} \mathrm{OH}$ band confirmed that the strongest lines are $>1 \mathrm{~K}$ and $\mathrm{G} 24.78$ was therefore added to the sample.

1 The James Clerk Maxwell Telescope is operated by the Joint Astronomy Centre, on behalf of the Particle Physics and Astronomy Research Council of the UK, The Netherlands Organization for Scientific Research and the National Research Council of Canada. Project IDs are m04bn12, m05an05, and m05bn11. 
Table 2. List of observed frequency settings and molecular lines covered at the JCMT and IRAM.

\begin{tabular}{|c|c|c|c|c|c|}
\hline Molecule & $\begin{array}{l}\text { Freq. } \\
\text { [GHz] }\end{array}$ & $\begin{array}{l}E_{\mathrm{u}} \\
{[\mathrm{K}]}\end{array}$ & $\begin{array}{l}\mu^{2} S \\
{\left[\mathrm{D}^{2}\right]}\end{array}$ & Transition & Additional molecules \\
\hline \multicolumn{6}{|c|}{ JCMT } \\
\hline \multirow[t]{2}{*}{$\mathrm{HCO}$} & 346.725 & 41.61 & 7.341 & $4_{0,4,5,4}-3_{0,3,4,3}$ & $\mathrm{C}_{2} \mathrm{H}_{5} \mathrm{CN} / \mathrm{C}_{2} \mathrm{H}_{5} \mathrm{OH} / \mathrm{H}_{2} \mathrm{C}^{18} \mathrm{O} / \mathrm{HCOOCH}_{3}$ \\
\hline & 348.778 & 172.36 & 5.313 & $4_{2,3,4,4}-3_{2,2,3,3}$ & $\mathrm{HCOOCH}_{3} / \mathrm{CH}_{3}{ }^{13} \mathrm{CN} / \mathrm{C}_{2} \mathrm{H}_{5} \mathrm{OH}$ \\
\hline \multirow[t]{2}{*}{$\mathrm{H}_{2} \mathrm{CO}$} & 218.222 & 20.96 & 16.2985 & $3_{0,3}-20,2$ & $\mathrm{CH}_{3} \mathrm{OH} / \mathrm{C}_{2} \mathrm{H}_{5} \mathrm{CN} / \mathrm{HCOOCH} \mathrm{H}_{3}$ \\
\hline & 364.275 & 158.42 & 52.1647 & $5_{3,3}-4,2$ & $\mathrm{C}_{2} \mathrm{H}_{5} \mathrm{OH}$ \\
\hline $\mathrm{CH}_{3} \mathrm{OH}$ & 338.344 & 5.3431 & 69.36 & $7_{3,4,0}-6_{3,4,0}$ & $\mathrm{HCOOCH}_{3}$ \\
\hline \multirow[t]{3}{*}{$\mathrm{CH}_{2} \mathrm{CO}$} & 240.187 & 88.01 & 71.489 & $12_{1,12}-11_{1,11}$ & $\mathrm{CH}_{3} \mathrm{OH} / \mathrm{H}_{2} \mathrm{C}^{18} \mathrm{O} / \mathrm{C}_{2} \mathrm{H}_{5} \mathrm{CN} / \mathrm{CH}_{3} \mathrm{CN} / \mathrm{HCOOCH}_{3}$ \\
\hline & 220.178 & 76.48 & 65.434 & $11_{1,11}-10_{1,10}$ & $\mathrm{CH}_{3}{ }^{13} \mathrm{CN} /{ }^{13} \mathrm{CH}_{3} \mathrm{OH} / \mathrm{HCOOCH} \mathrm{H}_{3}$ \\
\hline & 222.298 & 182.26 & 61.0830 & $11_{3,9}-10_{3,8}$ & $\mathrm{CH}_{3} \mathrm{OCH}_{3} / \mathrm{CH}_{3} \mathrm{CCH} / \mathrm{HCOOCH}_{3}$ \\
\hline $\mathrm{CH}_{3} \mathrm{CHO}$ & 226.590 & 71.30 & 77.779 & $12_{0,12}-11_{0,11}$ & $\mathrm{HCOOCH}_{3}$ \\
\hline \multirow[t]{3}{*}{$\mathrm{C}_{2} \mathrm{H}_{5} \mathrm{OH}$} & 230.991 & 85.53 & 48.953 & $16_{5,11}-16_{4,12}$ & $\mathrm{CH}_{3} \mathrm{OH} / \mathrm{C}_{2} \mathrm{H}_{5} \mathrm{CN}$ \\
\hline & 347.916 & 250.88 & 66.314 & $20_{4,17,0}-19_{4,16,0}$ & $\mathrm{C}_{2} \mathrm{H}_{5} \mathrm{CN} / \mathrm{HCOOCH}{ }_{3} / \mathrm{H}_{2} \mathrm{C}^{18} \mathrm{O}$ \\
\hline & 339.979 & 57.89 & 17.724 & $9_{4,6}-8_{3,5}$ & $\mathrm{C}_{2} \mathrm{H}_{5} \mathrm{CN}$ \\
\hline \multirow[t]{2}{*}{$\mathrm{HNCO}$} & 219.798 & 58.02 & 28.112 & $10_{0,10,11}-9_{0,9,10}$ & $\mathrm{H}_{2}{ }^{13} \mathrm{CO} / \mathrm{C}_{2} \mathrm{H}_{5} \mathrm{CN}$ \\
\hline & 352.898 & 187.25 & 43.387 & $16_{1,15,17}-15_{1,14,16}$ & $\mathrm{C}_{2} \mathrm{H}_{5} \mathrm{CN} / \mathrm{C}_{2} \mathrm{H}_{5} \mathrm{OH} / \mathrm{HCOOCH} \mathrm{H}_{3}$ \\
\hline $\mathrm{HN}^{13} \mathrm{CO}$ & 240.881 & 112.53 & 30.4313 & $11_{1,11,12}-10_{1,10,11}$ & $\mathrm{CH}_{3} \mathrm{OCH}_{3} / \mathrm{CH}_{3} \mathrm{OH} / \mathrm{HNCO}$ \\
\hline \multirow[t]{3}{*}{$\mathrm{NH}_{2} \mathrm{CHO}$} & 339.904 & 245.79 & 539.342 & $16_{6,11}-15_{6,10}$ & same setting as $\mathrm{C}_{2} \mathrm{H}_{5} \mathrm{OH}$ \\
\hline & 340.491 & 165.59 & 605.520 & $16_{3,14}-15_{3,13}$ & same setting as $\mathrm{CH}_{2} \mathrm{CO}$ \\
\hline & 345.183 & 151.59 & 664.219 & $17_{0,17}-16_{0,16}$ & $\mathrm{HCOOCH}_{3} / \mathrm{C}_{2} \mathrm{H}_{5} \mathrm{OH} /{ }^{13} \mathrm{CH}_{3} \mathrm{OH}$ \\
\hline \multirow[t]{5}{*}{$\mathrm{HCOOH}$} & 225.238 & 88.02 & 17.734 & $10_{3,8}-9_{3,7}$ & $\mathrm{H}_{2} \mathrm{CO} / \mathrm{HCOOCH}_{3} / \mathrm{CH}_{3} \mathrm{OCH}_{3} /{ }^{13} \mathrm{CH}_{3} \mathrm{OH}$ \\
\hline & 338.144 & 180.53 & 27.1548 & $15_{4,12}-14_{4,11}$ & $\mathrm{CH}_{3} \mathrm{OH} / \mathrm{C}_{2} \mathrm{H}_{5} \mathrm{OH}$ \\
\hline & 346.719 & 143.92 & 28.726 & $15_{2,13}-14_{2,12}$ & same setting as $\mathrm{HCO}$ \\
\hline & 356.137 & 158.67 & 30.6650 & $16_{2,15}-15_{2,14}$ & $\mathrm{NH}_{2} \mathrm{CHO} / \mathrm{HCOOCH} \mathrm{H}_{3} / \mathrm{C}_{2} \mathrm{H}_{5} \mathrm{CN} / \mathrm{H}_{2}{ }^{13} \mathrm{CO} / \mathrm{CH}_{3} \mathrm{OH}$ \\
\hline & & & & IRAM & \\
\hline \multirow[t]{4}{*}{$\mathrm{CH}_{2} \mathrm{CO}$} & 81.586 & 22.86 & 22.4974 & $4_{1,3}-3_{1,2}$ & \\
\hline & 140.127 & 39.97 & 41.1295 & $7_{1,7}-6_{1,6}$ & \\
\hline & 244.712 & 89.42 & 71.4841 & $12_{1,11}-11_{1,10}$ & \\
\hline & 262.619 & 140.63 & 25.3788 & $13_{2,12}-12_{2,11}$ & \\
\hline \multirow[t]{4}{*}{$\mathrm{CH}_{3} \mathrm{CHO}$} & 98.901 & 16.51 & 31.2087 & $5_{1,4}-4_{1,3}$ & \\
\hline & 112.249 & 21.14 & 37.9261 & $6,6-5$ & \\
\hline & 149.507 & 34.59 & 51.1868 & $8_{1,8}-7,7$ & \\
\hline & 168.093 & 42.66 & 57.7848 & $9_{1,9}-8_{1,8}$ & \\
\hline \multirow[t]{4}{*}{$\mathrm{HCOOH}$} & 223.916 & 71.93 & 18.7011 & $10_{2,9}-9_{2,8}$ & \\
\hline & 247.514 & 150.71 & 17.0080 & $11_{5,6 / 7}-10_{5,5 / 6}$ & \\
\hline & 257.975 & 83.91 & 23.2080 & $12_{1,12}-11_{1,11}$ & \\
\hline & 262.103 & 82.77 & 23.2998 & $12_{0,12}-11_{0,11}$ & \\
\hline
\end{tabular}

\subsection{Observed frequency settings}

The observed frequencies are shown in Table 2 and were selected based on whether they contained at least one strong line for a target molecule as well as lines of other interesting species. Strong lines of target molecules were chosen because of their high main-beam temperatures and minimum line confusion in line surveys of Orion A by Sutton et al. (1985) and Orion KL by Schilke et al. (1997) at $230 \mathrm{GHz}$ and $345 \mathrm{GHz}$ respectively. The aim was to cover at least two transitions for each molecule to determine rotation temperatures: one with $E_{\mathrm{u}}>100 \mathrm{~K}$, and one with $E_{\mathrm{u}}<100 \mathrm{~K}$. Table 2 shows the additional lines present in the rest frequency side band. The molecular species detected in the image band differed, because it varied per source. Finally, for $\mathrm{H}_{2} \mathrm{CO}, \mathrm{CH}_{3} \mathrm{OH}$, and $\mathrm{HNCO}$ lines of the isotopic species were observed to determine the optical depth of the main isotopologues.

An additional number of settings have been observed for $\mathrm{CH}_{2} \mathrm{CO}, \mathrm{CH}_{3} \mathrm{CHO}$, and $\mathrm{HCOOH}$ with the Institut de Radioastronomie Millimétrique $^{2}$ (IRAM) $30 \mathrm{~m}$ telescope for

${ }^{2}$ The IRAM $30 \mathrm{~m}$ telescope is operated by the Institut de Radioastronomie Millimétrique on behalf of the Centre National de la Recherche Scientifique of France, the Max Planck Gesellschaft of Germany, and Instituto Geográfico Nacional of Spain.
AFGL 2591, G75.78, NGC 7538 IRS1, and W 3( $\left.\mathrm{H}_{2} \mathrm{O}\right)$. The settings were chosen because of their high line strengths and low excitation temperatures. Combined with the JCMT settings, they allow for the determination of any cold component of these molecules.

\subsection{JCMT observations}

The frequencies given in the first part of Table 2 were observed for the 7 sources with the JCMT on Mauna Kea, Hawaii from August 2004 to January 2006. The beam size $\left(\theta_{\text {beam }}\right)$ is $20-21^{\prime \prime}$ for observations in the $230 \mathrm{GHz}$ band and $14^{\prime \prime}$ in the $345 \mathrm{GHz}$ band. The spectra were scaled from the observed antenna temperature scale, $T_{\mathrm{A}}^{*}$, to main beam temperatures, $T_{\mathrm{MB}}$, using main beam efficiencies $\eta_{\mathrm{MB}}$ of 0.69 and 0.63 at $230 \mathrm{GHz}$ and $345 \mathrm{GHz}$, respectively. The front-ends consisted of the facility receivers A3 and B3; the back-end was the Digital Autocorrelation Spectrometer (DAS), covering $500 \mathrm{MHz}$ instantaneous bandwidth with a spectral resolution of 312.5 and $625 \mathrm{kHz}$ respectively. Pointing was checked every $2 \mathrm{hrs}$ or whenever a new source was observed and was always within $3^{\prime \prime}$. To subtract atmospheric and instrumental backgrounds beam switching with a chop throw of $180^{\prime \prime}$ was used. We aimed for a $T_{\mathrm{rms}} \sim 20 \mathrm{mK}$ on the $T_{\mathrm{A}}^{*}$ scale when binned to a $\sim 1 \mathrm{~km} \mathrm{~s}^{-1}$ 
channel, which was obtained with integration times of $\sim 1 \mathrm{hr}$ at $230 \mathrm{GHz}$ and $2 \mathrm{hrs}$ at $345 \mathrm{GHz}$ dependent on weather. For NGC 6334 IRS1 the confusion limit was reached after 30 minutes of integration, however, at which point the observation was terminated. The absolute calibration is accurate to better than $15 \%$ from comparison to spectral line standards.

The JCMT B3 $345 \mathrm{GHz}$ receiver was operated in single side band mode to minimize line confusion. The A3 $230 \mathrm{GHz}$ receiver does not have the option of image sideband suppression. For line-rich sources like Orion (Sutton et al. 1985), it is difficult to assign a line to the correct sideband. For our sources the $230 \mathrm{GHz}$ spectra are not confusion limited except for NGC 6334 IRS1 (see Fig. 3). For NGC 6334 IRS1, pairs of spectra with $10 \mathrm{MHz}$ offsets were taken. This shifts lines in the image sideband by $20 \mathrm{MHz}$ with respect to those observed in the rest sideband making a unique identification possible.

\subsection{IRAM observations}

The frequencies given in the second part of Table 2 have been observed with the IRAM $30 \mathrm{~m}$ telescope. The beam size $\left(\theta_{\text {beam }}\right.$ in arcsec) is $29^{\prime \prime}$ at $86 \mathrm{GHz}, 17^{\prime \prime}$ at $140 \mathrm{GHz}$, and $10.5^{\prime \prime}$ at $235 \mathrm{GHz}$. The front-ends were the B100, C150, B230, and C270 facility receivers. The VESPA auto-correlator was used as the back-end, with a bandwidth of $120 \mathrm{MHz}$, and a channel spacing of $80 \mathrm{kHz}$. Pointing was checked every $1.5 \mathrm{hrs}$ and was always within 2-3". Atmospheric and instrumental backgrounds were subtracted through "wobbler" switching where the telescope alternately observes positions $+220^{\prime \prime}$ and $-220^{\prime \prime}$ away from the source. Integration times differed per source and depended on the atmospheric conditions, but were generally $30 \mathrm{~min}$ for AFGL 2591 and G75.78, and $1 \mathrm{hr}$ for NGC 7538 IRS1 and W $3\left(\mathrm{H}_{2} \mathrm{O}\right)$. All observations were converted to the main-beam temperature scale using $F_{\text {eff }} / B_{\text {eff }}$ of 0.78 at $86 \mathrm{GHz}$ to 0.46 at $260 \mathrm{GHz}$. Conveniently, all observations were performed in single-sideband mode.

\section{Data analysis}

\subsection{Rotation diagrams}

Line assignments were made by comparing the observed frequencies corrected for source velocity with the $\mathrm{JPL}^{3}, \mathrm{CDMS}^{4}$ and NIST ${ }^{5}$ catalogs. Possible assignments had to be within $\sim 1 \mathrm{MHz}$, unless the uncertainty of the frequencies in the catalogs was larger. For $\mathrm{NH}_{2} \mathrm{CHO}$, for example, lines were only assigned if multiple transitions were detected in the same spectrum.

Integrated intensities for the identified lines are given in Tables B.1-B.15. These were used to derive rotation temperatures and column densities through the rotation diagram method (Goldsmith \& Langer 1999) when three or more lines were detected over a sufficiently large energy range. The integrated main-beam temperatures are then related to the column density in the upper energy level by:

$\frac{N_{\mathrm{u}}}{g_{\mathrm{u}}}=\frac{3 k \int T_{\mathrm{MB}} \mathrm{d} V}{8 \pi^{3} v \mu^{2} S}$

\footnotetext{
3 http://spec.jpl.nasa.gov/ftp/pub/catalog/ catform.html

4 http://www .ph1. uni-koeln. de/vorhersagen/

5 http://physics.nist.gov/PhysRefData/

Micro/Html/contents.html
}

where $N_{\mathrm{u}}$ is the column density of the upper level, $g_{\mathrm{u}}$ is the degeneracy in the upper level, $k$ is Boltzmann's constant, $v$ is the transition frequency, $\mu$ is the dipole moment, and $S$ is the line strength. The total beam-averaged column density $N_{\mathrm{T}}$ in $\mathrm{cm}^{-2}$ can then be computed from:

$$
\frac{N_{\mathrm{u}}}{g_{\mathrm{u}}}=\frac{N_{\mathrm{T}}}{Q\left(T_{\mathrm{rot}}\right)} \mathrm{e}^{-E_{\mathrm{u}} / T_{\text {rot }}}
$$

where $Q\left(T_{\text {rot }}\right)$ is the rotational partition function, and $E_{\mathrm{u}}$ is the upper level energy in $\mathrm{K}$.

The calculated rotation temperatures and column densities can be used to make predictions for the intensities of other lines for a specific species. This was used as an independent check on line-assignments. If lines predicted to have high intensities in the observed frequency ranges are not seen, a detection is considered questionable. In the analysis, a correction has been made for the different beam-sizes at different frequencies. The assumption has been made that the maximum source size is equal to the smallest observed beam-size of the JCMT for all sources, i.e. $14^{\prime \prime}$. The calculations have also been performed assuming that the emission is extended with respect to the largest JCMT beamsize of $21^{\prime \prime}$. In this case, the rotation temperatures are higher and have larger errors by a factor of 2 . In reality, as will be discussed in Sect. 3.2, the hot core gas will be even more severely beam-diluted. Finally, the calibration uncertainties are taken into account in the rotation diagram analysis and are shown as errorbars on the rotation diagram plots.

When only very few lines were detected or only a small range in $E_{\mathrm{u}}$ was covered, no rotation temperatures or column densities could be derived. If the detection of the species was considered real, the column density was estimated assuming the rotation temperature to be the average for the same molecule in other sources. If no lines were detected, a $3 \sigma$ upper limit was determined. For lines from isotopologues, rotation temperatures equal to the main species were used to estimate the column densities.

A number of assumptions are implicitly made in the rotation diagram method. In short, they are that the excitation can be characterized by a single temperature $T_{\text {rot }}$ and that the lines are optically thin. Even though the first assumption will almost certainly be incorrect, the rotation diagram method does give the average excitation temperature of the region from which most of the molecular emission arises. If the lines are sub-thermally excited because the density is below the critical density $\left(n_{\mathrm{cr}}\right)$, the rotation temperature is a lower limit. This could also be partly responsible for the scatter in the rotation diagrams. Since for most molecules studied here no collisional rate coefficients are known, a more sophisticated statistical equilibrium analysis is not possible. The critical density, $n_{\mathrm{cr}}$, for the $\mathrm{CH}_{3} \mathrm{OH} 7_{6, K}-6_{6, K}$ transitions is $\sim 10^{6} \mathrm{~cm}^{-3}$ while for the $\mathrm{H}_{2} \mathrm{CO} 3_{0,3}-2_{0,2}$ transition it is $\sim 5 \times 10^{6} \mathrm{~cm}^{-3}$. Since $n_{\mathrm{cr}}$ is proportional to $\mu^{2}$ and $v^{3}$, transitions with high values for either will be most affected. Most species in this study have dipole moments $\mu$ close to the $\mathrm{CH}_{3} \mathrm{OH}$ value of 1.7 Debye. $\mathrm{H}_{2} \mathrm{CO}, \mathrm{CH}_{3} \mathrm{CHO}, \mathrm{HNCO}, \mathrm{NH}_{2} \mathrm{CHO}$, and $\mathrm{CH}_{3} \mathrm{CN}$ have dipole moments 2-3 times larger and for these species subthermal effects should thus be more important. Optical depth can significantly influence the results as well. Column densities derived from optically thick lines will be severely under- and rotation temperatures overestimated. Lines of isotopic species can be used to determine the optical depth. Alternatively, it is possible to predict which lines are optically thick based on the rotation diagram results and exclude those from the fit. In this paper both approaches have been used. A final uncertainty is infrared pumping. It is a well-studied phenomenon for HNCO 


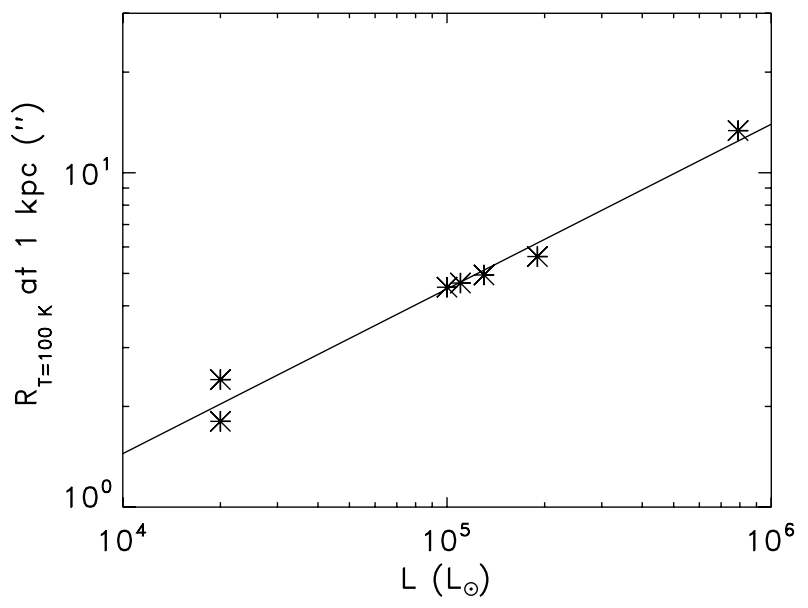

Fig. 2. Comparison of luminosity with source size where $T=100 \mathrm{~K}$. $R_{T=100 \mathrm{~K}}$ is given in arcsec assuming all sources to have a distance of $1 \mathrm{kpc}$. The solid line represent the best fit to the data.

(Churchwell et al. 1986). Its importance for other species is unknown, although all molecules have dipole-allowed mid-infrared transitions. However, no vibrationally excited lines have been detected in this survey except for $\mathrm{CH}_{3} \mathrm{OH}$. With these limitations the rotation diagram method gives a useful indication of the temperature region where the abundance of a molecule peaks.

\subsection{Beam dilution correction and hydrogen column density in hot gas}

If the emission from the complex organic species comes from a warm region where the temperature is higher than the ice evaporation temperature of $100 \mathrm{~K}$, it becomes important to properly take the amount of beam dilution into account, especially for inter-comparison of the sources. The region where the temperature is above $100 \mathrm{~K}$ is expected to be small $\left(\sim 1^{\prime \prime}\right)$ compared to the size of the single-dish beam, and is related to the luminosity $L$. Also, the beam-dilution depends on the distance as $d^{2}$. To correct for the amount of beam dilution we established a set of models for the dust envelopes of our sources based on SCUBA $850 \mu \mathrm{m}$ data $^{6}$. For simplification we fix the inner radii of the envelopes to $500 \mathrm{AU}$, the outer radii to $100000 \mathrm{AU}(\approx 0.5 \mathrm{pc})$ and adopt a power-law density profile, $n \propto r^{-1.5}$, typical of a free-falling core. $r_{\mathrm{o}}$ is chosen to be so large that gas extending beyond this radius will not significantly contribute. We assume that the total luminosity quoted in Table 1 is provided by a single $30000 \mathrm{~K}$ blackbody at the center of the envelope and fit the observed $850 \mu \mathrm{m}$ fluxes of each source by adjusting the mass of the envelope using the DUSTY dust radiative transfer code (Ivezić et al. 1999) as described in Jørgensen et al. (2002). The results of these models provide a temperature profile for each source from which the radius where the temperature increases above $100 \mathrm{~K}\left(R_{T=100 \mathrm{~K}}\right)$, and the beam-dilution can be estimated (see Table 3). Figure 2 compares the inferred source sizes of the warm gas in arcsec with luminosity of the sources with all distances set to $1 \mathrm{kpc}$. These correlate very strongly with luminosity as expected. Our results are consistent with the independently derived relation from dust modeling of a large range of sources, $R_{T=100 \mathrm{~K}} \approx 2.3 \times 10^{14}\left(\sqrt{L / L_{\odot}}\right) \mathrm{cm}$ (Doty private

${ }^{6}$ The SCUBA $850 \mu \mathrm{m}$ data were retrieved through the JCMT archive as a Guest User at the Canadian Astronomy Data Center, which is operated by the Dominion Astrophysical Observatory for the National Research Council of Canada's Herzberg Institute of Astrophysics. communication). In fact, the luminosity itself can be used to estimate the linear size of the region where the temperature is higher than $100 \mathrm{~K}$. We therefore adopt these radii for the beam dilution correction for molecules that unambiguously probe warm $\geq 100 \mathrm{~K}$ gas estimated from the rotation diagrams. The derived beam dilution $\left(\eta_{\mathrm{bf}}\right)$,

$$
\eta_{\mathrm{bf}}=\frac{\left(R_{T=100 \mathrm{~K}} / \boldsymbol{d}\right)^{2}}{\left(\theta_{\text {beam }} / 2\right)^{2}+\left(R_{T=100 \mathrm{~K}} / \boldsymbol{d}\right)^{2}}
$$

is then used to calculate source-averaged column densities $\left(N_{T \geq 100 \mathrm{~K}}\right)$ of hot molecules $(\mathrm{X})$ in Sect. 4.4:

$N_{T \geq 100 \mathrm{~K}}(\mathrm{X})=\frac{N_{\mathrm{T}}(\mathrm{X})}{\eta_{\mathrm{bf}}}$.

The radiative transfer models used to calibrate the $R_{T=100 \mathrm{~K}}-L$ relation can also be used to calculate the hydrogen mass in the inner warm regions and thereby provide an $\mathrm{H}_{2}$ column density to determine molecular abundances for $T \geq 100 \mathrm{~K}$. With the derived density and temperature profiles listed in Table 3 , the number of $\mathrm{H}_{2}$ molecules, $\operatorname{Mol}\left(\mathrm{H}_{2}\right)$, within $R_{T=100 \mathrm{~K}}$, can be calculated from:

$$
\begin{aligned}
\operatorname{Mol}\left(\mathrm{H}_{2}\right) & =\int_{r_{\mathrm{i}}}^{R_{T=100 \mathrm{к}}} 4 \pi r^{2} n_{\mathrm{i}}\left(\frac{r}{r_{\mathrm{i}}}\right)^{-\alpha} \mathrm{d} r \\
& =\frac{4 \pi n_{\mathrm{i}} r_{\mathrm{i}}^{\alpha}}{3-\alpha}\left(R_{T=100 \mathrm{~K}}^{3-\alpha}-r_{\mathrm{i}}^{3-\alpha}\right),
\end{aligned}
$$

where $n_{\mathrm{i}}$ is the density of $\mathrm{H}_{2}$ molecules at the inner radius, and $\alpha$ the power of the density profiles. The column density of $\mathrm{H}_{2}$ in gas with $T \geq 100 \mathrm{~K}, N_{T \geq 100 \mathrm{~K}}\left(\mathrm{H}_{2}\right)$ in $\mathrm{cm}^{-2}$ is then simply $\operatorname{Mol}\left(\mathrm{H}_{2}\right)$ divided by $\pi R_{T=100 \mathrm{~K}}^{2}$

$$
N_{T \geq 100 \mathrm{~K}}\left(\mathrm{H}_{2}\right)=\frac{4 n_{\mathrm{i}} r_{\mathrm{i}}^{\alpha}}{(3-\alpha) R_{T=100 \mathrm{~K}}^{2}}\left(R_{T=100 \mathrm{~K}}^{3-\alpha}-r_{\mathrm{i}}^{3-\alpha}\right) .
$$

Since both $N_{T \geq 100 \mathrm{~K}}\left(\mathrm{H}_{2}\right)$ and $N_{T \geq 100 \mathrm{~K}}(\mathrm{X})$ refer to column densities for the same temperature region, they can be used directly to calculate abundances for a species $\mathrm{X}$ in the hot gas through:

$[\mathrm{X}]=\frac{N_{T \geq 100 \mathrm{~K}}(\mathrm{X})}{N_{T \geq 100 \mathrm{~K}}\left(\mathrm{H}_{2}\right)}$.

It is clear from Table 3 that the derived values of $R_{T=100 \mathrm{~K}}$ and $N_{T \geq 100 \mathrm{~K}}\left(\mathrm{H}_{2}\right)$ are rather similar for most sources with the exception of AFGL 2591 and G24.78. AFGL 2591 has a significantly smaller and $\mathrm{G} 24.78$ a much larger radius and $\mathrm{H}_{2}$ column density. These are related to their low and very high luminosities. The beam-dilution for G24.78 is thus very similar to that for the other sources in our sample. This makes a good comparison between G24.78 and the other sources possible.

Some of our sources have previously been modeled in more detail (e.g., van der Tak et al. 2000; Mueller et al. 2002; Hatchell $\&$ van der Tak 2003); these models show some differences, e.g., in the slope of the density distribution from source to source and even for the same source depending on method. As an example, van der Tak et al. (2000) found that $R_{T=100 \mathrm{~K}}$ is $5.3 \times 10^{3} \mathrm{AU}$ for NGC 6334 IRS1 and $2.8 \times 10^{3}$ AU for W $3\left(\mathrm{H}_{2} \mathrm{O}\right)$ with a density slope $\alpha=2$. Both values are within $10-15 \%$ of our model result. Together with the good agreement with the models by Doty (private communication) this implies that the model-dependent uncertainty has a rather small effect on $R_{T=100 \mathrm{~K}}$ and the column densities. We therefore consider our adopted approach to provide the internally most consistent set of estimates - even though we 


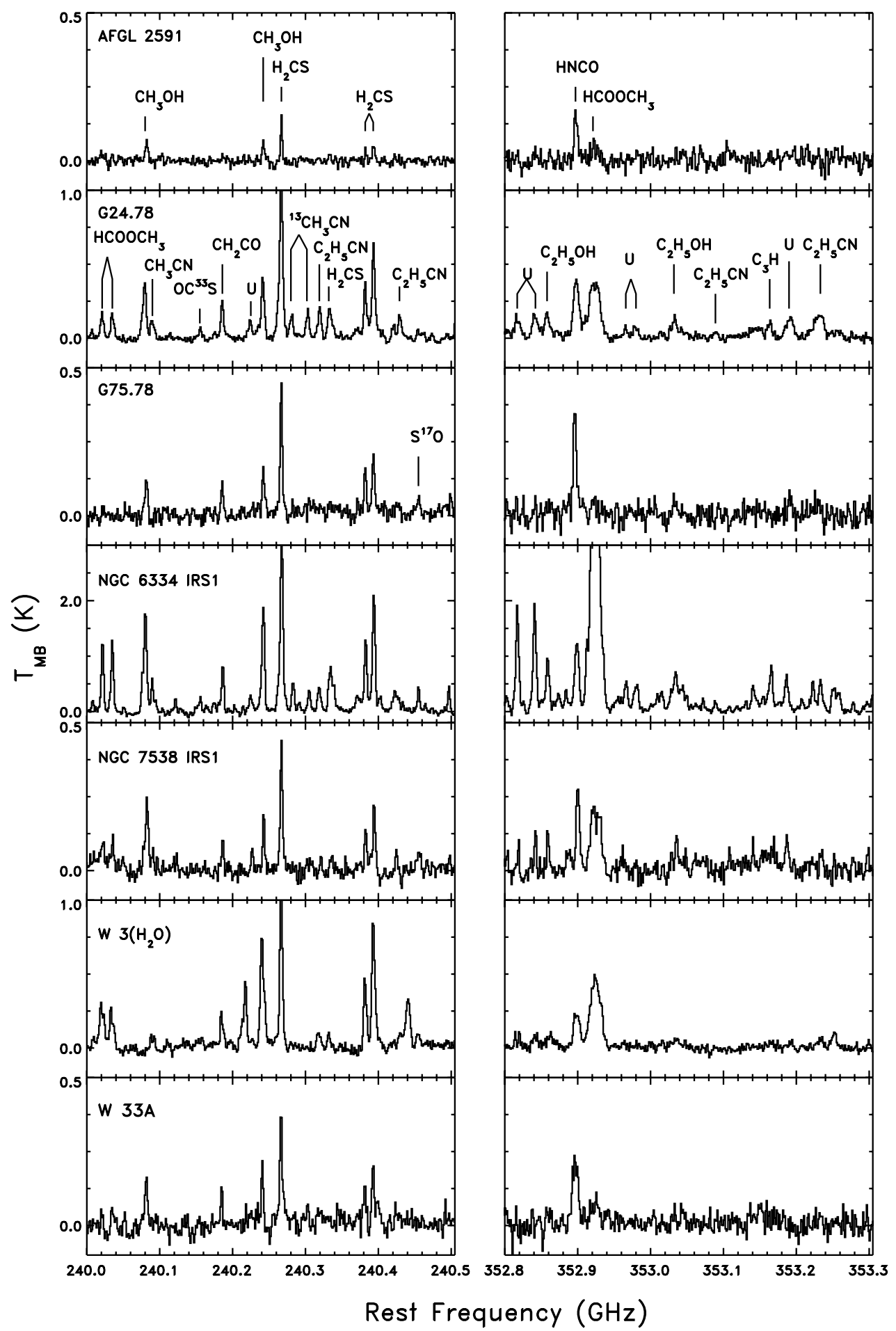

Fig. 3. Spectra centered at 240.25 and $353.05 \mathrm{GHz}$ for all sources. Note that the $T_{\mathrm{MB}}$ scales are different for individual sources.

caution that a full self-consistent set of models (explaining, e.g., both single-dish and interferometric continuum data) is required to estimate abundances to better than a factor 2-3.

Finally, interferometric observations have shown that even on scales as small as a few thousand AU, there may be strong chemical differentiation, e.g., oxygen-bearing molecules peaking at a different position than nitrogen-bearing species (Liu 2005; Blake et al. 1996, 1987; Wyrowski et al. 1999; Sutton et al. 1995). From single-dish observations of a single source, it is not possible to determine whether the emission of various species arises from different regions. A comparison of the abundances of the species studied in this paper for a number of sources does, however, show whether the emission likely comes from the same or a different region (Sect. 5).

\section{Results}

\subsection{General comparison between sources}

Figure 3 shows the spectra at 240.25 and $353.05 \mathrm{GHz}$ toward all sources and Tables B.1-B.15 contain all measured line intensities for the molecules discussed in this paper. There is a clear 
Table 3. Parameters of temperature and density profiles, and beamfilling factors derived from $850 \mu \mathrm{m}$ SCUBA data and source luminosities.

\begin{tabular}{|c|c|c|c|c|c|}
\hline Sources & $\begin{array}{l}n_{\mathrm{i}}^{a} \\
{\left[\mathrm{~cm}^{-3}\right]}\end{array}$ & $\begin{array}{l}R_{T=100 \mathrm{~K}} \\
{[\mathrm{AU}]}\end{array}$ & $\tau^{b}$ & $\begin{array}{l}N_{T \geq 100 \mathrm{~K}}\left(\mathrm{H}_{2}\right) \\
{\left[\mathrm{cm}^{-2}\right]}\end{array}$ & $\eta_{\mathrm{bf}}^{c}$ \\
\hline AFGL 2591 & $8.5(6)$ & $1.8(3)$ & 0.40 & $7.6(22)$ & $6.2(-2)$ \\
\hline G24.78 & $1.0(8)$ & $1.3(4)$ & 4.8 & $4.0(23)$ & $5.8(-2)$ \\
\hline G75.78 & $2.1(7)$ & $5.6(3)$ & 0.98 & $1.2(23)$ & $3.7(-2)$ \\
\hline NGC 6334 IRS1 & $3.8(7)$ & $4.7(3)$ & 1.8 & $2.4(23)$ & $1.3(-1)$ \\
\hline NGC 7538 IRS1 & $3.4(7)$ & $4.9(3)$ & 1.6 & $2.1(23)$ & $6.0(-2)$ \\
\hline $\mathrm{W} 3\left(\mathrm{H}_{2} \mathrm{O}\right)$ & $6.2(7)$ & $2.4(3)$ & 2.9 & $1.8(23)$ & $2.9(-2)$ \\
\hline W 33A & $4.1(7)$ & $4.5(3)$ & 1.9 & $2.6(23)$ & $2.6(-2)$ \\
\hline
\end{tabular}

${ }^{a}$ Density at inner radius of $500 \mathrm{AU} .^{b}$ The optical depth $\tau$ is given for the dust at $100 \mu \mathrm{m} .{ }^{c} \eta_{\text {bf }}$ is the beam-filling factor.

difference in the "richness" of the sources in molecular lines. The intensities and thus also column densities of "line-poorer" sources are lower for most organic species for sources such as AFGL 2591, G75.78, NGC 7538 IRS1, and W 33A. Some lines, such as the $\mathrm{HCOOCH}_{3} 31_{4,27}-30_{4,26}$ at $352.922 \mathrm{GHz}$, are weak relative to the $\mathrm{HNCO} 16_{1,15}-15_{1,14}$ at $352.898 \mathrm{GHz}$ for the "line-poorer" sources, but strong for the "line-richer" sources, i.e. G24.78, NGC 6334 IRS1, NGC 7538 IRS1, and W 3( $\left.\mathrm{H}_{2} \mathrm{O}\right)$. There therefore seems to be an intrinsic chemical difference between the "line-rich" and "line-poor" sources.

The two settings shown in Fig. 3 were aimed at detecting the $\mathrm{CH}_{2} \mathrm{CO} 12_{1,12}-11_{1,11}$ transition at $240.187 \mathrm{GHz}$ and the $\mathrm{C}_{2} \mathrm{H}_{5} \mathrm{OH} 21_{1,20,2}-20_{2,19,2}$ line at $352.858 \mathrm{GHz}$. Both transitions were detected in most sources, indicating that the selected settings are suitable for obtaining detections or otherwise limits. Many lines of other target molecules have been detected in these settings as well.

\subsection{Optical depth determinations}

Some species such as $\mathrm{CH}_{3} \mathrm{OH}, \mathrm{H}_{2} \mathrm{CO}$, and $\mathrm{CH}_{3} \mathrm{CN}$ have previously been found to be optically thick in their main lines (see e.g., Helmich \& van Dishoeck 1997). Lines for selected isotopic species were used to determine whether the lines of the main species are optically thick and to derive column densities for the main isotopologues (see Tables B.1, B.2, B.3, B.8, and B.10). For $\mathrm{H}_{2} \mathrm{CO}$ and $\mathrm{HNCO}$, the same transition could be used for different isotopologues. For $\mathrm{CH}_{3} \mathrm{CN}$, the optical depth was determined by comparing the column density derived from the rotation diagram analysis for the main species and that derived from the detected transition for the isotopologues. The ratios for the beam-averaged column densities are given in Table 4, and the corrected source-averaged column densities in Table 5. In the remainder of the paper a ${ }^{12} \mathrm{C} /{ }^{13} \mathrm{C}$ ratio value of 53 for the $4 \mathrm{kpc}$ molecular ring has been used (Wilson \& Rood 1994). Note that this value is uncertain, however, and known to depend on the distance to the galactic center. However, for simplicity we have assumed the same ratio for all sources.

The rotation diagram results by van der Tak et al. (2000) were not corrected for optical depth, because no isotopologues were observed. In our data, however, lines for $\mathrm{H}_{2}^{13} \mathrm{CO}$ and $\mathrm{H}_{2} \mathrm{C}^{18} \mathrm{O}$ are observed. The optical depth of $\mathrm{H}_{2} \mathrm{CO}$ has been determined from the $3_{1,2}-2_{1,1}$ transition. The observed $\mathrm{H}_{2} \mathrm{CO} / \mathrm{H}_{2}^{13} \mathrm{CO}$ ratio ranges from 6.5 for NGC 6334 IRS1 to 37 for AFGL 2591 and NGC 7538 IRS1, lower than the expected ratio, which implies that the main isotopologue is optically thick in many of its transitions. The results for $\mathrm{W} 3\left(\mathrm{H}_{2} \mathrm{O}\right)$ are consistent with the optical depth found by Helmich \& van Dishoeck (1997). The optical depth of $\mathrm{H}_{2}^{13} \mathrm{CO}$ was estimated based on the $5_{2,3}-4_{2,2}$ transition observed for both $\mathrm{H}_{2}^{13} \mathrm{CO}$ and $\mathrm{H}_{2} \mathrm{C}^{18} \mathrm{O}$. The $\mathrm{H}_{2}^{13} \mathrm{CO} / \mathrm{H}_{2} \mathrm{C}^{18} \mathrm{O}$ ratio is lower than the expected value of 5-8 for most sources, but it is unclear whether this difference is significant. We assume therefore for simplicity that $\mathrm{H}_{2}^{13} \mathrm{CO}$ is optically thin for all sources.

No direct comparison of the same transition is possible for $\mathrm{CH}_{3} \mathrm{OH}$ with ${ }^{13} \mathrm{CH}_{3} \mathrm{OH}$. Many detected lines have strengths that are lower by more than an order of magnitude compared to the strongest transitions. It is therefore possible to determine the column density of the main isotopic species by excluding lines predicted to be optically thick for the source-averaged column density from the rotation diagram. This also circumvents the additional error introduced by the uncertain isotopic ratios. As seen in Fig. A.2, this excludes mainly lines lying below the fit to the optically thin lines and results in a much better determined rotation temperature.

The limits on the $\mathrm{HNCO} / \mathrm{HN}^{13} \mathrm{CO}$ ratios are smaller than $\sim 53$, and HNCO could thus be optically thick for all sources. Note that the optical depth determination of HNCO is potentially complicated by the close spacing of the lines of the main species and its isotopologue of only $\sim 5 \mathrm{MHz}$. However, since most of our sources have line widths of only $3-4 \mathrm{~km} \mathrm{~s}^{-1}$, the upper limits for $\mathrm{HN}^{13} \mathrm{CO}$ are significant. Since $\mathrm{HN}^{13} \mathrm{CO}$ has not been detected for any of our sources and most sources studied by Zinchenko et al. (2000), HNCO is assumed to be optically thin throughout the remainder of this paper.

Since it was not one of the target molecules, $\mathrm{CH}_{3} \mathrm{CN}$ was not observed for all sources. Its lines and those of $\mathrm{CH}_{3}^{13} \mathrm{CN}$ were coincidentally present in the image sidebands for some of the sources. For G24.78, NGC 6334 IRS1, and W 33A, both the main species and its isotopologue have been detected and $\mathrm{CH}_{3} \mathrm{CN}$ is found to be optically thick in the 12-11 and 13-12 transitions with ratios ranging from 5.8 for G24.78 to 24 for NGC 6334 IRS1. For G24.78, this result confirms the findings by Beltrán et al. (2005).

Since $\mathrm{HCOOCH}_{3}$ and $\mathrm{CH}_{3} \mathrm{OCH}_{3}$ have relatively high column densities, predictions were made for which lines were optically thick. All lines detected for both molecules were found to be optically thin, if we assume that the emission does not come from a radius smaller than $R_{T=100 \mathrm{~K}}$.

\subsection{Rotation temperatures}

In the following subsection we discuss each molecule individually and compare it with literature; the main results are summarized at the end of this subsection. The rotation temperatures were derived from single temperature fits to rotation diagrams (see Sect. 3.1). Calibration uncertainties of $15 \%$ are shown as error bars on the rotation diagrams. All rotation diagrams are shown in Appendix 7, and resulting rotation temperatures in Table 6.

$\mathrm{H}_{2} \mathrm{CO}$ : For $\mathrm{H}_{2} \mathrm{CO}$, the data are taken from van der Tak et al. (2000) except for G24.78 and G75.78 (see Fig. A.1). The rotation temperatures for all sources except NGC 6334 IRS1 and W $3\left(\mathrm{H}_{2} \mathrm{O}\right)$ are $\sim 80 \mathrm{~K}$. NGC $6334 \mathrm{IRS} 1$ and $\mathrm{W} 3\left(\mathrm{H}_{2} \mathrm{O}\right)$ have temperatures of about $100 \mathrm{~K}$ higher. However, as the optical depths are similar for most sources, this temperature difference between the sources is real.

$\mathrm{CH}_{3} \mathrm{OH}$ : For $\mathrm{CH}_{3} \mathrm{OH}$ no clear temperature trend is seen, but the temperature is generally higher than $100 \mathrm{~K}$. This implies that the emission is coming from warm gas. The $\mathrm{CH}_{3} \mathrm{OH}$ rotation 
Table 4. Column density or line intensity ratios for $\mathrm{H}_{2} \mathrm{CO} / \mathrm{H}_{2}^{13} \mathrm{CO}, \mathrm{H}_{2}^{13} \mathrm{CO} / \mathrm{H}_{2} \mathrm{C}^{18} \mathrm{O}, \mathrm{HNCO} / \mathrm{HN}^{13} \mathrm{CO}$, and $\mathrm{CH}_{3} \mathrm{CN} / \mathrm{CH}_{3}^{13} \mathrm{CN}$ before correction for optical depth.

\begin{tabular}{l|ccccccc}
\hline \hline & \multicolumn{7}{c}{ Sources } \\
Species & AFGL 2591 & G24.78 & G75.78 & NGC 6334 IRS1 & NGC 7538 IRS1 & W 3(H $\left.\mathrm{H}_{2} \mathrm{O}\right)$ & W 33A \\
\hline $\mathrm{H}_{2} \mathrm{CO} / \mathrm{H}_{2}^{13} \mathrm{CO}^{a}$ & 37 & 9.3 & 22 & 6.5 & 37 & 31 & 14 \\
$\mathrm{H}_{2}^{13} \mathrm{CO} / \mathrm{H}_{2} \mathrm{C}^{18} \mathrm{O}^{b}$ & $<2.4$ & 2.8 & $>1.7$ & 2.4 & $<1.6$ & $>3.0$ & $>3.5$ \\
$\mathrm{HNCO} / \mathrm{HN}^{13} \mathrm{CO}^{c}$ & $>2.4$ & $>11$ & $>6.5$ & $>8.6$ & $>2.0$ & $>3.6$ & $>7.3$ \\
$\mathrm{CH}_{3} \mathrm{CN} / \mathrm{CH}_{3}^{13} \mathrm{CN}^{d}$ & - & 5.8 & $>5.9$ & 25 & 7 & $>9.5$ & 7.6 \\
\hline
\end{tabular}

${ }^{a}$ Derived from the $3_{1,2}-2_{1,1}$ transition. ${ }^{b}$ Derived from the $5_{2,3}-4_{2,2}$ transition. ${ }^{c}$ Derived from the $10_{0,10}-9_{0,9}$ transition. ${ }^{d}$ Derived from the overall column density determined from all detected transitions.

Table 5. Column densities $N$ for hot core molecules (source-averaged) and cold molecules (beam-averaged) ${ }^{a}\left[\mathrm{~cm}^{-2}\right]$.

\begin{tabular}{|c|c|c|c|c|c|c|c|}
\hline Species & AFGL 2591 & G24.78 & G75.78 & $\begin{array}{c}\text { Sources } \\
\text { NGC } 6334 \text { IRS1 }\end{array}$ & NGC 7538 IRS1 & W 3 $\left(\mathrm{H}_{2} \mathrm{O}\right)$ & W 33A \\
\hline \multicolumn{8}{|c|}{ Hot molecules } \\
\hline $\mathrm{H}_{2} \mathrm{CO}^{b}$ & $1.3(16)$ & $6.4(16)$ & $2.2(16)$ & $1.3(17)$ & $2.5(16)$ & $1.8(17)$ & $5.4(16)$ \\
\hline $\mathrm{H}_{2}^{13} \mathrm{CO}$ & $2.4(14)$ & $1.2(15)$ & $4.0(14)$ & $2.5(15)$ & $4.8(14)$ & $3.3(15)$ & $1.0(15)$ \\
\hline $\mathrm{H}_{2} \mathrm{C}^{18} \mathrm{O}$ & 7.4(13) & $4.3(14)$ & $<2.5(14)$ & $1.1(15)$ & $1.3(14)$ & $<1.7(15)$ & $<3.0(14)$ \\
\hline $\mathrm{CH}_{3} \mathrm{OH}^{c}$ & $4.7(16)$ & $2.8(17)$ & 1.1(17) & $9.7(17)$ & $1.2(17)$ & 1.0(18) & 2.0(17) \\
\hline${ }^{13} \mathrm{CH}_{3} \mathrm{OH}$ & $<1.8(15)$ & $2.9(16)$ & $4.3(15)$ & $8.5(16)$ & $6.7(15)$ & $3.2(16)$ & $6.5(15)$ \\
\hline $\mathrm{C}_{2} \mathrm{H}_{5} \mathrm{OH}$ & $<1.0(15)$ & 7.1(15) & $<2.4(15)$ & $1.9(16)$ & $5.7(15)$ & $8.4(15)$ & $4.7(15)$ \\
\hline HNCO & 8.3(14) & $5.0(15)$ & $3.8(15)$ & $4.3(15)$ & $2.3(15)$ & $4.9(15)$ & $6.6(15)$ \\
\hline $\mathrm{HN}^{13} \mathrm{CO}$ & $<4.7(14)$ & $<9.3(14)$ & $<1.2(15)$ & $<3.8(14)$ & $<1.2(14)$ & $<2.7(15$ & $<1.2(15)$ \\
\hline $\mathrm{NH}_{2} \mathrm{CHO}$ & $<1.3(15)$ & 7.2(14) & $2.0(14)$ & 7.4(14) & $5.7(14)$ & $1.3(15)$ & $2.1(15)$ \\
\hline $\mathrm{CH}_{3} \mathrm{CN}$ & $<3.5(15)$ & $5.9(16)^{d}$ & $1.8(15)$ & $2.9(16)^{d}$ & $<8.2(15)$ & $7.0(15)$ & $2.7(16)$ \\
\hline $\mathrm{CH}_{3}^{13} \mathrm{CN}$ & $<5.3(14)$ & $1.1(15)$ & $<3.0(14)$ & $5.6(14)$ & $<1.2(15)$ & $<7.2(14)$ & $<5.0(14)$ \\
\hline $\mathrm{C}_{2} \mathrm{H}_{5} \mathrm{CN}$ & $<7.5(14)$ & $4.0(15)$ & $<1.2(15)$ & $5.1(15)$ & $<9.2(14)$ & $4.5(15)$ & $<2.1(15)$ \\
\hline $\mathrm{HCOOCH}_{3}$ & $<2.4(16)$ & $3.1(16)$ & 7.1(15) & $1.2(17)$ & 1.4(16) & $5.2(16)$ & $2.5(16)$ \\
\hline $\mathrm{CH}_{3} \mathrm{OCH}_{3}$ & $<7.7(15)$ & $1.2(17)$ & $2.3(16)$ & $5.8(17)$ & $<1.6(16)$ & $1.5(17)$ & $2.7(16)$ \\
\hline \multicolumn{8}{|c|}{ Cold molecules } \\
\hline $\mathrm{CH}_{2} \mathrm{CO}$ & $1.6(13)$ & $2.1(14)$ & $6.4(13)$ & $7.2(14)$ & $9.7(13)$ & $1.1(14)$ & $6.3(13)$ \\
\hline $\mathrm{CH}_{3} \mathrm{CHO}$ & $3.1(12)$ & $<1.5(13)$ & $<2.1(13)$ & $<1.2(14)$ & $2.8(13)$ & $3.5(13)$ & $<3.0(13)$ \\
\hline $\mathrm{HCOOH}$ & $3.4(13)$ & 2.1(14) & $7.9(13)$ & $4.9(14)$ & $9.8(13)$ & $1.5(14)$ & $1.3(14)$ \\
\hline $\mathrm{CH}_{3} \mathrm{CCH}$ & $7.9(14)$ & $2.3(15)$ & $8.6(14)$ & $5.2(15)$ & $8.4(14)$ & $1.5(15)$ & $1.3(15)$ \\
\hline
\end{tabular}

${ }^{a}$ The column densities for the hot core molecules are corrected for beam-dilution using the values of $\eta_{\mathrm{bf}}$ listed in Table 2 . The cold molecules are given as a beam-averaged column density for a beam of $14^{\prime \prime} .{ }^{b}$ From $\mathrm{H}_{2}^{13} \mathrm{CO}$ multiplied by $53 .{ }^{c}$ From rotation diagram excluding optically thick lines. ${ }^{d}$ From $\mathrm{CH}_{3}^{13} \mathrm{CN}$ multiplied by 53 .

diagram for some sources like W 33A appears to consist of two temperature components as seen previously by van der Tak et al. (2000) (Fig. A.2). However, deducing the presence of two components from a rotation diagram is non-trivial as this behavior could also result from sub-thermal excitation and optical depth effects. Indeed, excluding lines of high optical depth leads to the disappearance of the two-component structure for most sources other than W 33A. The fits in Fig. A.2 are especially sensitive to lines with high excitation temperatures and are therefore thought to probe the hot component of the $\mathrm{CH}_{3} \mathrm{OH}$ gas.

$\mathrm{CH}_{2} \mathrm{CO}: \mathrm{CH}_{2} \mathrm{CO}$ has temperatures that are very low, generally only around $40 \mathrm{~K}$. Slightly higher temperatures are found for NGC 6334 IRS1 and $\mathrm{W} 3\left(\mathrm{H}_{2} \mathrm{O}\right)$. These temperatures suggest that this molecule is not present in hot regions, but rather in the cold envelope. The IRAM and JCMT detections for NGC 7538 IRS 1 and W $3\left(\mathrm{H}_{2} \mathrm{O}\right)$ are consistent. MacDonald et al. (1996) find very high values of $273 \mathrm{~K}$ for G34.3 based on three lines with $E_{\mathrm{u}}>100 \mathrm{~K}$. However the integrated intensity for the $\mathrm{CH}_{2} \mathrm{CO} 17_{1,16}-16_{1,15}$ line at $346.6 \mathrm{GHz}$ with $E_{\mathrm{u}}>150 \mathrm{~K}$ in this survey, also detected by MacDonald et al. (1996), is consistent with the low rotation temperature found in our survey.

$\mathrm{CH}_{3} \mathrm{CHO}$ : Due to unfavorable weather conditions, IRAM observations of $\mathrm{CH}_{3} \mathrm{CHO}$ have only been performed for AFGL 2591, G75.78, NGC 7538 IRS1, and W 3( $\left.\mathrm{H}_{2} \mathrm{O}\right)$.
Almost all targeted lines were detected toward the sources NGC 7538 IRS1 and $\mathrm{W} 3\left(\mathrm{H}_{2} \mathrm{O}\right)$. Both sources have rotation temperatures $<20 \mathrm{~K}$, consistent with the results found by Ikeda et al. (2001, 2002). Although its relatively high dipole moment of 2.69 D implies that sub-thermal excitation can play a role, it is unlikely that the temperature is above $100 \mathrm{~K}$, especially since molecules with similarly high dipole moments such as HNCO and $\mathrm{CH}_{3} \mathrm{CN}$ have much higher rotation temperatures.

$\mathrm{C}_{2} \mathrm{H}_{5} \mathrm{OH}: \mathrm{C}_{2} \mathrm{H}_{5} \mathrm{OH}$ consistently has temperatures of more than $100 \mathrm{~K}$. This is somewhat higher than was found by Ikeda et al. (2001), which could be due to the detection of more high excitation lines in this study. For the lower energy transitions, a steeper slope is observed, which indicates a lower temperature.

$\mathrm{HCOOH}: \mathrm{HCOOH}$ has relatively low temperatures ranging from $\sim 40 \mathrm{~K}$ for $\mathrm{G} 24.78$, and $\mathrm{W} 33 \mathrm{~A}$ to $\sim 70 \mathrm{~K}$ for NGC 6334 IRS 1 and NGC 7538 IRS1. For NGC 7538 IRS1 and W $3\left(\mathrm{H}_{2} \mathrm{O}\right)$, it was possible to combine results from both IRAM and the JCMT. For NGC 7538 IRS1, low rotation temperatures are confirmed, whereas for $\mathrm{W} 3\left(\mathrm{H}_{2} \mathrm{O}\right)$ a scatter of more than one order of magnitude is present. As the $\mathrm{W} 3(\mathrm{OH})$ region is close to W $3\left(\mathrm{H}_{2} \mathrm{O}\right)$ it is possible that emission from this region is picked up in one of the settings. Alternatively, $\mathrm{HCOOH}$ could be present in both hot and cold gas with only the cold component present 
Table 6. Derived rotation temperatures ${ }^{a}$ in K from rotation diagram analysis (see Appendix 7).

\begin{tabular}{|c|c|c|c|c|c|c|c|}
\hline Species & AFGL 2591 & $\mathrm{G} 24.78$ & G75.78 & $\begin{array}{c}\text { Sources } \\
\text { NGC } 6334 \text { IRS1 } \\
\end{array}$ & NGC 7538 IRS1 & $\mathrm{W} \mathrm{3}\left(\mathrm{H}_{2} \mathrm{O}\right)$ & W 33A \\
\hline $\mathrm{H}_{2} \mathrm{CO}$ & $89^{b}$ & $83 \pm 9$ & $69 \pm 6$ & $193^{b}$ & $87^{b}$ & $181^{b}$ & $88^{b}$ \\
\hline $\mathrm{CH}_{3} \mathrm{OH}$ & $147 \pm 11$ & $211 \pm 13$ & $113 \pm 7$ & $178 \pm 10$ & $156 \pm 10$ & $139 \pm 8$ & $259 \pm 16$ \\
\hline $\mathrm{C}_{2} \mathrm{H}_{5} \mathrm{OH}$ & [139] & $104 \pm 7$ & [139] & $166 \pm 15$ & $164 \pm 17$ & $129 \pm 16$ & $122 \pm 16$ \\
\hline HNCO & $64 \pm 8$ & $96 \pm 11$ & $108 \pm 13$ & $105 \pm 12$ & $278 \pm 88$ & $147 \pm 24$ & $85 \pm 8$ \\
\hline $\mathrm{NH}_{2} \mathrm{CHO}$ & [119] & $170 \pm 20$ & $78 \pm 22$ & $166 \pm 29$ & $164 \pm 28$ & $71 \pm 7$ & $40 \pm 13$ \\
\hline $\mathrm{CH}_{3} \mathrm{CN}$ & [218] & $261 \pm 20$ & $189 \pm 25$ & $170 \pm 13$ & [218] & $196 \pm 14$ & $278 \pm 44$ \\
\hline $\mathrm{C}_{2} \mathrm{H}_{5} \mathrm{CN}$ & [96] & $99 \pm 5$ & [96] & $92 \pm 3$ & [96] & $94 \pm 16$ & [96] \\
\hline $\mathrm{HCOOCH}_{3}$ & [119] & $121 \pm 6$ & $87 \pm 13$ & $144 \pm 7$ & $134 \pm 8$ & $109 \pm 7$ & $112 \pm 15$ \\
\hline $\mathrm{CH}_{3} \mathrm{OCH}_{3}$ & [130] & $134 \pm 12$ & [130] & $241 \pm 35$ & [130] & $94 \pm 5$ & $43 \pm 7$ \\
\hline $\mathrm{CH}_{2} \mathrm{CO}$ & [47] & $39 \pm 6$ & $40 \pm 6$ & $67 \pm 20$ & $37 \pm 4$ & $54 \pm 8$ & $45 \pm 7$ \\
\hline $\mathrm{CH}_{3} \mathrm{CHO}$ & [20] & [20] & [37.5] & {$[37.5]$} & $18 \pm 5$ & $16 \pm 3$ & {$[37.5]$} \\
\hline $\mathrm{HCOOH}$ & [55] & $42 \pm 7$ & [55] & $75 \pm 15$ & $73 \pm 12$ & $189 \pm 108$ & $38 \pm 6$ \\
\hline $\mathrm{CH}_{3} \mathrm{CCH}$ & $45 \pm 12$ & $59 \pm 6$ & $59 \pm 14$ & $63 \pm 12$ & $58 \pm 10$ & $82 \pm 15$ & $40 \pm 6$ \\
\hline
\end{tabular}

${ }^{a}$ The bracket notation indicates assumed rotation temperature, when no temperature could be derived from a rotation diagram. ${ }^{b} \mathrm{H}_{2} \mathrm{CO}$ data from van der Tak et al. (2000).

for NGC 7538 IRS1. Due to the larger beam size of the JCMT, the $230 \mathrm{GHz}$ observations are more sensitive to extended emission, whereas the IRAM $270 \mathrm{GHz}$ observations probe a more compact region. Since most sources have low rotation temperatures, we conclude that it is mostly located in a cold environment. Low rotation temperatures have previously been inferred for $\mathrm{HCOOH}$ in other high mass star forming regions (Ikeda et al. 2001).

HNCO: The rotation temperature of HNCO varies between the different sources. This is not unexpected since the HNCO excitation is known to be dominated by radiation and not collisions (Churchwell et al. 1986). It is therefore not likely to provide much information about the actual kinetic temperature of the species. However it does need to be close to an infrared source to be excited, and thus must be present in hot gas. Finally, it is important to note that excluding the line with $E_{\mathrm{u}}>300 \mathrm{~K}$ (see Fig. A.7) strongly reduces the inferred rotation temperature for NGC 6334 IRS 1 from $180 \mathrm{~K}$ to $106 \mathrm{~K}$.

$\mathrm{NH}_{2} \mathrm{CHO}: \mathrm{NH}_{2} \mathrm{CHO}$ has a variety of rotation temperatures. The scatter in the derived rotation temperatures appear to be relatively large, with especially NGC 7538 IRS1 being an outlier (Fig. A.8). There is also some indication that there may be two temperature components - most clearly seen for the sources where many lines with $E_{\mathrm{u}}>200 \mathrm{~K}$ are detected. Since $\mathrm{NH}_{2} \mathrm{CHO}$ has lines very close to the detection limit, this component may also be present for the other sources, but simply below the detection limit.

$\mathrm{CH}_{3} \mathrm{CN}$ : Rotation temperatures of $\mathrm{CH}_{3} \mathrm{CN}$ range from 170 $280 \mathrm{~K}$. It is thus always present in hot gas (see Fig. A.9). The particularly high temperatures for G24.78 and W 33A are upper limits due to high optical depths. Pankonin et al. (2001) find lower rotation temperatures of $89 \mathrm{~K}$ for $\mathrm{G} 24.78$ which confirm this picture. For NGC 6334 IRS1 only three lines with $E_{\mathrm{u}} \geq 500 \mathrm{~K}$ have been detected, making the resulting rotation temperature uncertain. However, it seems clear that the rotation temperature for $\mathrm{CH}_{3} \mathrm{CN}$ is high, and the species must be present in hot gas.

$\mathrm{C}_{2} \mathrm{H}_{5} \mathrm{CN}$ : The other cyanide, $\mathrm{C}_{2} \mathrm{H}_{5} \mathrm{CN}$, only has enough detected lines for three of the sources to allow a determination of the rotation temperature (see Fig. A.10). For all three sources temperatures of $\sim 90 \mathrm{~K}$ are found. Fewer lines have been detected for $\mathrm{W} 3\left(\mathrm{H}_{2} \mathrm{O}\right)$, but the fact that the results for this source are rather similar gives additional credibility to the derived temperatures.

$\mathrm{CH}_{3} \mathrm{CCH}$ : $\mathrm{CH}_{3} \mathrm{CCH}$ generally has rotation temperatures below $\sim 80 \mathrm{~K}$ - except for G24.78, NGC 6334 IRS1, and W $3\left(\mathrm{H}_{2} \mathrm{O}\right)$. The higher temperatures for these three sources are, however, questionable. Removing the point with $E_{\mathrm{u}}>$ $300 \mathrm{~K}$ gives significantly lower temperatures for G24.78 and NGC 6334 IRS1 (see Fig. A.11). The W 3( $\left.\mathrm{H}_{2} \mathrm{O}\right)$ generally has a higher uncertainty and scatter on the data, which may in fact cause the higher temperature found for this source.

$\mathrm{HCOOCH}_{3}: \mathrm{HCOOCH}_{3}$ is detected in almost all of the sources, but with a relatively large scatter on the data. The temperature generally seems to be between 100-150 K, with somewhat lower values when less lines have been detected. For G75.78 the results are inconclusive as the upper limits on high energy transitions are not significant. Somewhat lower temperatures were found by Ikeda et al. (2001), which could be due to a difference in the number of detected lines.

$\mathrm{CH}_{3} \mathrm{OCH}_{3}: \mathrm{CH}_{3} \mathrm{OCH}_{3}$ also appears to have a relatively large spread in rotation temperatures (see Fig. A.13). For W 33A, only lines with $E_{\mathrm{u}}<100 \mathrm{~K}$ were detected, which result in low rotation temperatures. The upper limits on lines with $E_{\mathrm{u}}>150 \mathrm{~K}$ are not significant, however, and do not exclude temperatures above $100 \mathrm{~K}$. Rotation temperatures above $100 \mathrm{~K}$ are commonly seen for $\mathrm{CH}_{3} \mathrm{OCH}_{3}$ (Ikeda et al. 2001).

In summary, the temperatures for most molecules are rather consistent between all sources. The molecules can clearly be divided into "hot" $(T>100 \mathrm{~K})$ and "cold" $(T<100 \mathrm{~K})$ where $\mathrm{H}_{2} \mathrm{CO}, \mathrm{CH}_{3} \mathrm{OH}, \mathrm{C}_{2} \mathrm{H}_{5} \mathrm{OH}, \mathrm{HNCO}, \mathrm{NH}_{2} \mathrm{CHO}, \mathrm{CH}_{3} \mathrm{CN}$, $\mathrm{C}_{2} \mathrm{H}_{5} \mathrm{CN}, \mathrm{HCOOCH}_{3}$, and $\mathrm{CH}_{3} \mathrm{OCH}_{3}$ belong to the first and $\mathrm{CH}_{2} \mathrm{CO}, \mathrm{CH}_{3} \mathrm{CHO}, \mathrm{HCOOH}$ and $\mathrm{CH}_{3} \mathrm{CCH}$ to the second category.

\subsection{Column densities}

Table 5 and Fig. 4 present the source-averaged column densities, i.e., corrected for beam dilution (Sect. 3.2), for the hot molecules per source. Absolute column densities are compared to determine the variability between different sources. Since we have assumed the beam dilution to be the same for all molecules, the trends for the beam-averaged column densities are similar. Molecules with rotation temperatures below $100 \mathrm{~K}$ are present in a different, cold region, presumably the envelope surrounding 


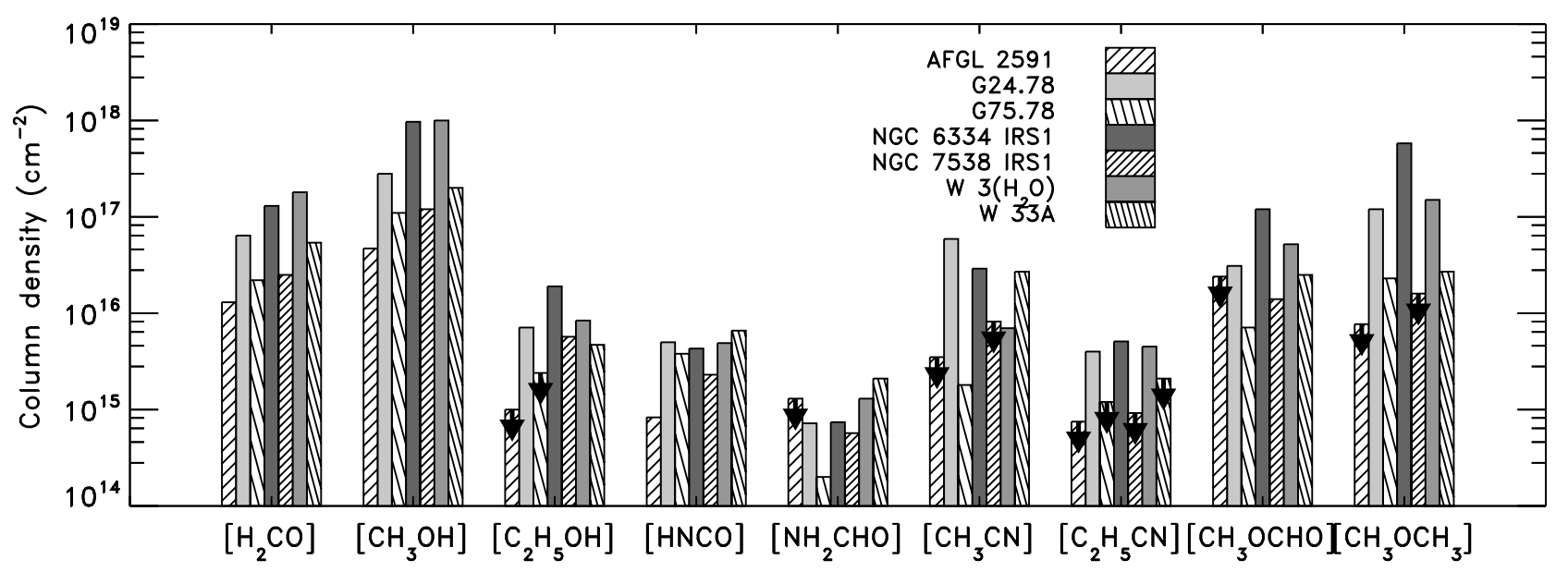

Fig. 4. Histogram of molecular column densities of hot molecules corrected for beam dilution for all sources for a source size defined by $T>100 \mathrm{~K}$.

the hot region, and beam-averaged column densities are therefore given for those. Thus, the column densities for the hot and cold molecules in Figs. 4 and 5 cannot be compared directly.

Clearly, most molecules have column densities that vary by about an order of magnitude in the hot gas between the different sources. The column density variations do not scale with the luminosity and thus total mass in the hot region. $\mathrm{CH}_{3} \mathrm{OH}, \mathrm{H}_{2} \mathrm{CO}$, but also $\mathrm{HCOOCH}_{3}$, and $\mathrm{CH}_{3} \mathrm{OCH}_{3}$ - if detected - have column densities that are orders of magnitude higher than those of $\mathrm{C}_{2} \mathrm{H}_{5} \mathrm{OH}, \mathrm{HNCO}$, and $\mathrm{NH}_{2} \mathrm{CHO}$. As will be discussed in Sect. 5 abundances show a similar trend. The advantage of comparing column densities is that they come directly from the observations and no assumption on the $\mathrm{H}_{2}$ column in the hot gas enters the analysis.

Most hot molecules have source-averaged column densities that are highest for the line-rich sources NGC 6334 IRS1, $\mathrm{G} 24.78$, and $\mathrm{W} 3\left(\mathrm{H}_{2} \mathrm{O}\right)$. For the oxygen-bearing molecules $\mathrm{C}_{2} \mathrm{H}_{5} \mathrm{OH}, \mathrm{CH}_{3} \mathrm{OCH}_{3}, \mathrm{HCOOCH}_{3}, \mathrm{G} 24.78$ has a higher column density than $\mathrm{W} 3\left(\mathrm{H}_{2} \mathrm{O}\right)$. W $3\left(\mathrm{H}_{2} \mathrm{O}\right)$ has a higher column density of $\mathrm{CH}_{3} \mathrm{OH}$ and $\mathrm{H}_{2} \mathrm{CO}$, however. Thus $\mathrm{H}_{2} \mathrm{CO}$ and $\mathrm{CH}_{3} \mathrm{OH}$ have variable column densities compared to the other oxygen-bearing molecules. Nonetheless the column density trends between the oxygen-bearing species are similar.

The $\mathrm{HNCO}$ and $\mathrm{NH}_{2} \mathrm{CHO}$ column densities peak for $\mathrm{W} 33 \mathrm{~A}$ and $\mathrm{G} 24.78$, and have very similar column density trends with respect to each other. W 33A has the highest and G75.78 the lowest column densities. NGC 7538 IRS1 has a relatively high column density for these species compared with the oxygenbearing species. The column densities of the nitrogen-bearing species do, therefore, behave different from the oxygen-bearing species.

$\mathrm{CH}_{3} \mathrm{CN}$ has a relatively high column density for $\mathrm{G} 24.78$ and W $33 \mathrm{~A}$, but the uncertainties make it more difficult to compare its column density trends with other molecules (see Sect. 4.3). The general $\mathrm{CH}_{3} \mathrm{CN}$ column density trends appear more similar to those of $\mathrm{HNCO}$ and $\mathrm{NH}_{2} \mathrm{CHO}$ than to the O-bearing species. However, if we consider only the two sources for which both the main species and its isotopologue $\mathrm{CH}_{3}^{13} \mathrm{CN}$ were detected with $E_{\mathrm{u}}<500 \mathrm{~K}$, the relative column densities appear more similar to those of the oxygen-bearing species.

Figure 5 shows the beam-averaged column densities for the cold molecules, $\mathrm{CH}_{2} \mathrm{CO}, \mathrm{HCOOH}$, and $\mathrm{CH}_{3} \mathrm{CCH}$. Clearly all three have very similar trends. NGC 6334 IRS1 has the highest column density and AFGL 2591 the lowest. For $\mathrm{CH}_{3} \mathrm{CHO}$, the number of sources with detections is limited and it was thus

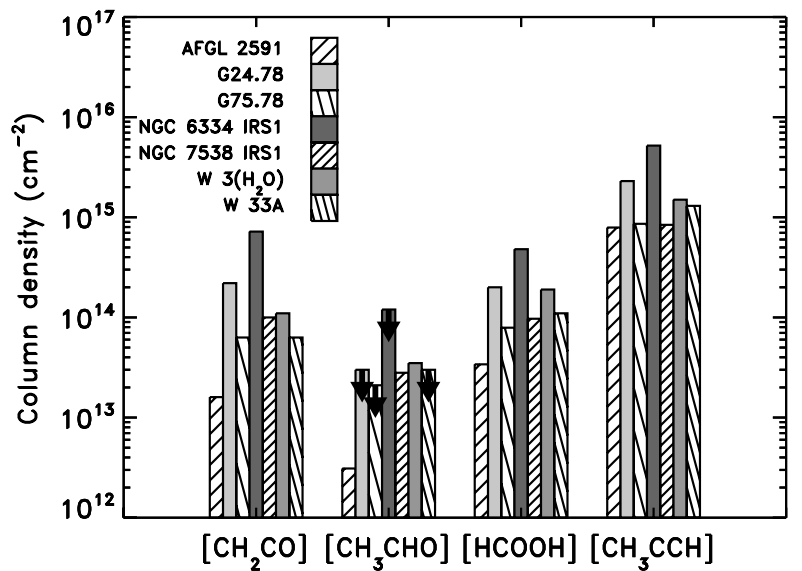

Fig. 5. Histogram of molecular beam-averaged column densities of the cold molecules for all sources.

not possible to compare its column density trends with the other species.

In summary, the molecular abundances vary about an order of magnitude between the sources. Furthermore, all oxygenbearing species have similar abundance trends, but the abundances of $\mathrm{HNCO}$ and $\mathrm{NH}_{2} \mathrm{CHO}$ behave differently.

\section{Column density and abundance correlations}

Molecular column densities and abundances can be compared between sources in different ways, two of which will be presented here. Abundances can be estimated relative to column densities of (i) $\mathrm{H}_{2}$ calculated on the basis of $\mathrm{CO}$, (ii) $\mathrm{H}_{2}$ derived from dust continuum observations (see Sect. 3.2) or (iii) one of the observed molecules, typically $\mathrm{CH}_{3} \mathrm{OH}$. The disadvantage of method (i) is that $\mathrm{CO}$ gas is likely extended over much larger scales than the hot molecules due its lower desorption temperature. Observations of high excitation lines of CO isotopologues which probe only hot gas, will make this method possible in the future. In this paper, we use (ii) and (iii), and adopt (i) only for the cold molecules.

Abundances with respect to $\mathrm{H}_{2}$ column densities from modeling of dust continuum observations (Sect. 3.2) and to $\mathrm{CH}_{3} \mathrm{OH}$ column densities (Sect. 5.2) have the advantage that they allow comparisons to "only material at high temperatures" or "species probing the regions solely of interest". Both approaches also 
Table 7. Molecular abundances $\left(N(\mathrm{X}) / N\left(\mathrm{H}_{2}\right)\right)$.

\begin{tabular}{|c|c|c|c|c|c|c|c|c|c|}
\hline & AFGL 2591 & $\mathrm{G} 24.78$ & G75.78 & NGC 6334 IRS1 & NGC 7538 IRS1 & $\mathrm{W} 3\left(\mathrm{H}_{2} \mathrm{O}\right)$ & W 33A & Average & $\sigma^{a}$ \\
\hline \multicolumn{10}{|c|}{ Hot molecules ${ }^{b}$} \\
\hline$\overline{\mathrm{H}_{2} \mathrm{CO}}$ & $1.7(-7)$ & $1.6(-7)$ & $1.8(-7)$ & $5.4(-7)$ & $1.2(-7)$ & $1.0(-6)$ & $2.1(-7)$ & $3.4(-7)$ & 3.2 \\
\hline $\mathrm{CH}_{3} \mathrm{OH}$ & $7.0(-7)$ & $6.5(-7)$ & $9.2(-7)$ & $4.0(-6)$ & $5.7(-7)$ & $5.4(-6)$ & 7.3(-7) & $1.9(-6)$ & 2.0 \\
\hline $\mathrm{C}_{2} \mathrm{H}_{5} \mathrm{OH}$ & $<1.4(-8)$ & $1.9(-8)$ & $2.0(-8)$ & $7.5(-8)$ & $2.5(-8)$ & $4.4(-8)$ & $1.8(-8)$ & $3.6(-8)$ & 2.3 \\
\hline HNCO & $7.0(-9)$ & $1.3(-8)$ & $3.2(-9)$ & $1.8(-8)$ & $1.1(-8)$ & $2.7(-8)$ & $2.5(-8)$ & $1.6(-8)$ & 0.91 \\
\hline $\mathrm{NH}_{2} \mathrm{CHO}$ & $<1.7(-8)$ & $1.8(-9)$ & $1.7(-9)$ & $3.1(-9)$ & $2.6(-9)$ & $5.6(-9)$ & $8.5(-9)$ & $3.9(-9)$ & 2.7 \\
\hline $\mathrm{CH}_{3} \mathrm{CN}$ & $<4.6(-8)$ & $1.5(-7)$ & $1.5(-8)$ & $1.2(-7)$ & $<3.9(-8)$ & $3.9(-8)$ & $1.0(-7)$ & $8.5(-8)$ & 5.6 \\
\hline $\mathrm{C}_{2} \mathrm{H}_{5} \mathrm{CN}$ & $<9.9(-9)$ & $1.0(-8)$ & $<1.0(-8)$ & $2.1(-8)$ & $<4.4(-9)$ & $2.5(-8)$ & $<8.1(-9)$ & $1.7(-8)$ & 0.77 \\
\hline $\mathrm{HCOOCH}_{3}$ & $<3.2(-7)$ & $7.3(-8)$ & $5.9(-8)$ & $4.6(-7)$ & $6.7(-8)$ & $2.9(-7)$ & $9.6(-8)$ & $1.7(-7)$ & 1.6 \\
\hline $\mathrm{CH}_{3} \mathrm{OCH}_{3}$ & $<1.0(-7)$ & $3.0(-7)$ & $1.9(-7)$ & $2.4(-6)$ & $<7.6(-8)$ & $8.3(-7)$ & $1.0(-7)$ & $7.7(-7)$ & 9.6 \\
\hline \multicolumn{10}{|c|}{ Cold molecules ${ }^{c}$} \\
\hline $\mathrm{CH}_{2} \mathrm{CO}$ & $3.1(-11)$ & $8.8(-10)$ & $8.5(-11)$ & $2.8(-10)$ & $4.1(-10)$ & $1.3(-10)$ & $4.1(-10)$ & $3.2(-10)$ & 2.9 \\
\hline $\mathrm{CH}_{3} \mathrm{CHO}$ & $6.1(-12)$ & $<6.3(-11)$ & $<2.8(-11)$ & $<4.7(-11)$ & $1.2(-10)$ & $4.1(-11)$ & $<1.9(-10)$ & $5.6(-11)$ & 5.8 \\
\hline $\mathrm{HCOOH}$ & $6.7(-11)$ & $8.8(-10)$ & $1.0(-10)$ & $1.9(-10)$ & $4.2(-10)$ & $1.8(-10)$ & $8.4(-10)$ & $3.8(-10)$ & 3.4 \\
\hline $\mathrm{CH}_{3} \mathrm{CCH}$ & $1.5(-9)$ & $9.6(-9)$ & $1.1(-9)$ & $2.1(-9)$ & $3.6(-9)$ & $1.8(-9)$ & $8.4(-9)$ & $4.0(-9)$ & 3.5 \\
\hline
\end{tabular}

${ }^{a} \sigma$ refers to the same order of magnitude as the average. ${ }^{b}$ The abundances are derived with respect to the column density of $\mathrm{H}_{2}$ within $R_{T=100 \mathrm{~K}}$ in Sect. 3.2 and Table 3. ${ }^{c}$ The abundances are derived using the CO column densities from van der Tak et al. (2000), except G24.78 and G75.78 for which the data comes from Cesaroni et al. (2003) and Hatchell et al. (1998) respectively. ${ }^{c} \sigma$ refers to the same order of magnitude as the average.

Table 8. Abundance correlations with respect to $\mathrm{H}_{2}$ for the abundances within $R_{T=100 \mathrm{~K}}$. for hot core molecules.

\begin{tabular}{lccccccccc}
\hline \hline & $\mathrm{H}_{2} \mathrm{CO}$ & $\mathrm{CH}_{3} \mathrm{OH}$ & $\mathrm{C}_{2} \mathrm{H}_{5} \mathrm{OH}$ & $\mathrm{HNCO}$ & $\mathrm{NH}_{2} \mathrm{CHO}$ & $\mathrm{CH}_{3} \mathrm{CN}$ & $\mathrm{HCOOCH}_{3}$ & $\mathrm{CH}_{3} \mathrm{OCH}_{3}$ & $\mathrm{HCOOH}$ \\
\hline $\mathrm{H}_{2} \mathrm{CO}$ & 1.00 & 0.98 & 0.76 & 0.46 & 0.53 & -0.07 & 0.88 & 0.75 & 0.76 \\
$\mathrm{CH}_{3} \mathrm{OH}$ & 0.98 & 1.00 & 0.86 & 0.38 & 0.39 & -0.07 & 0.92 & 0.86 & 0.70 \\
$\mathrm{C}_{2} \mathrm{H}_{5} \mathrm{OH}$ & 0.76 & 0.86 & 1.00 & 0.02 & 0.22 & 0.12 & 0.92 & 0.95 & 0.30 \\
$\mathrm{HNCO}$ & 0.46 & 0.38 & 0.02 & 1.00 & 0.38 & 0.81 & 0.16 & -0.27 & 0.98 \\
$\mathrm{NH}_{2} \mathrm{CHO}$ & 0.53 & 0.39 & 0.22 & 0.38 & 1.00 & 0.17 & 0.42 & -0.02 & 0.65 \\
$\mathrm{CH}_{3} \mathrm{CN}$ & -0.07 & -0.07 & 0.12 & -0.81 & 0.17 & 1.00 & 0.29 & 0.20 & -0.51 \\
$\mathrm{HCOOCH}_{3}$ & 0.88 & 0.92 & 0.92 & 0.16 & 0.42 & 0.29 & 1.00 & 0.90 & 0.49 \\
$\mathrm{CH}_{3} \mathrm{OCH}_{3}$ & 0.75 & 0.86 & 0.95 & -0.27 & -0.02 & 0.20 & 0.90 & 1.00 & 0.09 \\
$\mathrm{HCOOH}^{a}$ & 0.76 & 0.70 & 0.30 & 0.98 & 0.65 & -0.51 & 0.49 & 0.09 & 1.00 \\
\hline
\end{tabular}

$a$ Assuming that the $\mathrm{HCOOH}$ emission comes from within $R_{T=100 \mathrm{~K}}$.

have disadvantages, however. Since $\mathrm{H}_{2}$ is not directly observed, one has to rely on other tracers, in our case dust. Extrapolations of density and temperature profiles are made to scales smaller than actually probed by the observations. $\mathrm{CH}_{3} \mathrm{OH}$ is directly observed, but this method implicitly assumes that the abundance of $\mathrm{CH}_{3} \mathrm{OH}$ is constant from source to source. If this is not the case incorrect correlations of abundances with respect to $\mathrm{CH}_{3} \mathrm{OH}$ can be found, as we will return to in Sect. 5.2.

\subsection{Abundances in $T \geq 100 \mathrm{~K}$ gas}

Table 7 lists the molecular abundances within the gas with $T \geq 100 \mathrm{~K}$ for each source in our sample calculated through Eq. (7). The abundances have the same trends between the different sources as the column densities. Most molecules have abundances that vary one order of magnitude from source to source, as was also seen for $\mathrm{CH}_{3} \mathrm{OH}$ by van der Tak et al. (2000). The standard deviation on the average abundances is larger than our estimated uncertainty of a factor 2-3 (Sect. 3). Thus the observed variations are real. Furthermore, the overall abundances are relatively high compared to values in the literature. This is because we have determined the abundances with respect to the $\mathrm{H}_{2}$ column density within $R_{T=100 \mathrm{~K}}$, whereas in e.g., Ikeda et al. (2001) they are determined based on $\mathrm{CO}$ transitions, which trace gas that is cooler and extended with respect to the hot core.

The abundances of the species detected in our sources with $T \geqslant 100 \mathrm{~K}$ were compared by estimating the Pearson correlation coefficients between $\log \left(\mathrm{X} / \mathrm{H}_{2}\right)$ vs. $\log \left(\mathrm{Y} / \mathrm{H}_{2}\right)$ (see Table 8$)$.

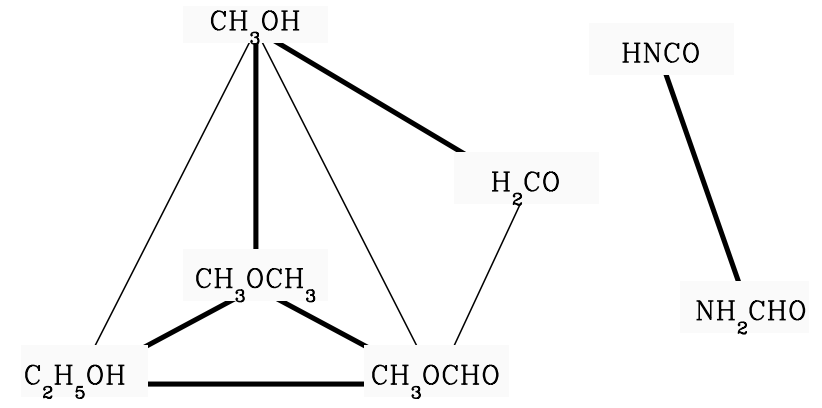

Fig. 6. Empirical correlations between the different molecules based on the Pearson correlation coefficients. All solid lines indicate correlations coefficients $>0.8$ and the thick lines $>0.9$. When two species correlate, it does not mean that they are directly chemically related. Two species can also correlate if they are both formed from the same mother species.

$\mathrm{C}_{2} \mathrm{H}_{5} \mathrm{CN}$ is not compared with the other species due to the low number of sources with detections. Although the number of sources for the other molecules are limited and correlations therefore only suggestive, a number of interesting trends are seen. These result from groups of molecules with very similar abundance trends.

First, the abundances of the nitrogen-bearing species do not correlate with those of oxygen-bearing species. Strong correlations are, however, found between the oxygen-bearing species $\mathrm{H}_{2} \mathrm{CO}, \mathrm{CH}_{3} \mathrm{OH}, \mathrm{C}_{2} \mathrm{H}_{5} \mathrm{OH}, \mathrm{HCOOCH}_{3}$, and $\mathrm{CH}_{3} \mathrm{OCH}_{3}$. Figure 7 shows the abundances of all hot oxygen-bearing species with 


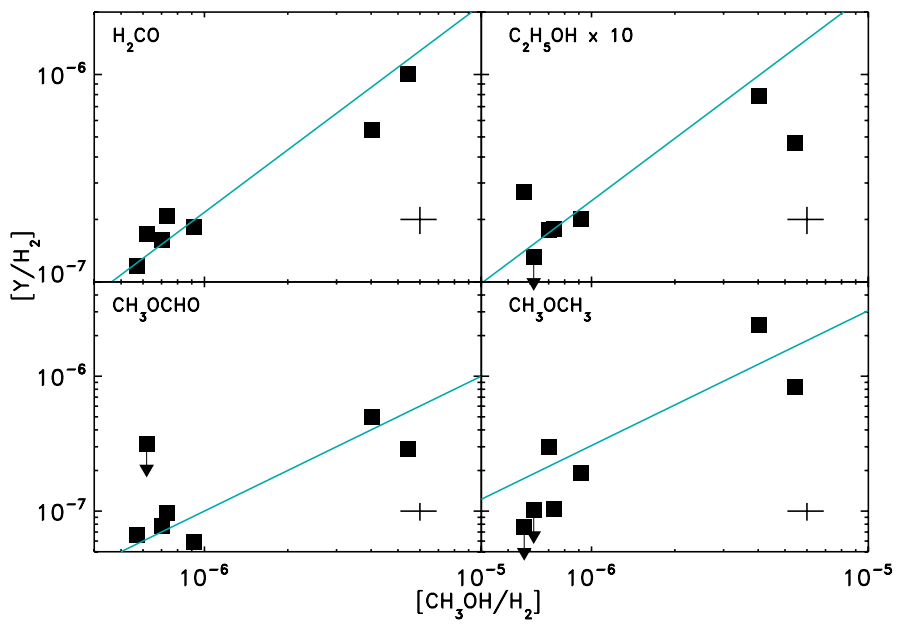

Fig. 7. Comparison of molecular abundances with respect to $\mathrm{H}_{2}$ within $R_{T=100 \mathrm{~K}}$ for the oxygen-bearing molecules. The gray lines indicate the linear fit to the data. An error-bar representing the calibration uncertainties is depicted in the lower right corner.

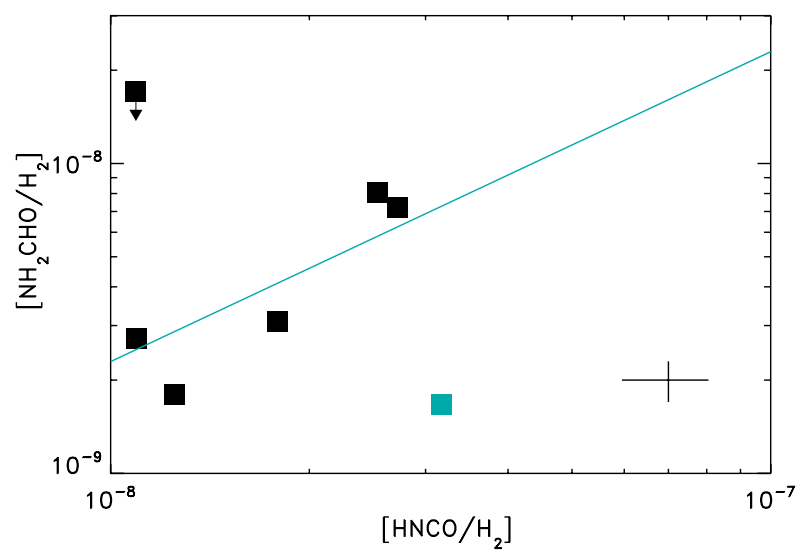

Fig. 8. Comparison of molecular abundances with respect to $\mathrm{H}_{2}$ for $\mathrm{HNCO}$ with $\mathrm{NH}_{2} \mathrm{CHO}$ within $R_{T=100 \mathrm{~K}}$. The source indicated in gray is G75.78 and the limit is AFGL 2591. An error-bar representing the calibration uncertainties is depicted in the lower right corner.

respect to $\mathrm{H}_{2}$ compared to $\mathrm{CH}_{3} \mathrm{OH} / \mathrm{H}_{2}$. The nitrogen-bearing species $\mathrm{HNCO}$ and $\mathrm{NH}_{2} \mathrm{CHO}$ also appear to be well correlated, which follows from the column density trends (Sect. 4 and shown in Fig. 8). The $\mathrm{NH}_{2} \mathrm{CHO}$ abundance for $\mathrm{G} 75.78$ is uncertain, as only few lines were detected. The correlation coefficient is 0.38 with this source included and 0.92 without.

If the $\mathrm{HCOOH}$ emission is assumed to arise in hot instead of cold gas, its abundance correlates with very few molecular species. Its strongest correlation is with HNCO with a coefficient of 0.98 . This result is surprising and due to the low rotation temperatures for $\mathrm{HCOOH}$ questionable.

The abundances of the hot molecules presented in Table 7 and Fig. 7 assume the same beam dilution factor corresponding to $R_{T=100 \mathrm{~K}}$. As Table 6 shows, the rotation diagram temperatures of several species are significantly higher than $100 \mathrm{~K}$. The $T=200 \mathrm{~K}$ radius is typically a factor of $\sim 3$ smaller than that for $100 \mathrm{~K}$ so that the beam dilution and abundances can be a factor $\sim 9$ larger. If all emission of hot molecules would arise from a smaller region, the correlations would remain the same. If some species are present in $100 \mathrm{~K}$ gas and others in $200 \mathrm{~K}$ gas, the correlations would disappear, however. The differences in rotation temperatures in Table 6 are assumed to arise largely from other effects such as optical depth, sub-thermal excitation, or the detection of very high or low lying energy levels affecting the overall fit. Future interferometric observations of multiple high mass sources could determine whether the assumption of a single source size for all molecules is correct.

For the molecules that have abundances that do correlate, the abundance ratios were calculated with respect to either $\mathrm{CH}_{3} \mathrm{OH} / \mathrm{H}_{2}$ or $\mathrm{HNCO} / \mathrm{H}_{2}$ and are shown in Table 9. Figure 6 shows the empirical relations for molecules with Pearson coefficients of 0.8 and higher. Per set of species the ratios vary no more than a factor of three, the previously found uncertainty in the abundances. $\mathrm{H}_{2} \mathrm{CO}, \mathrm{HCOOCH}_{3}$, and $\mathrm{CH}_{3} \mathrm{OCH}_{3}$ have 510 times lower abundances than $\mathrm{CH}_{3} \mathrm{OH}$. $\mathrm{NH}_{2} \mathrm{CHO}$ is a factor 3 times lower than HNCO. Possibly, coefficients between 0.8-0.9 are present between species that are not directly chemically related, but that are both strongly correlated with a third species.

\subsection{Abundances with respect to $\mathrm{CH}_{3} \mathrm{OH}$}

The Pearson correlation coefficients of $\log \left(\mathrm{X} / \mathrm{CH}_{3} \mathrm{OH}\right)$ vs. $\log \left(\mathrm{Y} / \mathrm{CH}_{3} \mathrm{OH}\right)$ differ significantly from the correlations in Sect. 5.1. First, strong correlations are not present between the same species. This is due to the variability of the $\mathrm{CH}_{3} \mathrm{OH}$ abundance between the different sources, and to the dependence of the correlations on three $\left(\mathrm{X}, \mathrm{Y}\right.$, and $\left.\mathrm{CH}_{3} \mathrm{OH}\right)$ rather than two ( $\mathrm{X}$ and $\mathrm{Y}$ ) species. The abundances of two species with respect to $\mathrm{CH}_{3} \mathrm{OH}$ will correlate when their abundances with respect to $\mathrm{H}_{2}$ correlate but also when the abundance of one of the species correlates with that of $\mathrm{CH}_{3} \mathrm{OH}$. This makes it difficult to use correlations of abundance ratios with respect to $\mathrm{CH}_{3} \mathrm{OH}$ to chemically link molecules. Instead it is better to compare $\mathrm{X} / \mathrm{CH}_{3} \mathrm{OH}$ with the $\mathrm{CH}_{3} \mathrm{OH}$ column density or abundance, i.e. $\mathrm{N}\left(\mathrm{CH}_{3} \mathrm{OH}\right)$ or $\mathrm{CH}_{3} \mathrm{OH} / \mathrm{H}_{2}$ as has been done by e.g., Requena-Torres et al. (2006).

\subsection{Comparison to other well known sources}

The abundance ratios with respect to $\mathrm{CH}_{3} \mathrm{OH}$ are compared in Table 9 to other well-studied high mass star forming regions, specifically the Orion Compact Ridge (Sutton et al. 1995), G34.3 (MacDonald et al. 1996), Sgr B2(N) (Nummelin et al. 2000), and G327.3 (Gibb et al. 2000a). The ratios for the Orion Compact Ridge all agree within the error bars for $\mathrm{H}_{2} \mathrm{CO}$ and $\mathrm{HCOOCH}_{3} \cdot \mathrm{CH}_{3} \mathrm{OCH}_{3}$ has a relatively low abundance with respect to $\mathrm{CH}_{3} \mathrm{OH}$. Only three lines have been detected for this species in the Compact Ridge and it has a rather low excitation temperature of $75 \mathrm{~K}$ implying that it is perhaps present in a colder region.

In contrast, the relative abundances for $\mathrm{G} 34.3$ deviate more from those in our work. The $\mathrm{H}_{2} \mathrm{CO} / \mathrm{CH}_{3} \mathrm{OH}$ ratio by MacDonald et al. (1996) is probably a lower limit as only one line was detected for $\mathrm{G} 34.3$ and the column density of $\mathrm{H}_{2}^{13} \mathrm{CO}$ was calculated to be higher than the main $\mathrm{H}_{2} \mathrm{CO}$ isotopologue based on their respective line intensities. Both $\mathrm{C}_{2} \mathrm{H}_{5} \mathrm{OH}$ and $\mathrm{HCOOCH}_{3}$ have relatively high abundances with respect to $\mathrm{CH}_{3} \mathrm{OH}$. This could potentially be due to high optical depth in the lines of $\mathrm{CH}_{3} \mathrm{OH}$. MacDonald et al. (1996) assumed the emission to be optically thin, and thus underestimate the $\mathrm{CH}_{3} \mathrm{OH}$ column density. The relative abundances of $\mathrm{C}_{2} \mathrm{H}_{5} \mathrm{OH}$ and $\mathrm{HCOOCH}_{3}$ are similar between $\mathrm{G} 34.3$ and the sources studied in this paper.

The abundance ratios with respect to $\mathrm{CH}_{3} \mathrm{OH}$ for Sgr B2(N) from Nummelin et al. (2000) appear to be significantly lower than for the sources in our sample. This is due to the $\mathrm{CH}_{3} \mathrm{OH}$ 
Table 9. Average abundance ratio for our sources and other well-known high mass YSOs with respect to $\mathrm{CH}_{3} \mathrm{OH}$ for the oxygen-bearing species and with respect to $\mathrm{HNCO}$ for $\mathrm{NH}_{2} \mathrm{CHO} . \sigma$ is the standard deviation between the sources in our sample.

\begin{tabular}{|c|c|c|c|c|c|c|}
\hline Molecule & abundance $\operatorname{ratio}(\sigma)$ & Orion Compact Ridge ${ }^{a}$ & $\mathrm{G} 34.3^{b}$ & Sgr B2(N) ${ }^{c}$ & $\mathrm{G} 327.3^{d}$ & GC clouds ${ }^{e}$ \\
\hline \multicolumn{7}{|c|}{ with respect to $\mathrm{CH}_{3} \mathrm{OH}$} \\
\hline $\mathrm{H}_{2} \mathrm{CO}$ & $0.22 \pm 0.05$ & 0.10 & 0.009 & $>0.0025$ & - & $\sim 0.01$ \\
\hline $\mathrm{C}_{2} \mathrm{H}_{5} \mathrm{OH}$ & $0.025 \pm 0.013$ & 0.004 & 0.19 & 0.005 & 0.05 & $\sim 0.04$ \\
\hline $\mathrm{HCOOCH}_{3}$ & $0.10 \pm 0.03$ & 0.08 & 0.86 & 0.005 & 0.96 & $\sim 0.04$ \\
\hline $\mathrm{CH}_{3} \mathrm{OCH}_{3}$ & $0.31 \pm 0.20$ & 0.05 & - & 0.015 & 7 & $\sim 0.04$ \\
\hline \multicolumn{7}{|c|}{ with respect to HNCO } \\
\hline $\mathrm{NH}_{2} \mathrm{CHO}$ & $0.36 \pm 0.08$ & 1 & - & 0.23 & 0.07 & \\
\hline
\end{tabular}

${ }^{a}$ Sutton et al. (1995). ${ }^{b}$ MacDonald et al. (1996). ${ }^{c}$ Nummelin et al. (2000). ${ }^{d}$ Gibb et al. (2000a). ${ }^{e}$ Requena-Torres et al. (2006).

emission being decomposed into a core and a halo component for Sgr B2(N), whereas that of the other molecules is not. For this source it is more relevant to compare the relative ratios between the different molecules. The $\mathrm{C}_{2} \mathrm{H}_{5} \mathrm{OH}$ abundance is high compared to $\mathrm{HCOOCH}_{3}$ and $\mathrm{CH}_{3} \mathrm{OCH}_{3}$. However, the $\mathrm{HCOOCH}_{3} / \mathrm{CH}_{3} \mathrm{OCH}_{3}$ and the $\mathrm{NH}_{2} \mathrm{CHO} / \mathrm{HNCO}$ ratios of 0.33 are similar to those for our sources.

G327.3 in the study of Gibb et al. (2000a) has a $\mathrm{C}_{2} \mathrm{H}_{5} \mathrm{OH} / \mathrm{CH}_{3} \mathrm{OH}$ abundance ratio a factor of 2 higher compared to the average for our sample. Small deviations could be caused by their relatively low rotation temperature for $\mathrm{C}_{2} \mathrm{H}_{5} \mathrm{OH}$ of $66 \mathrm{~K}$. $\mathrm{HCOOCH}_{3}$ and $\mathrm{CH}_{3} \mathrm{OCH}_{3}$ have relatively high abundances with respect to $\mathrm{CH}_{3} \mathrm{OH}$, but $\mathrm{HCOOCH}_{3} / \mathrm{CH}_{3} \mathrm{OCH}_{3}$ is within a factor two of the ratio derived for our sample. Again $\mathrm{NH}_{2} \mathrm{CHO} / \mathrm{HNCO}$ is the same within error to our sample.

Molecular abundance ratios can also be compared to those found in shocked gas in the galactic center by Requena-Torres et al. (2006). Their sources have relatively constant ratios of complex molecules with respect to $\mathrm{CH}_{3} \mathrm{OH}$ of 0.04 . The $\mathrm{H}_{2} \mathrm{CO} / \mathrm{CH}_{3} \mathrm{OH}$ and $\mathrm{CH}_{3} \mathrm{OCH}_{3} / \mathrm{CH}_{3} \mathrm{OH}$ ratios are significantly higher for our hot cores. Small differences may be due to the fact that Requena-Torres et al. (2006) observed rotational transitions with $E_{\mathrm{u}}<40-50 \mathrm{~K}$, whereas lines with excitation energies that range from $20-900 \mathrm{~K}$ have been observed in this study.

In summary, the overall emerging picture is that of relatively constant abundance ratios between various molecules comparable to the sources for our sample. Distinct differences for individual species can often be ascribed to specific observation or analysis problems.

\subsection{Comparison with ice abundances}

It is interesting to relate the gas-phase abundances derived above to the ice abundances from mid-infrared observations. Of the sources in our sample, AFGL 2591, NGC 7538 IRS1 and W 33A were also observed at mid-infrared wavelengths with ISO (Gibb et al. 2004). Table 10 lists the abundances of the ice species from that paper assuming an $\mathrm{H}_{2} \mathrm{O}$ abundance of $10^{-4}$ with respect to $\mathrm{H}_{2}$. W $33 \mathrm{~A}$ is particularly rich in organics in the solid state whereas the other two sources mainly have upper limits. The solid state abundances of $\mathrm{CH}_{3} \mathrm{OH}$ are at least an order of magnitude higher than the comparable source-averaged gas phase abundances. The $\mathrm{H}_{2} \mathrm{CO}$ abundance of $\sim 2 \times 10^{-6}$, although more uncertain, is also larger by an order of magnitude (Keane et al. 2001). For $\mathrm{W} 33 \mathrm{~A}$, however, the solid $\mathrm{H}_{2} \mathrm{CO} / \mathrm{CH}_{3} \mathrm{OH}$ abundance ratio is consistent with the gas phase abundance ratio.

Where detected toward high mass YSOs, solid $\mathrm{HCOOH}$ and $\mathrm{CH}_{3} \mathrm{CHO}$ have abundances of $10^{-6}-10^{-5}$ and $\sim 10^{-5}$ respectively (Schutte et al. 1999; Keane et al. 2001; Gibb et al. 2000b, 2004). Similar abundances for solid $\mathrm{HCOOH}$ are found toward background stars by Knez et al. (2005). These absolute solid state abundances are four to five orders of magnitude higher than the gas phase abundances for the same sources.

The XCN band is detected in many objects and usually assigned to $\mathrm{OCN}^{-}$(Grim \& Greenberg 1987; Demyk et al. 1998; Pendleton et al. 1999; Gibb et al. 2000b; van Broekhuizen et al. 2005). $\mathrm{OCN}^{-}$is thought to convert to and evaporate off grains as $\mathrm{HNCO}$ (Sect. 6.1). Abundances of solid $\mathrm{OCN}^{-}$vary and range from $1 \times 10^{-7}-4 \times 10^{-6}$ (van Broekhuizen et al. 2005; Thi et al. 2006). Gas phase abundances of HNCO are factors of 1001000 times lower.

Many of the species are expected to have abundances in the ice below the detection limit. Boudin et al. (1998) determined upper limits for the column densities of a number of more complex organic molecules, including $\mathrm{C}_{2} \mathrm{H}_{6}$ and $\mathrm{C}_{2} \mathrm{H}_{5} \mathrm{OH}$ toward NGC 7538 IRS9. The upper limit on the $\mathrm{C}_{2} \mathrm{H}_{5} \mathrm{OH}$ abundance is $1.2 \times 10^{-6}$ with $\mathrm{C}_{2} \mathrm{H}_{5} \mathrm{OH} / \mathrm{CH}_{3} \mathrm{OH}<0.28$. This is consistent with the $\mathrm{C}_{2} \mathrm{H}_{5} \mathrm{OH} / \mathrm{CH}_{3} \mathrm{OH}$ abundance ratio of 0.009 in the gas phase for our sample of sources.

In summary, the absolute ice abundances of observed "first generation" species, $\mathrm{CH}_{3} \mathrm{OH}$ and $\mathrm{OCN}^{-}$, are $10-10^{2}$ times higher compared to the gas phase values, and as much as a factor of $10^{4}-10^{5}$ for $\mathrm{HCOOH}$ and $\mathrm{CH}_{3} \mathrm{CHO}$.

\section{Discussion and comparison to astrochemical models}

\subsection{General model considerations}

Pure gas phase chemistry models such as presented in e.g., Lee et al. (1996), are unable to explain the high abundances of many complex organics, especially of highly saturated molecules in hot gas phase environments. $\mathrm{CH}_{3} \mathrm{OH}$, for example, is estimated to have abundances of $\sim 10^{-12}$ through pure gas phase chemistry, whereas abundances of $10^{-6}$ are found. For $\mathrm{CH}_{3} \mathrm{CN}$ abundances of $\sim 10^{-10}$ are modeled (Lee et al. 1996) whereas abundances of $\sim 10^{-7}$ are detected. Furthermore, they are not able to explain the presence of complex organics in ices by simple freeze-out of gas phase species (see Herbst 2005, for a review). For highly saturated molecules, solid state chemistry provides a likely alternative. Here one can distinguish basic grain surface chemistry and chemistry induced by energetic processing (UV irradiation, energetic particle bombardment and/or thermal heating) which can proceed also inside the ice.

Surface chemistry models have been developed by several groups (e.g., Hasegawa \& Herbst 1993; Charnley 2001; Keane 2001) (see Fig. 1). The results are generally very sensitive to the atomic $\mathrm{C}, \mathrm{O}$, and $\mathrm{N}$ abundances in the gas. Moreover, the dust temperature $\left(T_{\text {dust }}\right)$ plays a crucial role in the mobility of the atoms and radicals as well as the availability of $\mathrm{CO}$ as a reaction 
Table 10. Solid state abundances with respect to $\mathrm{H}_{2}$, assuming $\mathrm{H}_{2} \mathrm{O}$ ice to have an abundance of $10^{-4}$.

\begin{tabular}{|c|c|c|c|c|c|c|}
\hline Species & $\begin{array}{l}\text { W } 33 \mathrm{~A}^{a} \\
10^{-5}\end{array}$ & $\begin{array}{l}\text { NGC } 7538 \text { IRS }^{b}{ }^{b} \\
10^{-5}\end{array}$ & $\begin{array}{l}\text { AFGL } 2591^{b} \\
10^{-5}\end{array}$ & $\begin{array}{l}\mathrm{HH} 46^{c} \text { (low mass) } \\
10^{-5}\end{array}$ & $\begin{array}{l}\mathrm{CK} 2^{c} \text { (field star) } \\
10^{-5}\end{array}$ & gas phase ${ }^{d}$ \\
\hline $\mathrm{H}_{2} \mathrm{CO}$ & 0.65 & - & - & - & - & $3.2(-7)$ \\
\hline $\mathrm{CH}_{3} \mathrm{OH}$ & $1.4-1.7$ & $<0.4$ & 1.4 & 1.2 & $<0.11$ & $2.0(-6)$ \\
\hline $\mathrm{HCOOH}$ & $0.37-0.71$ & 2.2 & $<1.7$ & $<1.5$ & 0.11 & $3.8(-10)$ \\
\hline $\mathrm{CH}_{3} \mathrm{CHO}$ & 0.98 & 1.2 & $<0.66$ & - & - & $5.6(-11)$ \\
\hline $\mathrm{OCN}^{-}$ & 0.63 & $<0.05$ & - & $\lesssim 0.12$ & - & $1.6(-8)^{e}$ \\
\hline
\end{tabular}

${ }^{a}$ From Gibb et al. (2000b); Dartois et al. (1999); Schutte et al. (1999); Whittet et al. (2001); Demyk et al. (1998). ${ }^{b}$ From Gibb et al. (2004). ${ }^{c}$ From Knez et al. (2005) and references therein. ${ }^{d}$ Average abundances from this paper. ${ }^{e}$ Assuming that $\mathrm{OCN}^{-}$evaporates as $\mathrm{HNCO}$.

partner on the grain, which evaporates at $T_{\text {dust }}>20 \mathrm{~K}$ (Tielens \& Hagen 1982; Caselli et al. 1993). However, if CO is located in an ice environment that is dominated by $\mathrm{H}_{2} \mathrm{O}$ it will be available for reactions in the ice up to much higher temperatures (Sandford \& Allamandola 1993; Collings et al. 2003).

If grain surface chemistry is the explanation for our observed correlations, the constant abundance ratios for different sources must imply very similar conditions during ice formation, at least of the ice layer that contains the "hot" molecules. This is also confirmed by the similarity between the composition of ices observed toward background stars compared to those toward low and high mass star forming regions (Knez et al. 2005). Perhaps the simplest explanation is that the bulk of the ice forms at similarly low temperature conditions in which the bulk of the oxygen and nitrogen are in atomic form and $\mathrm{C} / \mathrm{CO}$ is at a fairly constant ratio, around 0.01 as computed for dense clouds (Gredel et al. 1989). When these "first generation" species evaporate together and have similar destruction rates, a constant abundance ratio would result even in regions where the temperatures of the gas and UV-flux are very different.

In contrast, "second generation" species are expected to peak at different times dependent on their formation and destruction processes. While this argument has been used to explain the anti-coincidences between the nitrogen and oxygen-bearing species (Caselli et al. 1993; Rodgers \& Charnley 2003), it is inconsistent with our observed correlations of supposedly "second generation" species $\mathrm{HCOOCH}_{3}$ and $\mathrm{CH}_{3} \mathrm{OCH}_{3}$ with other "first generation" oxygen-bearing molecules. Indeed, in models by Garrod \& Herbst (2006) where $\mathrm{HCOOCH}_{3}$ is formed in the solid state, many of the oxygen-bearing species have similar gas phase abundance variations throughout the chemical evolution and have constant abundance ratios. Solid state formation is therefore more likely for the supposedly "second generation" oxygen-bearing species. However, the abundances of oxygenbearing and nitrogen-bearing species do not correlate. This can be due to a different time-dependence of formation and destruction or a variable $\mathrm{N} / \mathrm{C}$ abundance ratio.

Laboratory experiments show that beyond a certain minimum dose of irradiation the reaction products often do reach a constant plateau (Gerakines et al. 1996; Moore \& Hudson 2000; van Broekhuizen et al. 2004; Hagen et al. 1979). Oxygenbearing species, such as $\mathrm{H}_{2} \mathrm{CO}$, and nitrogen-bearing species, e.g., $\mathrm{OCN}^{-}$and $\mathrm{NH}_{2} \mathrm{CHO}$, can be formed this way (Grim et al. 1989). However, there is not enough information in the literature on the formation of the more complex molecules observed here to make a quantitative test of this scheme. It is plausible, though, that an equilibrium between formation and destruction is reached in interstellar ices and could be responsible for the constant abundance ratios between the oxygen-bearing species or $\mathrm{HNCO} / \mathrm{NH}_{2} \mathrm{CHO}$.
Recent work by Garrod \& Herbst (2006) combines both grain surface chemistry and UV-induced chemistry with thermal evolution of the ices during the protostellar phase. In particular, radicals created in the ices by ultraviolet radiation become mobile at the higher dust temperatures during the warm-up phase and lead to the formation of many complex organic species. This suggests that the ice composition changes with temperature. Potentially only the ices on grains that are close to the evaporation temperature have similar relative abundances to those observed in the gas phase. Since the detected ice features are observed in a column, they will contain both cold and warmer ices, which complicates the comparison of the ice abundances with the gas phase, even within one source.

Species such as $\mathrm{HCOOH}$ and $\mathrm{CH}_{3} \mathrm{CHO}$ are detected with much lower column densities in the gas phase than in the ice (see Sect. 5.4) and have low rotation temperatures. Possibly, these species are formed in the solid state at low temperatures and destroyed due to reactions at high temperatures. Since their desorption temperatures are typically $\sim 100 \mathrm{~K}$ (Viti et al. 2004), thermal desorption cannot account for their low temperatures. However, non-thermal mechanisms induced by, for example, cosmic rays (Léger et al. 1985), can explain the low gas phase abundances if they cause a small fraction $\left(10^{-4}\right)$ of the ice to evaporate (see Sect. 6.2). Alternatively, cold gas phase ion-molecule reactions are able to reproduce the abundances of e.g., $\mathrm{CH}_{3} \mathrm{CHO}$ and $\mathrm{CH}_{2} \mathrm{CO}$ (Lee et al. 1996, see also Sect. 6.2).

Ices are expected to be layered because different molecules such as $\mathrm{H}_{2} \mathrm{O}, \mathrm{CO}$, and $\mathrm{N}_{2}$ form or condense at different densities. Since nitrogen is transformed into $\mathrm{N}_{2}$ deepest in the cloud it is expected to freeze-out last. To form species such as $\mathrm{HNCO}$ or $\mathrm{NH}_{2} \mathrm{CHO}$ a more reactive form of nitrogen, i.e. $\mathrm{N}$-atoms are needed. $\mathrm{N}$-atoms could potentially be present in a non-hydrogen bonding layer dominated by $\mathrm{CO}$ or a layer dominated by $\mathrm{H}_{2} \mathrm{O}$. If they were present in the non-hydrogen bonding layer a small fraction of non-thermal desorption would result in cold gas phase N-bearing species. The lack of these cold Nbearing molecules and high rotation temperatures of $\mathrm{HNCO}$ and $\mathrm{NH}_{2} \mathrm{CHO}$ suggests that they desorb at higher temperatures and must thus be present in a different, more tightly bound ice layer.

In summary, pure gas-phase reactions cannot reproduce the abundances of most species depicted in Fig. 1, and second generation gas phase chemistry is inconsistent with the observed correlations for the oxygen-bearing species. Constant abundance ratios after ice evaporation can be explained either by similar initial conditions for ice formation or an equilibrium between formation and destruction due to energetic processes. The low abundances of cold gas phase species could be due to gas phase ion-molecule reactions or non-thermal desorption of a small fraction of the ices e.g., by cosmic rays. 


\subsection{Individual molecules}

This subsection elaborates on the general conclusions stated in Sect. 6.1 for individual molecules, grouped according to the different branches of Fig. 1.

$\mathrm{H}_{2} \mathrm{CO}$ and $\mathrm{CH}_{3} \mathrm{OH}: \mathrm{CH}_{3} \mathrm{OH}$ and $\mathrm{H}_{2} \mathrm{CO}$ are molecules commonly expected to originate from grain-surface chemistry. They are formed through successive hydrogenation of $\mathrm{CO}$ on grains, a scheme that has been tested experimentally by Hiraoka et al. (2002), Watanabe et al. (2004), and Fuchs et al. (in prep.). Both $\mathrm{H}_{2} \mathrm{CO}$ and $\mathrm{CH}_{3} \mathrm{OH}$ have been detected in these experiments with different abundance ratios dependent on the exact conditions. $\mathrm{H}_{2} \mathrm{CO}$ can also be formed by UV-irradiation of $\mathrm{CH}_{3} \mathrm{OH}$ containing ices (Allamandola et al. 1988; Bernstein et al. 1995). However, the high ice abundances of $\mathrm{CH}_{3} \mathrm{OH}$ (e.g., Gibb et al. 2004) and the constant abundance ratio between $\mathrm{H}_{2} \mathrm{CO} / \mathrm{CH}_{3} \mathrm{OH}$ in this paper are inconsistent with this $\mathrm{CH}_{3} \mathrm{OH}$ destruction mechanism. Our data imply that hydrogenation reactions are more feasible formation mechanisms.

Furthermore as discussed in Sect. 5.4, the solid state abundance of $\mathrm{CH}_{3} \mathrm{OH}$ appears to be at least an order of magnitude higher than the comparable source-averaged gas phase abundances. This could be due to a number of effects: i) $\mathrm{CH}_{3} \mathrm{OH}$ is partly destroyed upon evaporation, ii) intrinsic $\mathrm{CH}_{3} \mathrm{OH}$ ice variations from source to source (Brooke et al. 1999; Dartois et al. 1999; Pontoppidan et al. 2004), iii) an underestimate of the beam-filling factor of the $\mathrm{CH}_{3} \mathrm{OH}$ emitting gas. Possibly, all three factors contribute to the relatively low gas phase abundance.

$\mathrm{CH}_{2} \mathrm{CO}, \mathrm{CH}_{3} \mathrm{CHO}$, and $\mathrm{C}_{2} \mathrm{H}_{5} \mathrm{OH}$ : in Fig. $1 \mathrm{CH}_{2} \mathrm{CO}$, $\mathrm{CH}_{3} \overline{\mathrm{CHO}}$, and $\mathrm{C}_{2} \mathrm{H}_{5} \mathrm{OH}$ are thought to be interrelated through successive hydrogenation as well as to $\mathrm{H}_{2} \mathrm{CO}$ and $\mathrm{CH}_{3} \mathrm{OH}$ by successive $\mathrm{H}$ - and $\mathrm{C}$-atom addition. All three species are expected to evaporate from the ice together with $\mathrm{H}_{2} \mathrm{O}$ (Viti et al. 2004) and have similar rotation temperatures. This is not the case, however. Indeed, interferometric observations of $\mathrm{CH}_{3} \mathrm{CHO}$ in high mass star forming regions show that $\mathrm{CH}_{3} \mathrm{CHO}$ emission is extended with respect to hot cores species such as $\mathrm{HCOOCH}_{3}$ and $\mathrm{CH}_{3} \mathrm{OCH}_{3}$ (Liu 2005). This suggest that $\mathrm{CH}_{2} \mathrm{CO}, \mathrm{CH}_{3} \mathrm{CHO}$, and $\mathrm{C}_{2} \mathrm{H}_{5} \mathrm{OH}$ gas are not present in the same region. Possibly, $\mathrm{H}$-atom addition to $\mathrm{CH}_{2} \mathrm{CO}$ and $\mathrm{CH}_{3} \mathrm{CHO}$ on grains is very efficient and completely converts them to $\mathrm{C}_{2} \mathrm{H}_{5} \mathrm{OH}$ at high temperatures, so that only $\mathrm{C}_{2} \mathrm{H}_{5} \mathrm{OH}$ evaporates from the ice and is detected in the warm inner regions. Non-thermal desorption of a small fraction due to e.g., cosmic ray spot heating of $\mathrm{CH}_{2} \mathrm{CO}$ and $\mathrm{CH}_{3} \mathrm{CHO}$ ice in cold regions could explain the low gas phase abundances and rotation temperatures, as well as the high ice abundances of $\mathrm{CH}_{3} \mathrm{CHO}$. Alternatively, $\mathrm{C}_{2} \mathrm{H}_{5} \mathrm{OH}$ could be formed through another surface reaction related to $\mathrm{CH}_{3} \mathrm{OH}$ and $\mathrm{H}_{2} \mathrm{CO}$ formation, explaining its constant abundance ratio.

For $\mathrm{CH}_{2} \mathrm{CO}$ and $\mathrm{CH}_{3} \mathrm{CHO}$ there are also potential gas phase formation mechanisms. Millar \& Nejad (1985) argue that $\mathrm{CH}_{2} \mathrm{CO}$ could result from radiative associative reactions between $\mathrm{CH}_{3}^{+}$and $\mathrm{CO}$. Assuming that $\mathrm{CH}_{3} \mathrm{CO}^{+}$dissociative recombination results in $\mathrm{CH}_{2} \mathrm{CO}$ for $50 \%$ of the cases, this would allow for $\mathrm{CH}_{2} \mathrm{CO}$ abundances of $\sim 10^{-10}$, comparable to our observed abundances and also to those by Turner et al. (1999). Gas phase models by Lee et al. (1996) predict fractional abundances of $5 \times 10^{-12}$ for $\mathrm{CH}_{3} \mathrm{CHO}$ and its isomers. This is lower than the abundances of Ikeda et al. (2001) and Charnley (2004) but close to the abundances for some of our sources. Herbst \& Leung (1989) proposed that $\mathrm{H}_{3} \mathrm{O}^{+}$and $\mathrm{C}_{2} \mathrm{H}_{2}$ react to form $\mathrm{CH}_{3} \mathrm{CHO}$ after dissociative recombination, which results in higher abundances of up to $\sim 10^{-10}$ in dark clouds. Many of these conclusions depend on high branching ratios toward these products in dissociative recombination. If three body break-up prevails as found for some species, pure gas phase production becomes untenable (Geppert et al. 2005).

$\mathrm{HCOOH}$ : High abundances of $\mathrm{HCOOH}$ in the ice, low gas phase rotation temperatures, and orders of magnitude lower abundances in the gas phase compared to the solid state can be due to two reasons: i) $\mathrm{HCOOH}$ is quickly destroyed in the gas phase upon evaporation, and ii) $\mathrm{HCOOH}$ is abundant in low temperature ice, but destroyed at higher temperatures due to reactions in the ice. Gas phase destruction is a possibility, but it is unclear why the destruction rate of $\mathrm{HCOOH}$ would be orders of magnitude larger compared to other species. Even if this would be the case, most high mass star-forming regions are expected to have an evaporation front that moves outward through the envelope as the luminosity increases. $\mathrm{HCOOH}$ should thus continuously freshly evaporate from icy grains. The second possibility of $\mathrm{HCOOH}$ destruction in the ice at high temperatures is much more likely and can be tested in the laboratory. The lower gas phase abundance can then be explained by a small fraction of the ice $\left(\sim 10^{-4}\right)$ that evaporates due to non-thermal desorption mechanisms. The low rotation temperatures of $\sim 40-70 \mathrm{~K}$ for most sources in our sample are also consistent with this picture. Finally, it can explain the high $\mathrm{HCOOH}$ abundances in shocked regions by e.g. Requena-Torres et al. (2006), where the ice is warmed up and evaporated over much shorter timescales.

The precise formation of $\mathrm{HCOOH}$ through surface chemistry still remains a puzzle, however. In Fig. 1 the formation mechanisms in the solid state is either through $\mathrm{CO}$ or $\mathrm{CO}_{2}$. Laboratory experiments indicate that it only evaporates at very high temperatures $(\sim 100 \mathrm{~K})$ similar to $\mathrm{H}_{2} \mathrm{O}$ (Collings et al. 2004). This is even the case for $\mathrm{HCOOH}$ diluted in $\mathrm{CO}$ or $\mathrm{CO}_{2}$ ices (Bisschop et al., in prep.). Keane (2001) predicts the formation of $\mathrm{HCOOH}$ through successive atom addition to $\mathrm{CO}$ and finds that the $\mathrm{HCOOH}$ ice concentration is proportional to the $\mathrm{O} / \mathrm{O}_{2}$ ratio. Alternatively, Allen \& Robinson (1977) proposed the reaction $\mathrm{HCO}+\mathrm{OH}$ in the solid state leading to $\mathrm{HCOOH}$. New models by Garrod \& Herbst (2006) have $\mathrm{HCOOH}$ gas phase abundances that are much higher than found for our sources with most of the $\mathrm{HCOOH}$ actually formed in the gas. If this occurs at intermediate temperatures, a fraction of the $\mathrm{HCOOH}$ may freeze out on grains. Further laboratory experiments are needed to elucidate the exact formation mechanism for $\mathrm{HCOOH}$.

$\mathrm{HNCO}$ and $\mathrm{NH}_{2} \mathrm{CHO}$ : $\mathrm{HNCO}$ formation has been explained by surface chemistry formation and gas phase reactions (Turner et al. 1999; Keane 2001). Both Turner et al. (1999) and Keane (2001) argue that $\mathrm{NH}_{2} \mathrm{CHO}$ is formed on grain-surfaces due to its high level of hydrogen saturation. The strong correlation between the two species in Sect. 5.1 suggests they are related. Alternatively, both $\mathrm{OCN}^{-}$and $\mathrm{NH}_{2} \mathrm{CHO}$ can form in ices due to energetic processes such as UV-irradiation (van Broekhuizen et al. 2004; Muñoz Caro \& Schutte 2003; Allamandola et al. 1999). Van Broekhuizen et al.(2004) conclude that thermal formation of $\mathrm{OCN}^{-}$can, however, also not be ruled out. Concluding, solid state processes appear to be the most likely formation mechanism for both species, whether they involve energetic processing or not.

$\mathrm{HCOOCH}_{3}$ and $\mathrm{CH}_{3} \mathrm{OCH}_{3}: \quad \mathrm{HCOOCH}_{3}$ and $\mathrm{CH}_{3} \mathrm{OCH}_{3}$ were previously thought to form from protonated methanol in the gas phase (Millar et al. 1991). Horn et al. (2004) recently found the barrier for the gas phase formation of $\mathrm{HCOOCH}_{3}$ to be higher than previously anticipated. Moreover, the gas phase routes assume that $\mathrm{H}_{2} \mathrm{COOCH}_{3}^{+}$and $\left(\mathrm{CH}_{3}\right)_{2} \mathrm{OH}^{+}$recombine 
to $\mathrm{HCOOCH}_{3}$ and $\mathrm{CH}_{3} \mathrm{OCH}_{3}$ respectively. Measurements by Geppert et al. $(2004,2005)$ have shown that dissociative recombination of $\mathrm{CH}_{3} \mathrm{OH}_{2}^{+}$mostly results in a three-body break-up instead of its deprotonated counterpart. If this would also be the case for species such as $\mathrm{HCOOCH}_{3}$ and $\mathrm{CH}_{3} \mathrm{OCH}_{3}$, they are more likely to be at least partially formed on grain surfaces. The constant abundance ratios between both species and $\mathrm{CH}_{3} \mathrm{OH}$ also confirm this scenario. Indeed Garrod \& Herbst (2006) explain surface formation of $\mathrm{HCOOCH}_{3}$ and $\mathrm{CH}_{3} \mathrm{OCH}_{3}$ through reactions of $\mathrm{CH}_{3} \mathrm{O}$ and $\mathrm{HCO}$ radicals, first proposed by Allen \& Robinson (1977).

$\mathrm{CH}_{3} \mathrm{CN}, \mathrm{C}_{2} \mathrm{H}_{5} \mathrm{CN}$, and $\mathrm{CH}_{3} \mathrm{CCH}$ : $\mathrm{CH}_{3} \mathrm{CN}$ can be formed from the fast association reaction $\mathrm{CH}_{3}^{+}+\mathrm{HCN}$ and the radiative association reaction of $\mathrm{CH}_{3}+\mathrm{CN}$ (Charnley et al. 1992). The abundances in the gas phase for Orion are, however, $\sim 10^{-10}$ (Charnley et al. 1992) compared to $10^{-8}$ in our sources. The relatively high abundances plus the high degree of hydrogenation for $\mathrm{C}_{2} \mathrm{H}_{5} \mathrm{CN}$ and $\mathrm{CH}_{3} \mathrm{CN}$ imply that they are possibly formed on grain-surfaces. $\mathrm{CH}_{3} \mathrm{CCH}$ usually has very low rotation temperatures, and its formation is explained in dark and translucent clouds through gas phase ion-molecule or neutral-neutral reactions.

In summary, most species, such as $\mathrm{H}_{2} \mathrm{CO}, \mathrm{CH}_{3} \mathrm{OH}$, $\mathrm{C}_{2} \overline{\mathrm{H}_{5} \mathrm{OH}, \mathrm{HCOOCH}} 3$, and $\mathrm{CH}_{3} \mathrm{OCH}_{3}$ probably result from "first generation" chemistry in ices, likely dominated by surface chemistry. This is possibly also true for $\mathrm{CH}_{3} \mathrm{CN}$ and $\mathrm{C}_{2} \mathrm{H}_{5} \mathrm{CN}$. $\mathrm{CH}_{2} \mathrm{CO}, \mathrm{CH}_{3} \mathrm{CHO}, \mathrm{HCOOH}$ and $\mathrm{CH}_{3} \mathrm{CCH}$ have all been detected in the gas with low rotation temperatures and, for some species, abundances that are orders of magnitude lower than those in ices. Non-thermal desorption of a small fraction of the ice $\left(\sim 10^{-4}\right)$ is sufficient to explain the abundances in the cold gas phase. For $\mathrm{CH}_{2} \mathrm{CO}, \mathrm{CH}_{3} \mathrm{CHO}$, and $\mathrm{HCOOH}$ formation plus destruction in the ice at higher temperature are plausible, but gas phase chemistry cannot be excluded. Models of gas phase reactions are able to accurately reproduce the observed $\mathrm{CH}_{3} \mathrm{CCH}$ abundances.

\section{Summary and conclusions}

We have performed a survey of selected frequency settings for 7 high mass YSOs. The survey was targeted at detecting species thought to be produced by the grain surface chemistry depicted in Fig. 1. Other species such as $\mathrm{CH}_{3} \mathrm{CN}, \mathrm{C}_{2} \mathrm{H}_{5} \mathrm{CN}, \mathrm{CH}_{3} \mathrm{CCH}$, $\mathrm{HCOOCH}_{3}$ and $\mathrm{CH}_{3} \mathrm{OCH}_{3}$ have also been detected. To compare abundances between sources, the source luminosity and $850 \mu \mathrm{m}$ dust emission was used to constrain the radius within which $T \geq$ $100 \mathrm{~K}$ and the column density out to this radius, $N_{T \geq 100 \mathrm{~K}}$. The main conclusion derived in this work are:

- Most detected molecules have similar rotation temperatures for all sources. The following molecules can be classified as cold $(T<100 \mathrm{~K}): \mathrm{CH}_{2} \mathrm{CO}, \mathrm{CH}_{3} \mathrm{CHO}, \mathrm{HCOOH}$, and $\mathrm{CH}_{3} \mathrm{CCH}$; and the following as hot $(T \geq 100 \mathrm{~K}): \mathrm{H}_{2} \mathrm{CO}$, $\mathrm{CH}_{3} \mathrm{OH}, \mathrm{C}_{2} \mathrm{H}_{5} \mathrm{OH}, \mathrm{HNCO}, \mathrm{NH}_{2} \mathrm{CHO}, \mathrm{CH}_{3} \mathrm{CN}, \mathrm{C}_{2} \mathrm{H}_{5} \mathrm{CN}$, $\mathrm{HCOOCH}_{3}$, and $\mathrm{CH}_{3} \mathrm{OCH}_{3}$.

- Groups of molecules have their highest column densities for the same sources. This is the case for the oxygenbearing species $\mathrm{H}_{2} \mathrm{CO}, \mathrm{CH}_{3} \mathrm{OH}, \mathrm{C}_{2} \mathrm{H}_{5} \mathrm{OH}, \mathrm{HCOOCH}_{3}$ and $\mathrm{CH}_{3} \mathrm{OCH}_{3}$. HNCO and $\mathrm{NH}_{2} \mathrm{CHO}$ have their highest column in other sources than the oxygen-bearing species, but both are highest for the same sources. Due to optical depth effects and a limited number of detections it is difficult to establish the trends for $\mathrm{CH}_{3} \mathrm{CN}$ and $\mathrm{C}_{2} \mathrm{H}_{5} \mathrm{CN}$.
- Absolute abundances in the hot regions vary by an order of magnitude. Relative abundances of the oxygen-bearing species and the two nitrogen-bearing species are, however, very constant. The absolute abundances are much higher than can be produced by gas phase chemistry. The constant abundance ratios plus the similar rotation temperatures imply that the oxygen-bearing species, $\mathrm{H}_{2} \mathrm{CO}, \mathrm{CH}_{3} \mathrm{OH}$, $\mathrm{C}_{2} \mathrm{H}_{5} \mathrm{OH}, \mathrm{HCOOCH}_{3}$ and $\mathrm{CH}_{3} \mathrm{OCH}_{3}$, as well as the two nitrogen-bearing species, $\mathrm{HNCO}$ and $\mathrm{NH}_{2} \mathrm{CHO}$, share a common solid state formation scheme. This can be the result of very similar conditions during ice formation or a balance between formation and destruction in the ice. The oxygenbearing species and the two nitrogen-bearing species are not related, however. The abundances of two cyanides, $\mathrm{CH}_{3} \mathrm{CN}$ and $\mathrm{C}_{2} \mathrm{H}_{5} \mathrm{CN}$, are likely due to "first generation" ice chemistry as well.

- $\mathrm{CH}_{2} \mathrm{CO}, \mathrm{CH}_{3} \mathrm{CHO}, \mathrm{CH}_{3} \mathrm{CCH}$ and $\mathrm{HCOOH}$ have very low rotation temperatures. The formation of $\mathrm{CH}_{2} \mathrm{CO}, \mathrm{CH}_{3} \mathrm{CHO}$, and $\mathrm{HCOOH}$ can be explained by solid state or gas phase reactions. For $\mathrm{HCOOH}$ and $\mathrm{CH}_{3} \mathrm{CHO}$ gas phase abundances are a factor of $10^{4}$ lower than those observed in the solid state. Solid state formation for these species is thus more likely. A low fraction of non-thermal desorption could be responsible for the low gas phase abundances. Models of ion-molecule reactions in the cold gas phase can, however, also reproduce the abundances of $\mathrm{CH}_{2} \mathrm{CO}$ and $\mathrm{CH}_{3} \mathrm{CHO}$. $\mathrm{CH}_{3} \mathrm{CCH}$ on the other hand is probably created by cold gas phase chemistry, as its abundance is similar to that found in dark clouds. Interestingly, no cold N-bearing molecules are found.

The abundance correlations and branching ratios determined in this paper are key to understanding chemical relationships between these complex organic molecules and addressing their origins. Future spatially resolved observations with interferometers such as ALMA will make it possible to confirm molecular relations and address the chemical variations within each source. Additional laboratory experiments can explore the pathways to the formation of the most abundant species given these observational constraints of constant abundance ratios. Taken together such studies will be important to fully understand the chemistry of complex organic molecules in star forming regions.

Acknowledgements. We thank Peter Schilke for supplying the XCLASS program used to calculate line intensities, and Remo Tilanus and Alain Castets for the support for the observations at the JCMT and IRAM, respectively. We are also grateful for useful discussions with Steve Doty, Eric Herbst, Miguel Requena-Torres, Floris van der Tak, Xander Tielens, as well as Malcolm Walmsley and an anonymous referee for comments on the paper. Funding was provided by NOVA, the Netherlands Research School for Astronomy and a NWO Spinoza grant. The research of J.K.J. was supported by NASA Origins Grant NAG5-13050.

\section{References}

Allamandola, L. J., Sandford, S. A., \& Valero, G. J. 1988, Icarus, 76, 225 Allamandola, L. J., Bernstein, M. P., Sandford, S. A., \& Walker, R. L. 1999, Space Sci. Rev., 90, 219

Allen, M., \& Robinson, G. W. 1977, ApJ, 212, 396

Beltrán, M. T., Cesaroni, R., Neri, R., et al. 2005, A\&A, 435, 901

Bernstein, M. P., Sandford, S. A., Allamandola, L. J., Chang, S., \& Scharberg, M. A. 1995, ApJ, 454, 327

Blake, G. A., Sutton, E. C., Masson, C. R., \& Phillips, T. G. 1987, ApJ, 315, 621 Blake, G. A., Mundy, L. G., Carlstrom, J. E., et al. 1996, ApJ, 472, L49

Boogert, A. C. A., \& Ehrenfreund, P. 2004, in Astrophysics of Dust, ed. A. N. Witt, G. C. Clayton, \& B. T. Draine, ASP Conf. Ser. 309, 547

Boonman, A. M. S., Stark, R., van der Tak, F. F. S., et al. 2001, ApJ, 553, L63 Boudin, N., Schutte, W. A., \& Greenberg, J. M. 1998, A\&A, 331, 749 
Brooke, T. Y., Sellgren, K., \& Geballe, T. R. 1999, ApJ, 517, 883 Caselli, P., Hasegawa, T. I., \& Herbst, E. 1993, ApJ, 408, 548

Cesaroni, R., Codella, C., Furuya, R. S., \& Testi, L. 2003, A\&A, 401, 227

Charnley, S. B. 1995, Ap\&SS, 224, 251

Charnley, S. B. 2001, ApJ, 562, L99

Charnley, S. B. 2004, Adv. Space Res., 33, 23

Charnley, S. B., Tielens, A. G. G. M., \& Millar, T. J. 1992, ApJ, 399, L71

Churchwell, E., Wood, D., Myers, P. C., \& Myers, R. V. 1986, ApJ, 305, 405

Churchwell, E., Walmsley, C. M., \& Cesaroni, R. 1990, A\&AS, 83, 119

Collings, M. P., Dever, J. W., Fraser, H. J., \& McCoustra, M. R. S. 2003, Ap\&SS, 285,633

Collings, M. P., Anderson, M. A., Chen, R., et al. 2004, MNRAS, 354, 1133

Dartois, E., Schutte, W., Geballe, T. R., et al. 1999, A\&A, 342, L32

Demyk, K., Dartois, E., D’Hendecourt, L., et al. 1998, A\&A, 339, 553

Forster, J. R., \& Caswell, J. L. 1989, A\&A, 213, 339

Garrod, R. T., \& Herbst, E. 2006, A\&A, 457, 927

Geppert, W. D., Thomas, R., Semaniak, J., et al. 2004, ApJ, 609, 459

Geppert, W. D., Hellberg, F., Österdahl, J., et al. 2005, in ed. D. C. Lis, G. A. Blake, \& E. Herbst, IAU Symp. 231, 117

Gerakines, P. A., Schutte, W. A., \& Ehrenfreund, P. 1996, A\&A, 312, 289

Gibb, E., Nummelin, A., Irvine, W. M., Whittet, D. C. B., \& Bergman, P. 2000a, ApJ, 545, 309

Gibb, E. L., Whittet, D. C. B., Schutte, W. A., et al. 2000b, ApJ, 536, 347

Gibb, E. L., Whittet, D. C. B., Boogert, A. C. A., \& Tielens, A. G. G. M. 2004, ApJS, 151, 35

Goldsmith, P. F., \& Langer, W. D. 1999, ApJ, 517, 209

Gredel, R., Lepp, S., Dalgarno, A., \& Herbst, E. 1989, ApJ, 347, 289

Grim, R. J. A., \& Greenberg, J. M. 1987, ApJ, 321, L91

Grim, R. J. A., Greenberg, J. M., de Groot, M. S., et al. 1989, A\&AS, 78, 161

Hagen, W., Allamandola, L. J., \& Greenberg, J. M. 1979, Ap\&SS, 65, 215

Hasegawa, T. I., \& Herbst, E. 1993, MNRAS, 263, 589

Hatchell, J., \& van der Tak, F. F. S. 2003, A\&A, 409, 589

Hatchell, J., Thompson, M. A., Millar, T. J., \& MacDonald, G. H. 1998, A\&AS, 133,29

Helmich, F. P., \& van Dishoeck, E. F. 1997, A\&AS, 124, 205

Herbst, E. 2005, in The Dusty and Molecular Universe: A Prelude to Herschel and ALMA, ed. A. Wilson, 205

Herbst, E., \& Leung, C. M. 1989, ApJS, 69, 271

Hiraoka, K., Sato, T., Sato, S., et al. 2002, ApJ, 577, 265

Horn, A., Møllendal, H., Sekiguchi, O., et al. 2004, ApJ, 611, 605

Ikeda, M., Ohishi, M., Nummelin, A., et al. 2001, ApJ, 560, 792

Ikeda, M., Ohishi, M., Nummelin, A., et al. 2002, ApJ, 571, 560

Ivezić, Ž., Nenkova, M., \& Elitzur, M. 1999, User Manual for DUSTY, University of Kentucky Internal Report

Jørgensen, J. K., Schöier, F. L., \& van Dishoeck, E. F. 2002, A\&A, 389, 908

Keane, J. V. 2001, Ph.D. Thesis, Rijks Universiteit Groningen

Keane, J. V., Tielens, A. G. G. M., Boogert, A. C. A., Schutte, W. A., \& Whittet, D. C. B. 2001, A\&A, 376, 254

Knez, C., Boogert, A. C. A., Pontoppidan, K. M., et al. 2005, ApJ, 635, L145

Lee, H.-H., Herbst, E., Pineau des Forets, G., Roueff, E., \& Le Bourlot, J. 1996, A\&A, 311, 690
Léger, A., Jura, M., \& Omont, A. 1985, A\&A, 144, 147

Liu, S.-Y. 2005, in IAU Symp. 231, ed. D. C. Lis, G. A. Blake, \& E. Herbst, 217

MacDonald, G. H., Gibb, A. G., Habing, R. J., \& Millar, T. J. 1996, A\&AS, 119, 333

Millar, T. J. 1996, in Molecules in Astrophysics: Probes, \& Processes, ed. E. F. van Dishoeck, IAU Symp. 178, 75

Millar, T. J., \& Nejad, L. A. M. 1985, MNRAS, 217, 507

Millar, T. J., Herbst, E., \& Charnley, S. B. 1991, ApJ, 369, 147

Moore, M. H., \& Hudson, R. L. 2000, Icarus, 145, 282

Muñoz Caro, G. M., \& Schutte, W. A. 2003, A\&A, 412, 121

Mueller, K. E., Shirley, Y. L., Evans, N. J., \& Jacobson, H. R. 2002, ApJS, 143, 469

Nummelin, A., Bergman, P., Hjalmarson, Å., et al. 2000, ApJS, 128, 213

Pankonin, V., Churchwell, E., Watson, C., \& Bieging, J. H. 2001, ApJ, 558, 194

Pendleton, Y. J., Tielens, A. G. G. M., Tokunaga, A. T., \& Bernstein, M. P. 1999, ApJ, 513, 294

Pontoppidan, K. M., Fraser, H. J., Dartois, E., et al. 2003, A\&A, 408, 981

Pontoppidan, K. M., van Dishoeck, E. F., \& Dartois, E. 2004, A\&A, 426, 925

Requena-Torres, M. A., Martín-Pintado, J., Rodríguez-Franco, A., et al. 2006, A\&A, 455, 971

Rodgers, S. D., \& Charnley, S. B. 2003, ApJ, 585, 355

Sandford, S. A., \& Allamandola, L. J. 1993, ApJ, 417, 815

Schilke, P., Benford, D. J., Hunter, T. R., Lis, D. C., \& Phillips, T. G. 2001, ApJS, 132,281

Schilke, P., Groesbeck, T. D., Blake, G. A., \& Phillips, T. G. 1997, ApJS, 108, 301

Schutte, W. A., Boogert, A. C. A., Tielens, A. G. G. M., et al. 1999, A\&A, 343, 966

Sutton, E. C., Blake, G. A., Masson, C. R., \& Phillips, T. G. 1985, ApJS, 58, 341

Sutton, E. C., Peng, R., Danchi, W. C., et al. 1995, ApJS, 97, 455

Thi, W.-F., van Dishoeck, E. F., Dartois, E., et al. 2006, A\&A, 449, 251

Tielens, A. G. G. M., \& Charnley, S. B. 1997, Origins Life Evol. B., 27, 23

Tielens, A. G. G. M., \& Hagen, W. 1982, A\&A, 114, 245

Turner, B. E., Terzieva, R., \& Herbst, E. 1999, ApJ, 518, 699

van Broekhuizen, F. A., Keane, J. V., \& Schutte, W. A. 2004, A\&A, 415, 425

van Broekhuizen, F. A., Pontoppidan, K. M., Fraser, H. J., \& van Dishoeck, E. F. 2005, A\&A, 441, 249

van der Tak, F. F. S., van Dishoeck, E. F., Evans, N. J., \& Blake, G. A. 2000, ApJ, 537, 283

Viti, S., Collings, M. P., Dever, J. W., McCoustra, M. R. S., \& Williams, D. A. 2004, MNRAS, 354, 1141

Watanabe, N., Nagaoka, A., Shiraki, T., \& Kouchi, A. 2004, ApJ, 616, 638

Whittet, D. C. B., Pendleton, Y. J., Gibb, E. L., et al. 2001, ApJ, 550, 793

Wilson, T. L., \& Rood, R. 1994, ARA\&A, 32, 191

Wyrowski, F., Schilke, P., Walmsley, C. M., \& Menten, K. M. 1999, ApJ, 514, L43

Zhang, Q. 2005, in IAU Symp. 227, ed. R. Cesaroni, M. Felli, E. Churchwell, \& M. Walmsley, 135

Zinchenko, I., Henkel, C., \& Mao, R. Q. 2000, A\&A, 361, 1079 
S. E. Bisschop et al.: Testing grain-surface chemistry in massive hot-core regions, Online Material p 1

\section{Online Material}


S. E. Bisschop et al.: Testing grain-surface chemistry in massive hot-core regions, Online Material p 2

\section{Appendix A: Rotation diagrams per molecule for all sources}

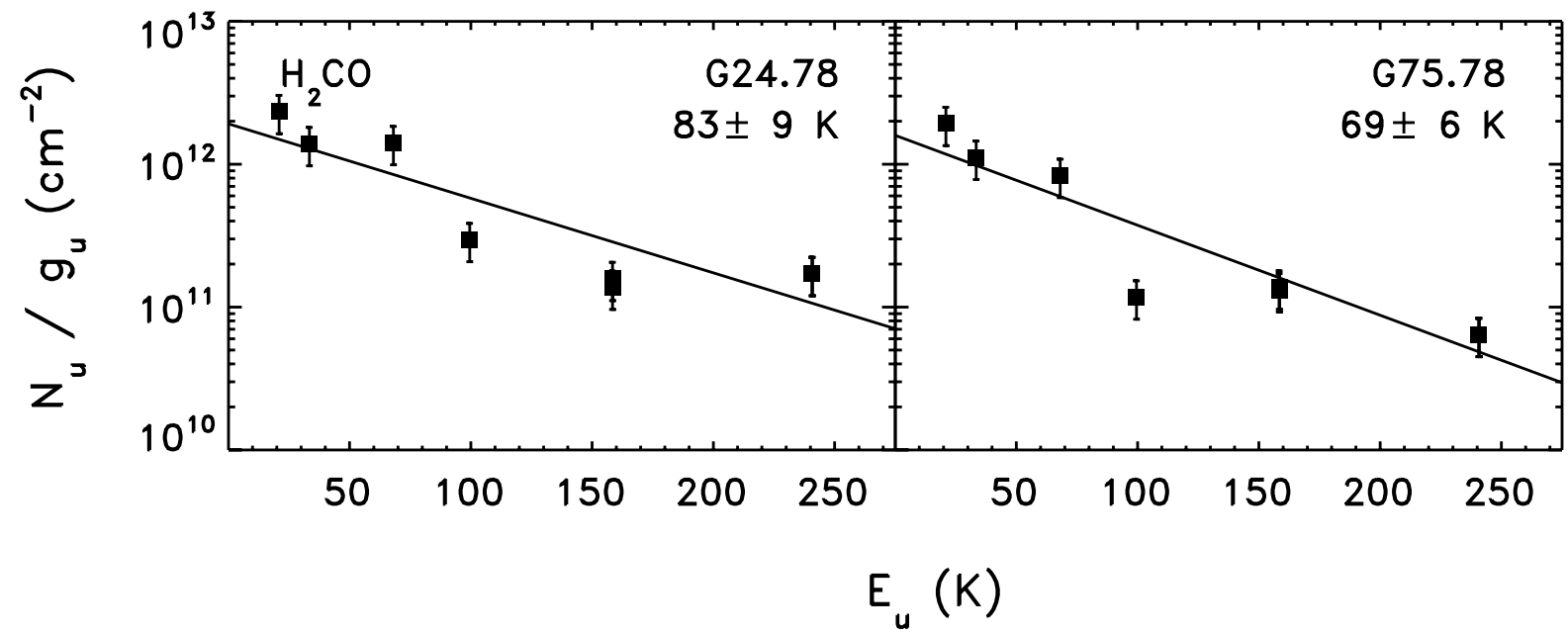

Fig. A.1. Rotation diagrams for $\mathrm{H}_{2} \mathrm{CO}$ for $\mathrm{G} 24.78$, and $\mathrm{G} 75.78$. 
S. E. Bisschop et al.: Testing grain-surface chemistry in massive hot-core regions, Online Material p 3

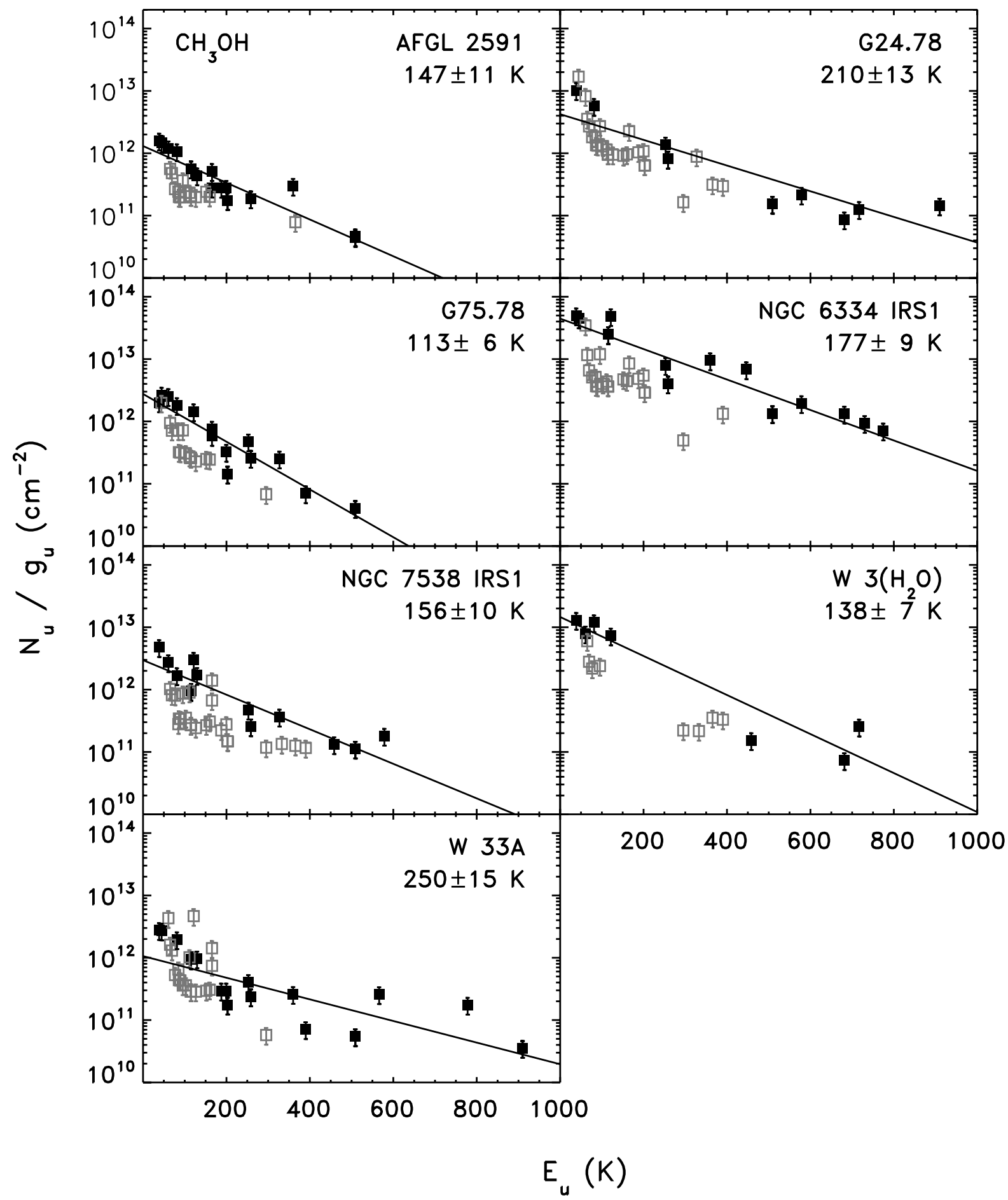

Fig. A.2. Rotation diagrams for $\mathrm{CH}_{3} \mathrm{OH}$ for respectively AFGL2591, G24.78, G75.78, NGC 6334IRS1, NGC 7538IRS1, W3(H2O), and W33A. The filled black squares are optically thin lines, the open gray squares optically thick lines, based on the estimated column densities. The rotation temperatures are fits to the optically thin lines only. 
S. E. Bisschop et al.: Testing grain-surface chemistry in massive hot-core regions, Online Material p 4

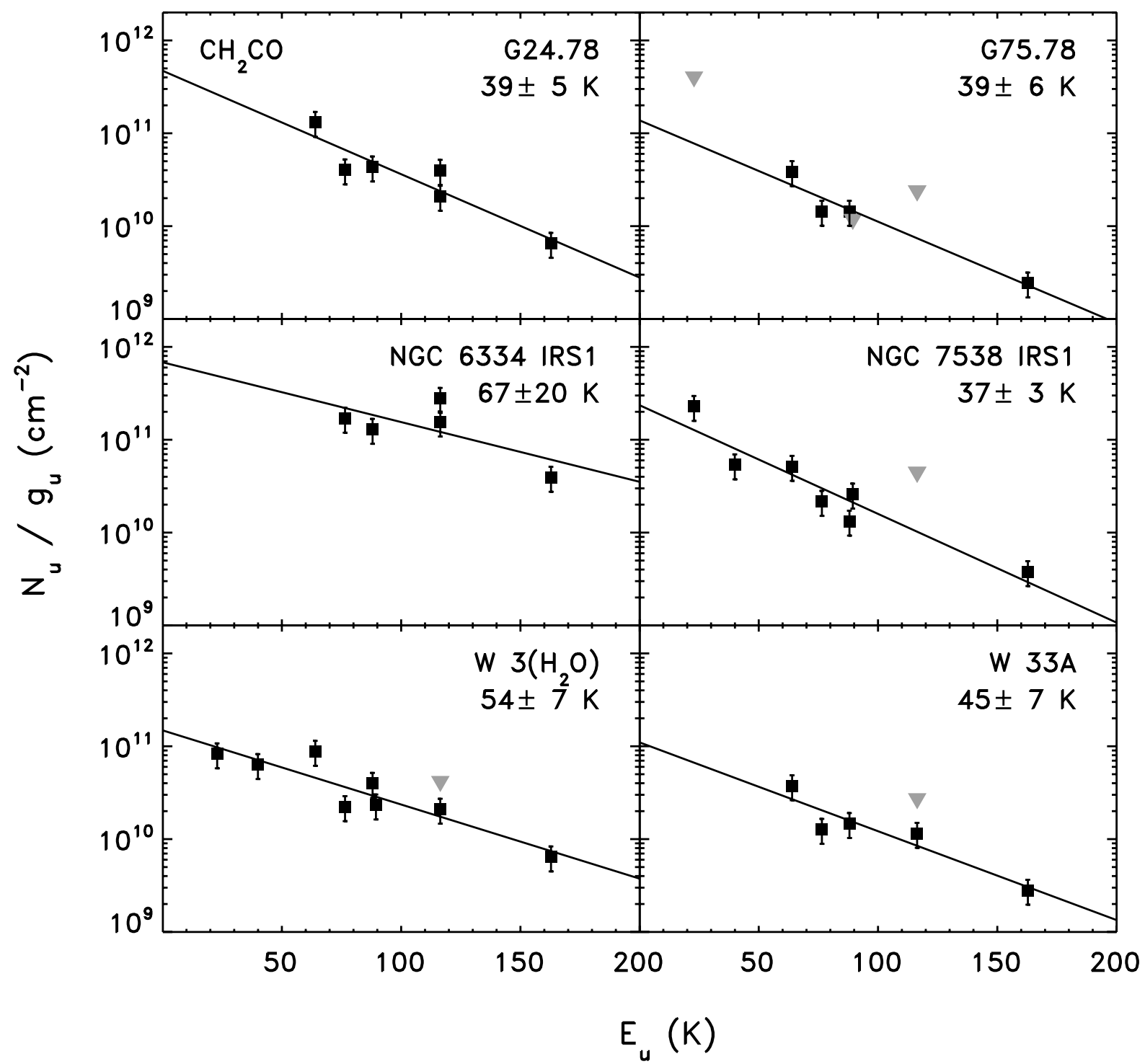

Fig. A.3. Rotation diagrams for $\mathrm{CH}_{2} \mathrm{CO}$ for respectively G24.78, G75.78, NGC 6334IRS1, NGC 7538, W3( $\left.\mathrm{H}_{2} \mathrm{O}\right)$, and W33A. The gray triangles indicate upper limits.

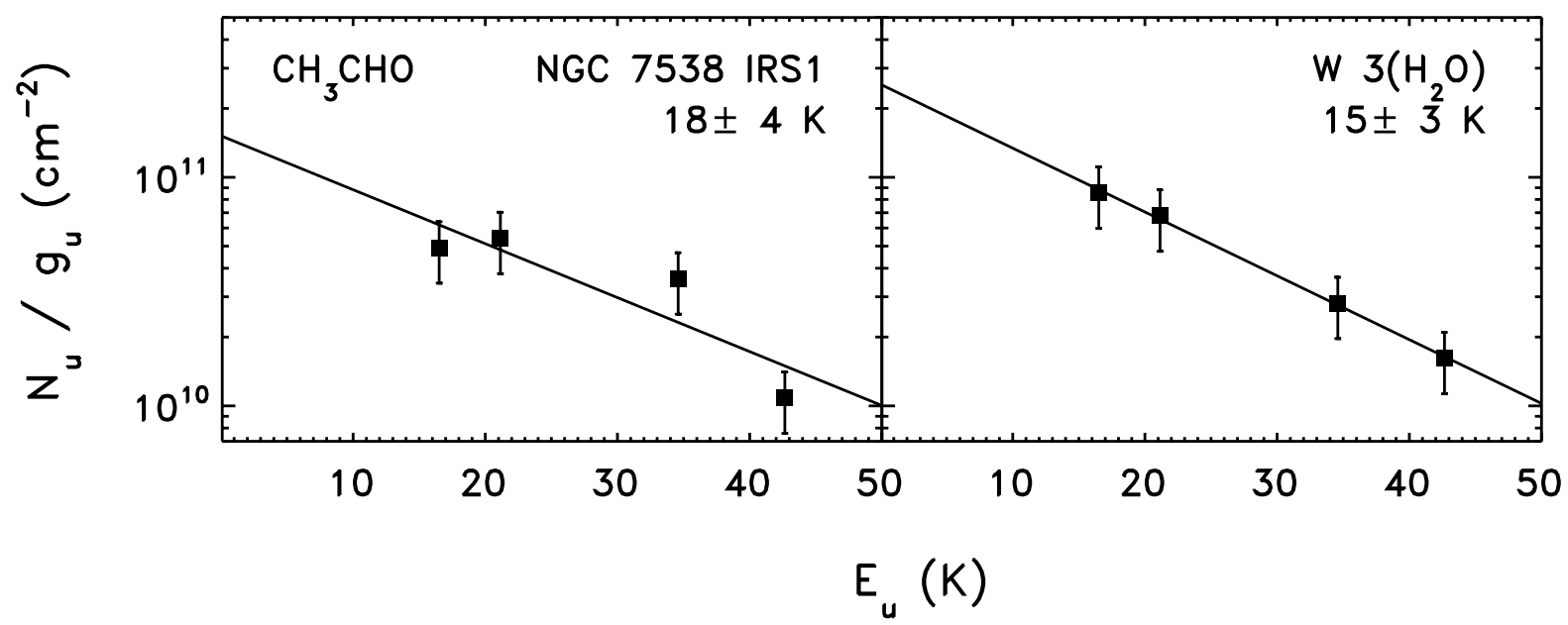

Fig. A.4. Rotation diagrams for $\mathrm{CH}_{3} \mathrm{CHO}$ for respectively NGC $7538 \mathrm{IRS} 1, \mathrm{~W} 3\left(\mathrm{H}_{2} \mathrm{O}\right)$, and W33A. 
S. E. Bisschop et al.: Testing grain-surface chemistry in massive hot-core regions, Online Material p 5

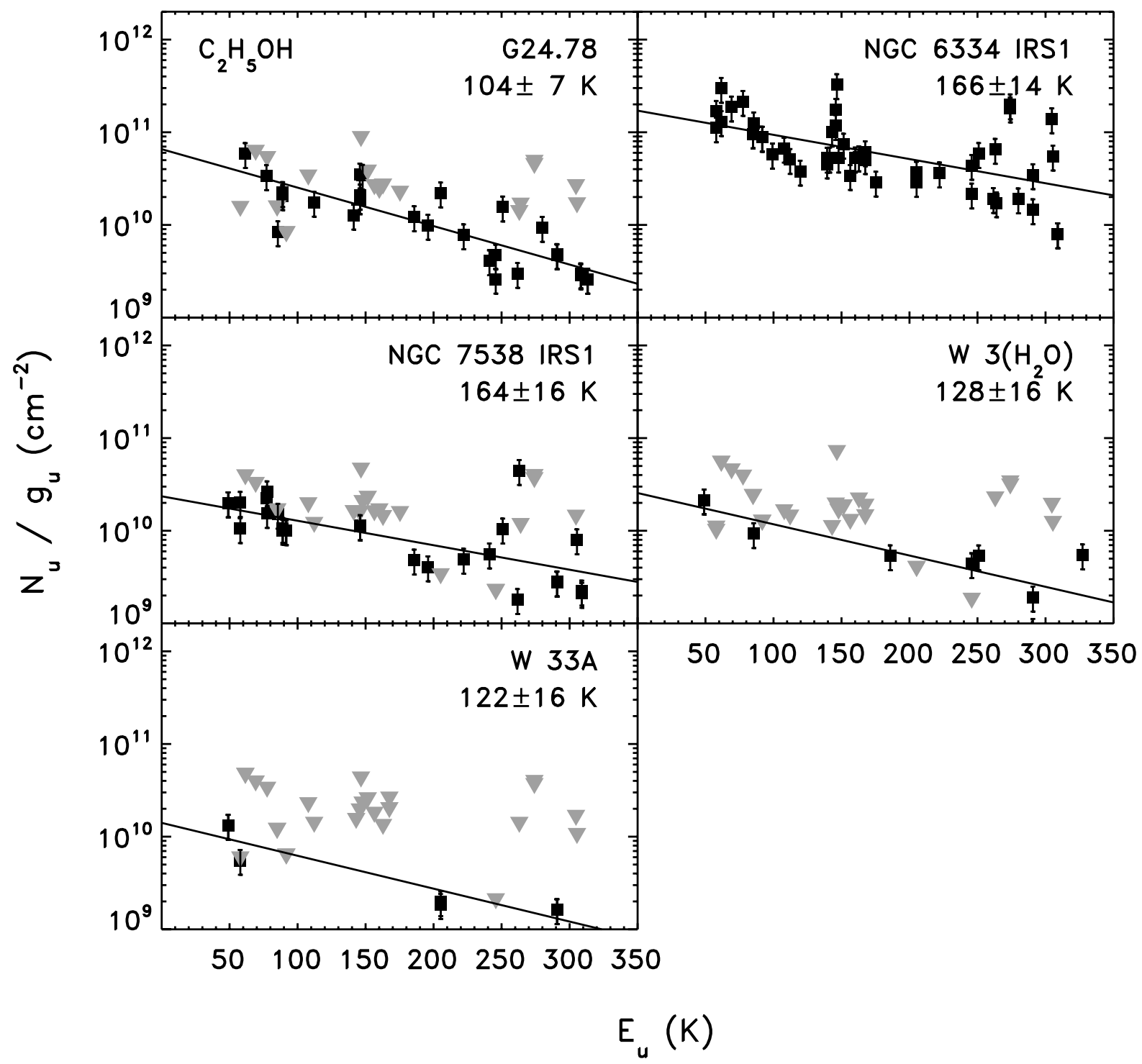

Fig. A.5. Rotation diagrams for $\mathrm{C}_{2} \mathrm{H}_{5} \mathrm{OH}$ for respectively G24, NGC 6334IRS1, NGC 7538IRS1, W3( $\left.\mathrm{H}_{2} \mathrm{O}\right)$, and W33A. The gray triangles indicate upper limits. 
S. E. Bisschop et al.: Testing grain-surface chemistry in massive hot-core regions, Online Material p 6

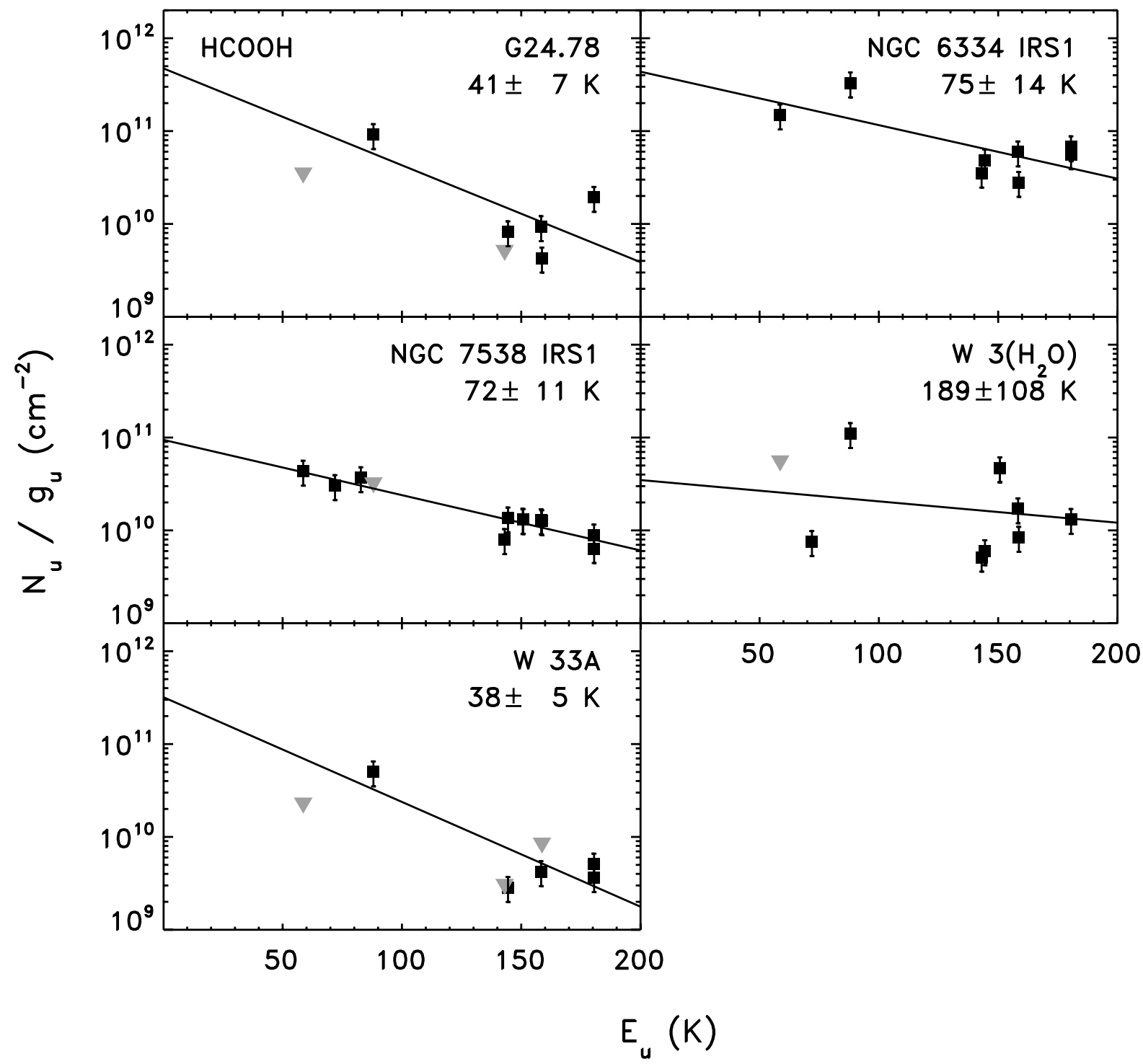

Fig. A.6. Rotation diagrams for $\mathrm{HCOOH}$ for respectively G24.78, NGC 6334IRS1, NGC 7538IRS1, W3( $\left.\mathrm{H}_{2} \mathrm{O}\right)$, and W33A. The gray triangles indicate upper limits. 
S. E. Bisschop et al.: Testing grain-surface chemistry in massive hot-core regions, Online Material p 7

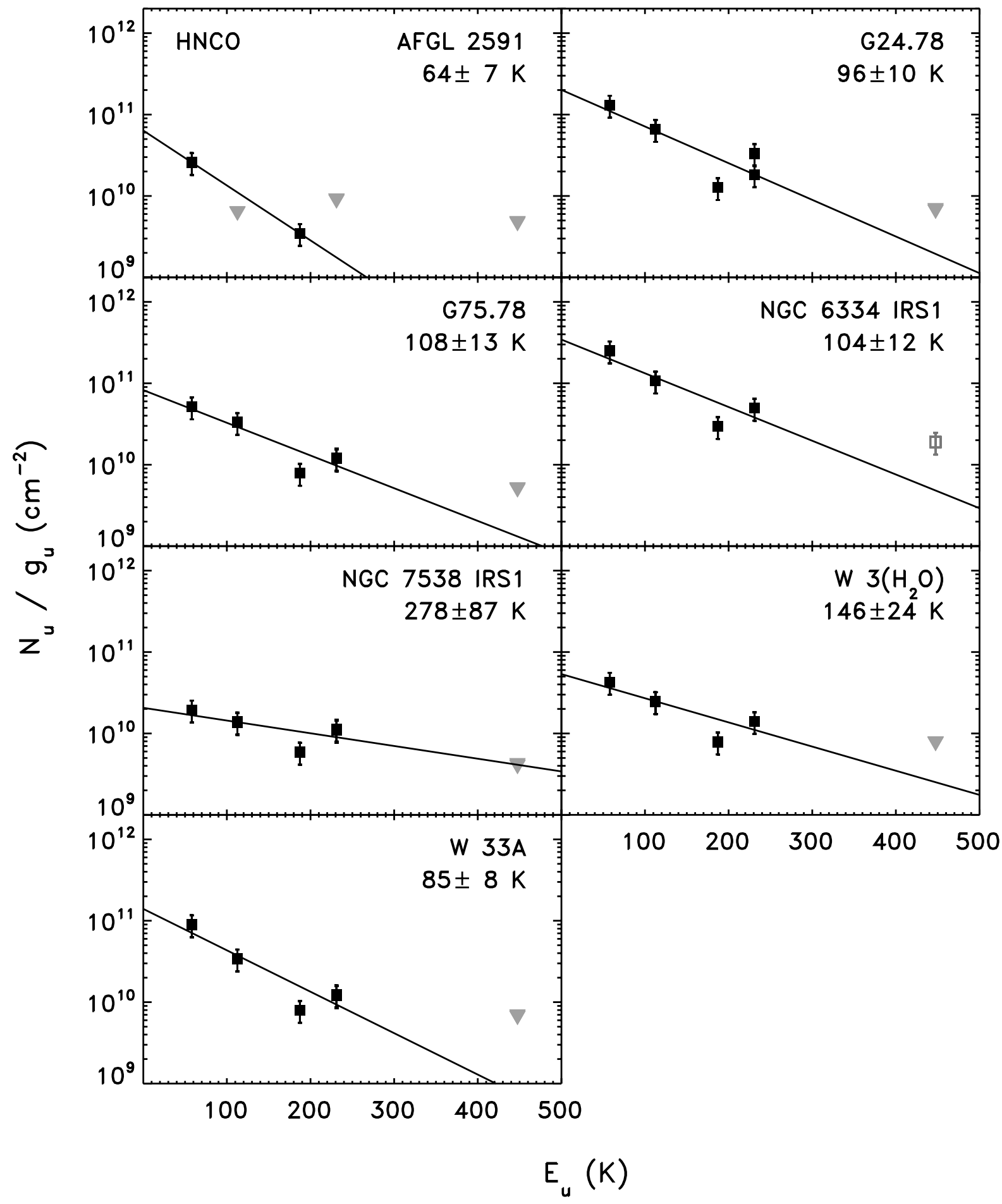

Fig. A.7. Rotation diagrams for HNCO for respectively G24.78, G75.78, NGC 6334IRS1, NGC 7538IRS1, W3( $\left.\mathrm{H}_{2} \mathrm{O}\right)$, and W33A. The filled black squares are the points included and the gray squares excluded from the fit. The gray triangles indicate upper limits. 
S. E. Bisschop et al.: Testing grain-surface chemistry in massive hot-core regions, Online Material $p 8$

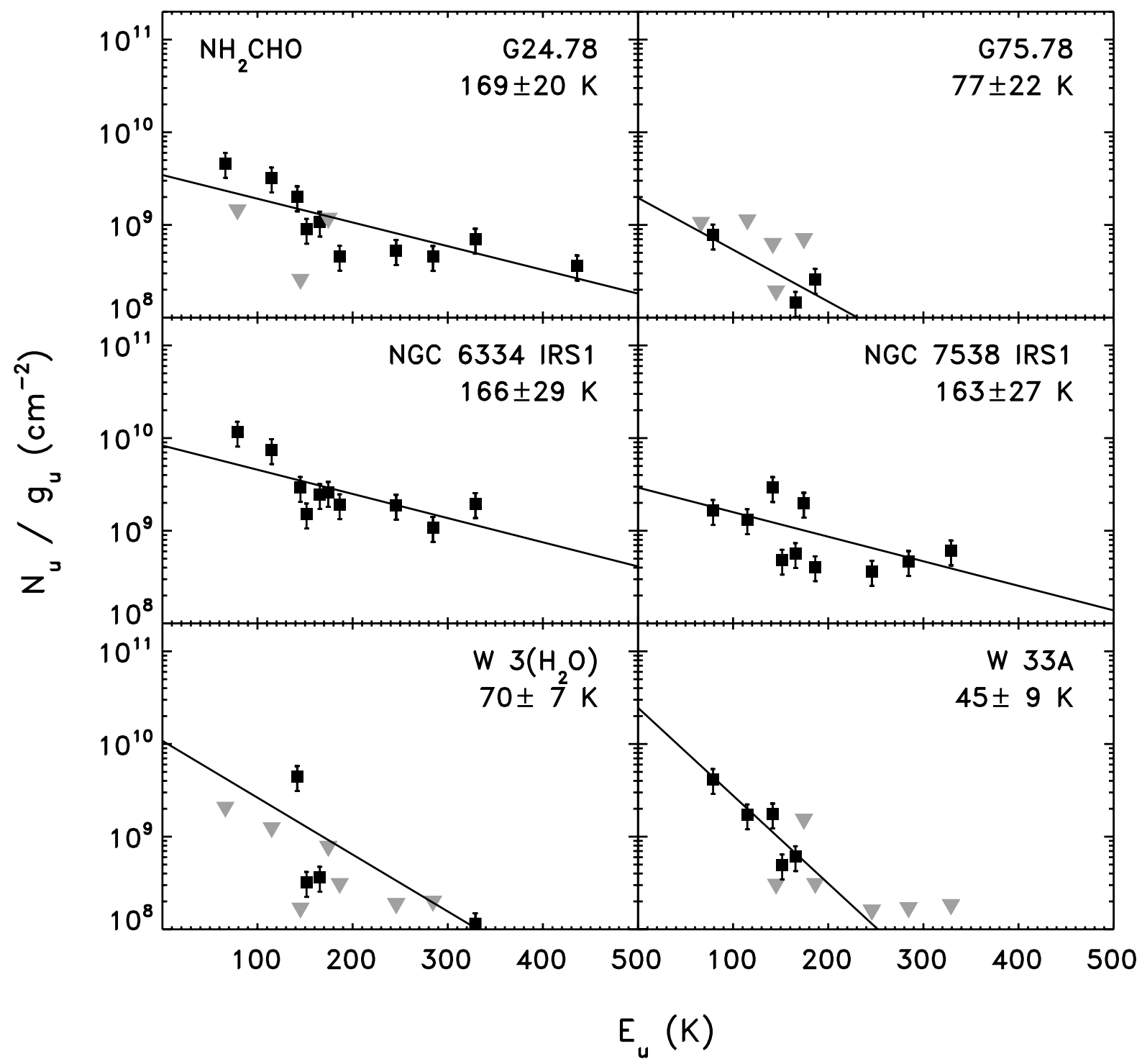

Fig. A.8. Rotation diagrams for $\mathrm{NH}_{2} \mathrm{CHO}$ for respectively G24.78, G75.78, NGC 6334IRS1, NGC 7538IRS1, W3( $\left.\mathrm{H}_{2} \mathrm{O}\right)$, and W33A. The gray triangles indicate upper limits. 
S. E. Bisschop et al.: Testing grain-surface chemistry in massive hot-core regions, Online Material p 9

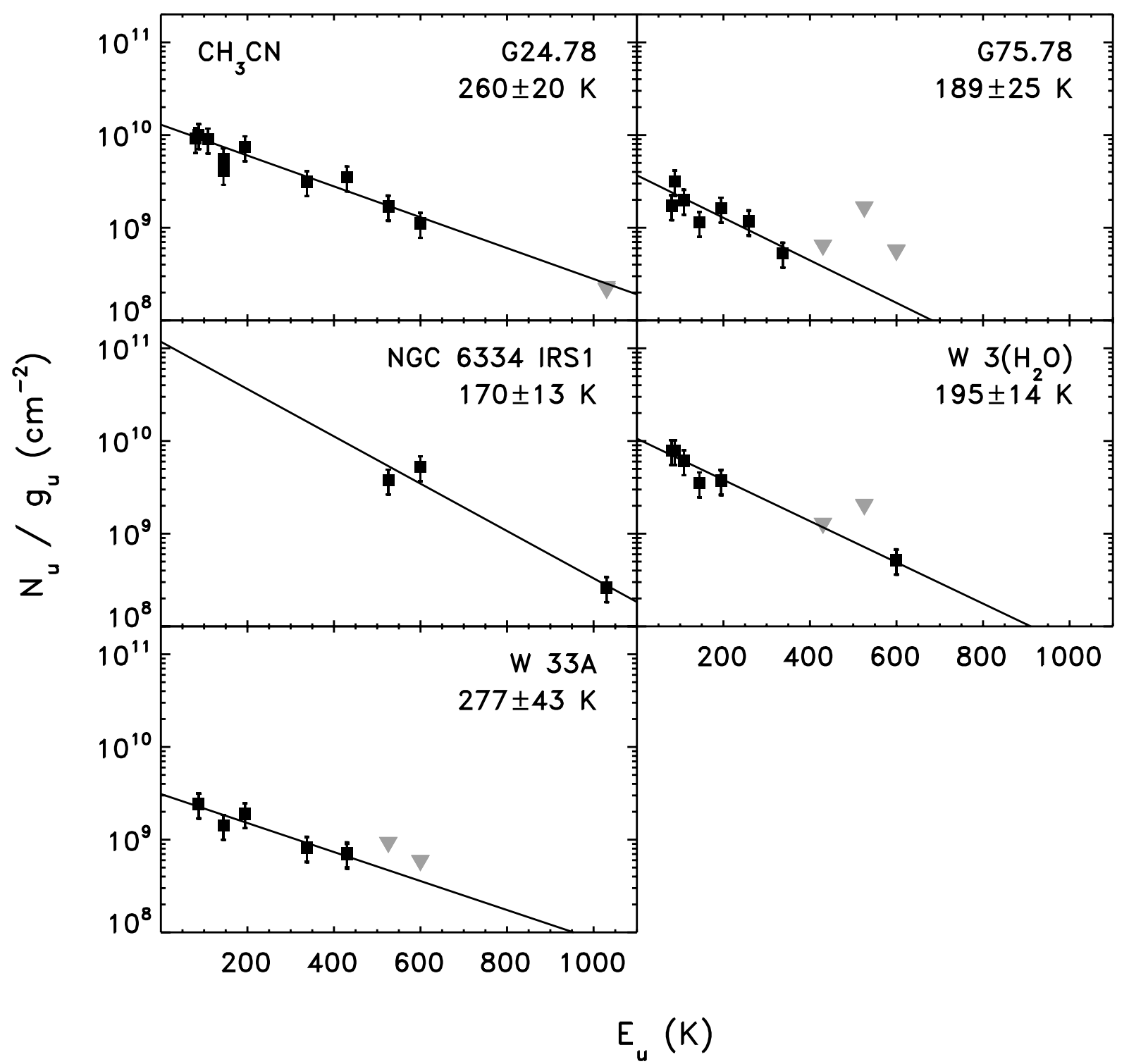

Fig. A.9. Rotation diagrams for $\mathrm{CH}_{3} \mathrm{CN}$ for respectively G24.78, G75.78, NGC 6334IRS1, W3 $\left(\mathrm{H}_{2} \mathrm{O}\right)$, and W33A. The gray triangles indicate upper limits. 
S. E. Bisschop et al.: Testing grain-surface chemistry in massive hot-core regions, Online Material p 10

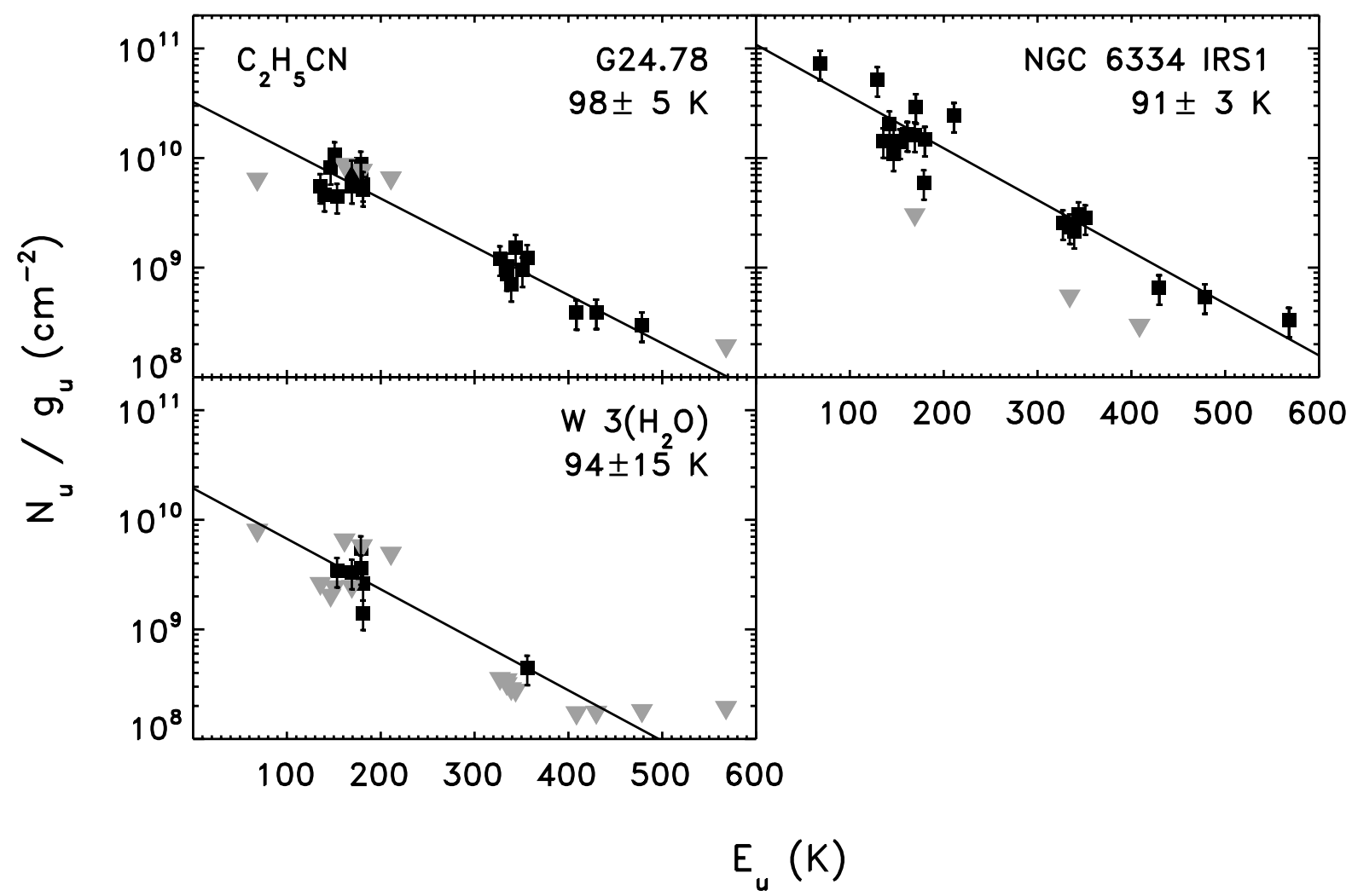

Fig. A.10. Rotation diagrams for $\mathrm{C}_{2} \mathrm{H}_{5} \mathrm{CN}$ for respectively G24.78, and NGC 6334IRS1. The gray triangles indicate upper limits. 
S. E. Bisschop et al.: Testing grain-surface chemistry in massive hot-core regions, Online Material p 11

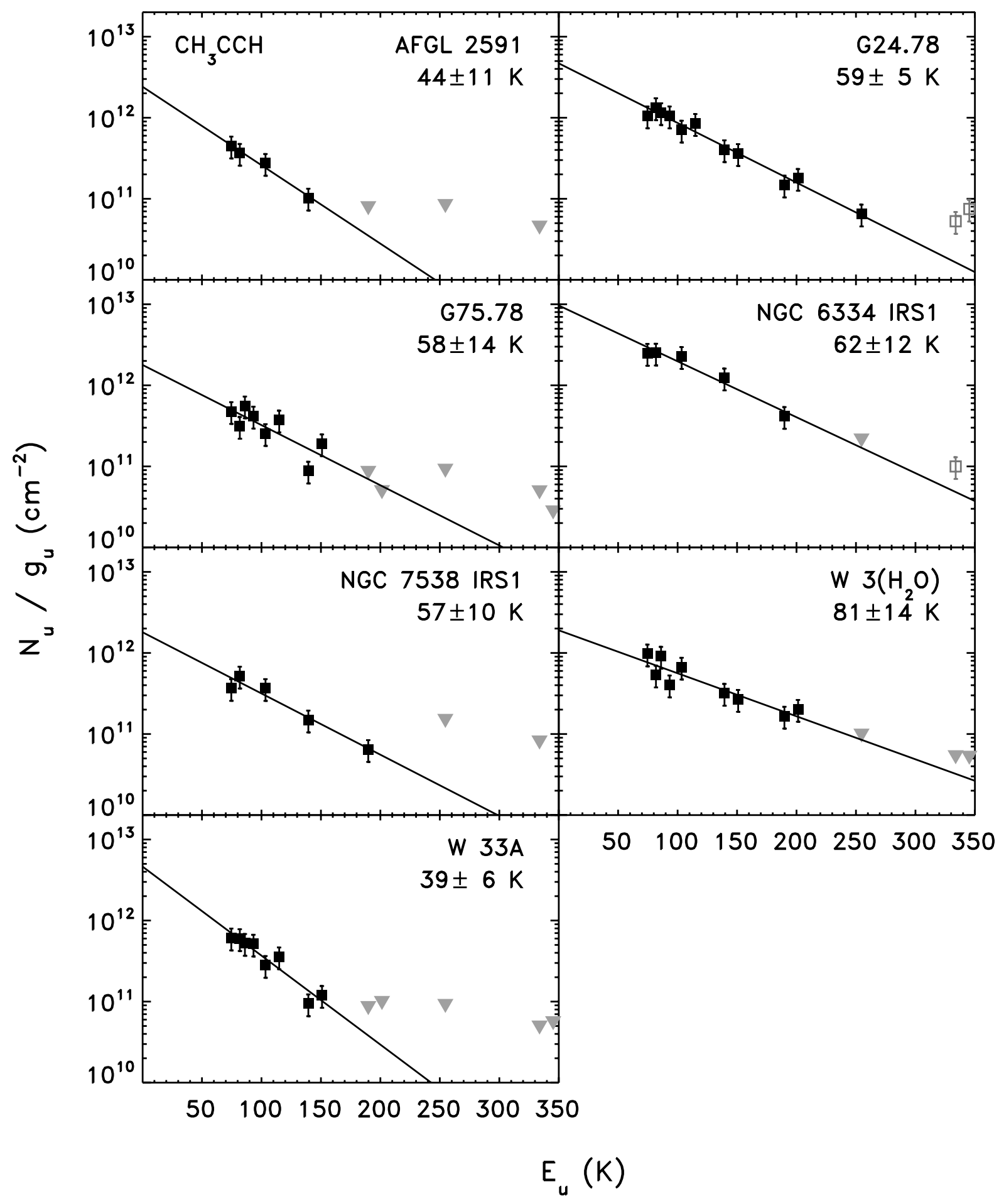

Fig. A.11. Rotation diagrams for $\mathrm{CH}_{3} \mathrm{CCH}$ for respectively AFGL2591, G24.78, G75.78, NGC 6334IRS1, NGC 7538IRS1, W3(H2O), and W33A. The filled black squares are the points included, the gray squares excluded from the fit and the gray triangles indicate upper limits. 
S. E. Bisschop et al.: Testing grain-surface chemistry in massive hot-core regions, Online Material p 12

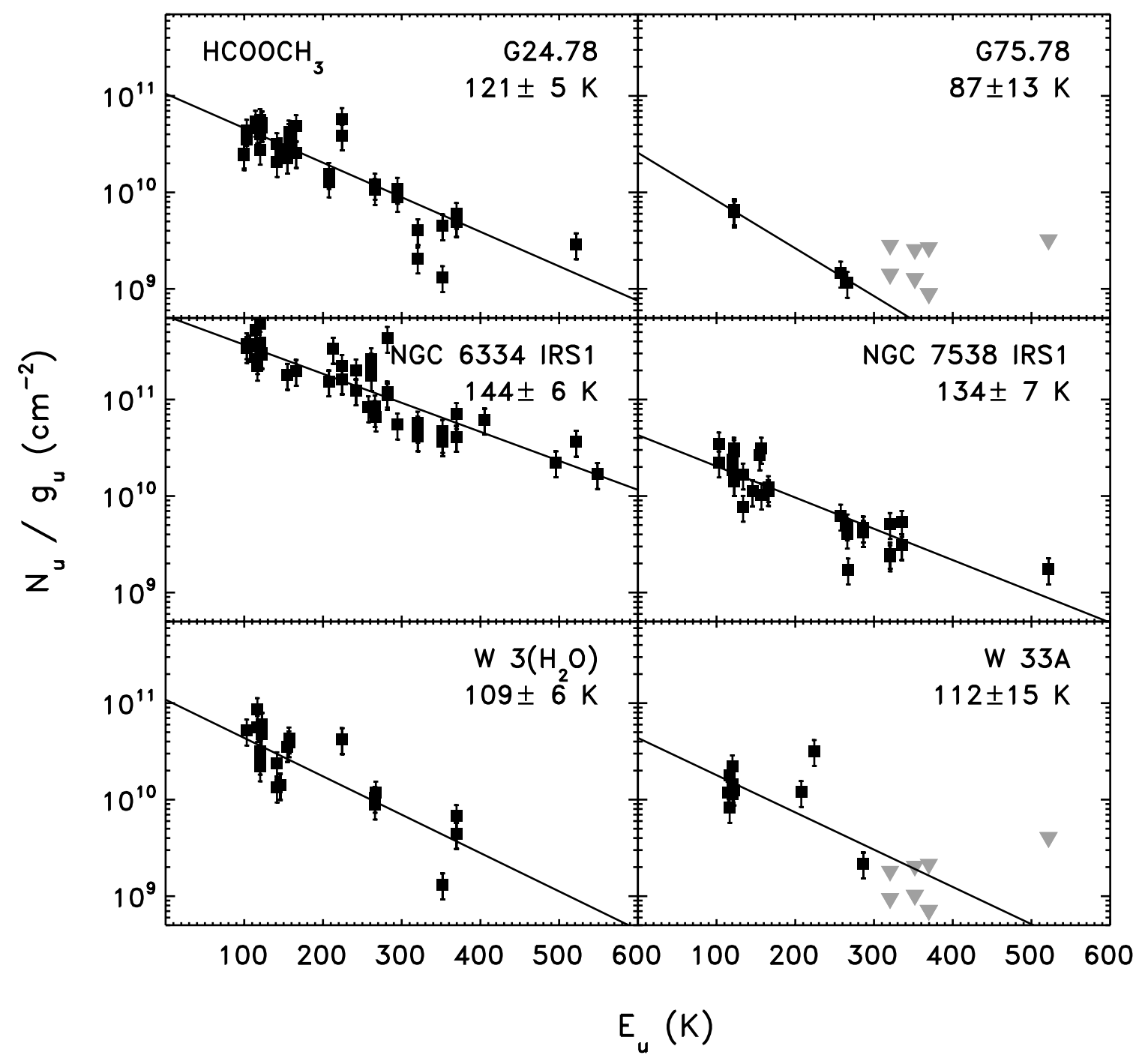

Fig. A.12. Rotation diagrams for $\mathrm{HCOOCH}_{3}$ for respectively G24.78, G75.78, NGC 6334IRS1, NGC 7538IRS1, W3( $\left.\mathrm{H}_{2} \mathrm{O}\right)$, and W33A. The filled black squares are the points included and the gray triangles indicate upper limits. 
S. E. Bisschop et al.: Testing grain-surface chemistry in massive hot-core regions, Online Material p 13

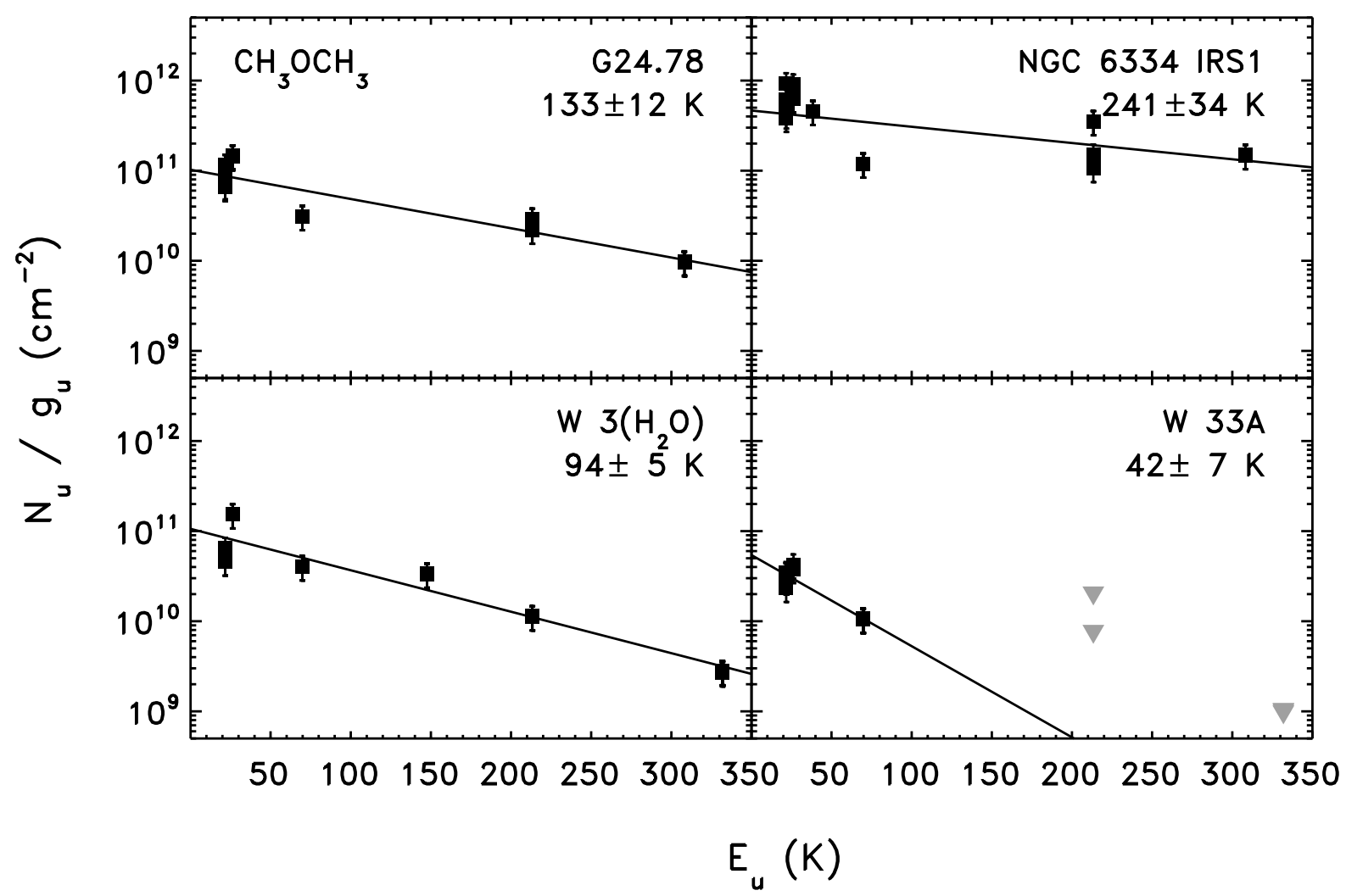

Fig. A.13. Rotation diagrams for $\mathrm{CH}_{3} \mathrm{OCH}_{3}$ for respectively G24.78, NGC 6334IRS1, W3 $\left(\mathrm{H}_{2} \mathrm{O}\right)$, and W33A. The filled black squares are the points included and the gray triangles indicate upper limits. 
S. E. Bisschop et al.: Testing grain-surface chemistry in massive hot-core regions, Online Material p 14

\section{Appendix B: Detected lines per species for all sources}

Table B.1. Observed line fluxes $\int T_{\mathrm{MB}} \mathrm{d} V\left(\mathrm{~K} \mathrm{~km} \mathrm{~s}^{-1}\right)$ for $\mathrm{H}_{2} \mathrm{CO}$ and its isotopic species.

\begin{tabular}{|c|c|c|c|c|c|c|c|c|}
\hline $\begin{array}{l}\text { Frequency } \\
{[\mathrm{GHz}]}\end{array}$ & Transition & AFGL 2591 & $\mathrm{G} 24.78$ & G75.78 & $\begin{array}{c}\text { Sources } \\
\text { NGC 6334 IRS1 }\end{array}$ & NGC 7538 IRS1 & W $3\left(\mathrm{H}_{2} \mathrm{O}\right)$ & W 33A \\
\hline \multicolumn{9}{|c|}{$\mathrm{H}_{2} \mathrm{CO}$} \\
\hline 218.222 & $3_{0,3}-2_{0,2}$ & - & 17 & 14 & - & - & - & - \\
\hline 218.476 & $3_{2,2}-2$ & - & 5.6 & 3.3 & - & - & - & - \\
\hline 225.698 & $3_{1,2}-2,1$ & 15 & 27 & 22 & 57 & 31 & 34 & 22 \\
\hline 363.946 & $5_{2,4}-4_{2,3}$ & - & 15 & 5.9 & - & - & - & - \\
\hline 364.103 & $5_{4,1 / 2}-4_{4,0 / 1}$ & - & 7.3 & 2.7 & - & - & - & - \\
\hline 364.275 & $5_{3,3}-4_{3,2}$ & - & 16 & 7.5 & - & - & - & - \\
\hline 364.289 & $5_{3,2}-4_{3,1}$ & - & 18 & 7.9 & - & - & - & - \\
\hline \multicolumn{9}{|c|}{$\mathrm{H}_{2}^{13} \mathrm{CO}$} \\
\hline 219.909 & $3,2_{1,2}-2_{1}$ & 0.41 & 2.9 & 1.0 & 8.8 & 0.84 & 1.1 & 1.6 \\
\hline 356.176 & $5_{2,3}-4_{2,2}$ & $<0.36$ & 2.4 & 0.55 & 6.3 & $<0.41$ & 0.96 & 0.92 \\
\hline \multicolumn{9}{|c|}{$\mathrm{H}_{2} \mathrm{C}^{18} \mathrm{O}$} \\
\hline 348.032 & $5_{2,3}-4_{2,2}$ & 0.15 & 0.85 & $<0.32$ & 2.6 & 0.26 & $<0.32$ & $<0.26$ \\
\hline
\end{tabular}

- means frequency not observed.

Table B.2. Observed line fluxes $\int T_{\mathrm{MB}} \mathrm{d} V\left(\mathrm{~K} \mathrm{~km} \mathrm{~s}^{-1}\right)$ for $\mathrm{CH}_{3} \mathrm{OH}$ in the $230 \mathrm{GHz}$ window.

\begin{tabular}{|c|c|c|c|c|c|c|c|c|}
\hline $\begin{array}{l}\text { Frequency } \\
{[\mathrm{GHz}]}\end{array}$ & Transition & AFGL 2591 & $\mathrm{G} 24.78$ & G75.78 & $\begin{array}{c}\text { Sources } \\
\text { NGC } 6334 \text { IRS1 } \\
\end{array}$ & NGC 7538 IRS1 & $\mathrm{W} 3\left(\mathrm{H}_{2} \mathrm{O}\right)$ & W33A \\
\hline \multicolumn{9}{|c|}{$\mathrm{CH}_{3} \mathrm{OH}$} \\
\hline 218.440 & $4_{3,1,0}-3_{2,1,0}$ & - & 12.5 & 3.0 & - & - & - & - \\
\hline 219.994 & $23_{14,9,0}-22_{14,8,0}$ & $<0.36$ & $<0.49$ & $<0.26$ & 2.0 & $<0.32$ & $<0.47$ & $<0.41$ \\
\hline 220.079 & $8_{4,4,0}-7_{4,3,0}$ & 0.55 & 4.1 & 1.1 & 18 & 1.3 & 3.6 & 0.54 \\
\hline 227.815 & $16_{9,8,0,1}-15_{9,7,0,1}$ & - & 2.1 & 0.60 & - & 0.87 & 1.8 & - \\
\hline 229.939 & $19_{12,7,0,2}-20_{12,8,0,2}$ & $<0.31$ & 0.56 & $<0.32$ & 5.1 & 0.47 & $<0.38$ & $<0.25$ \\
\hline 230.027 & $3_{1,3,0}-4_{2,3,0}$ & 0.53 & 3.4 & 0.68 & 17 & 1.6 & 4.3 & 0.92 \\
\hline 230.293 & $22_{2200}-21_{3190}$ & $<0.31$ & 0.38 & $<0.32$ & $5.1^{a}$ & $<0.41$ & 0.68 & $<0.25$ \\
\hline 230.369 & $22_{13,9,0}-21_{13,8,0}$ & $<0.31$ & 0.26 & $<0.32$ & 4.0 & 0.67 & 0.22 & $<0.25$ \\
\hline 231.281 & $10_{6,4,0,2}-9_{6,3,0,2}$ & 0.34 & $7.6^{b}$ & 0.93 & 13 & 0.82 & 4.5 & 1.7 \\
\hline 232.417 & $10_{6,4,0,1}-9_{6,3,0,1}$ & 0.64 & 2.8 & 0.72 & 10 & $<0.38$ & - & 0.94 \\
\hline 232.784 & $18_{11,8,0,1}-17_{11,7,0,1}$ & - & - & - & 17 & - & - & - \\
\hline 232.927 & $14_{681}-14_{771}$ & - & - & - & 1.7 & - & - & - \\
\hline 232.946 & $10_{470}-11_{570}$ & - & - & - & 16 & - & - & - \\
\hline 233.097 & $13_{671}-13_{761}$ & - & - & - & 0.83 & - & - & - \\
\hline 234.683 & $4_{3,1,0,2}-5_{3,2,0,2}$ & 0.62 & 4.3 & 1.3 & 18 & 1.4 & 4.1 & 2.2 \\
\hline 234.698 & $5_{1,5,0}-6_{2,5,0,5}$ & $<0.24$ & $<0.36$ & 0.31 & 10 & 0.64 & 1.6 & 1.0 \\
\hline 240.242 & $5_{4,1,0}-6_{4,2,0,5}$ & 0.50 & 3.7 & 0.85 & 12 & 0.79 & 5.6 & 0.92 \\
\hline 240.741 & $26_{3,23,0}-26_{2,24,0}$ & $<0.25$ & 0.66 & $<0.3$ & 4.8 & 0.47 & 0.33 & $<0.20$ \\
\hline 240.960 & $5_{3,2,1,1}-4_{3,2,1,1} c^{c}$ & 0.54 & $3.0^{d}$ & 0.61 & 17 & 1.1 & 3.4 & 0.94 \\
\hline 241.043 & $22_{6,16,0}-23_{5,18,0}$ & $<0.25$ & $<0.40$ & $<0.3$ & 2.6 & 0.45 & $<0.54$ & $<0.26$ \\
\hline 241.057 & $9_{3,6,0}-10_{0,10,0}$ & $<0.25$ & $<0.40$ & $<0.3$ & 3.3 & $<0.35$ & $<0.54$ & $<0.26$ \\
\hline 248.282 & $17_{10,7,0,2}-17_{10,8,0,1}$ & - & - & - & - & $<0.35$ & 3.0 & - \\
\hline 248.885 & $16_{10,7,0,2}-16_{9,7,0,1}$ & 0.60 & 2.4 & 0.87 & - & 0.96 & 2.7 & $<0.20$ \\
\hline \multicolumn{9}{|c|}{${ }^{13} \mathrm{CH}_{3} \mathrm{OH}$} \\
\hline 220.363 & $17_{3150}-18_{0180}$ & $<0.19$ & 0.15 & $<0.36$ & 1.3 & $<0.30$ & $<0.46$ & $<0.19$ \\
\hline 223.332 & $6_{4,3,1,2}-7_{5,3,1,2}$ & $<0.25$ & - & - & 1.3 & $<0.36$ & - & - \\
\hline 225.571 & $14_{7,8,0}-13_{6,8,0}$ & $<0.32$ & 0.64 & $<0.24$ & 0.84 & $<0.32$ & 0.50 & $<0.23$ \\
\hline 239.169 & $19_{2170}-19_{0190}$ & - & $<0.49$ & 0.19 & - & - & $<0.38$ & $<0.29$ \\
\hline 241.036 & $22_{0220}-21_{3180}$ & $<0.25$ & $<0.40$ & $<0.30$ & 0.83 & $<0.35$ & $<0.36$ & $<0.42$ \\
\hline
\end{tabular}

- means frequency not observed. ${ }^{a}$ Blend with $\mathrm{HCOOCH}_{3} .{ }^{b}$ Blend with $\mathrm{CH}_{3} \mathrm{CN} .{ }^{c}$ Blend with $5_{2,3,2}-44_{2,3,2} \cdot{ }^{d}$ Blend with $\mathrm{HCOOCH}_{3}$. 
S. E. Bisschop et al.: Testing grain-surface chemistry in massive hot-core regions, Online Material p 15

Table B.3. Observed line fluxes $\int T_{\mathrm{MB}} \mathrm{d} V\left(\mathrm{~K} \mathrm{~km} \mathrm{~s}^{-1}\right)$ for $\mathrm{CH}_{3} \mathrm{OH}$ in the $345 \mathrm{GHz}$ window and its isotopic species.

\begin{tabular}{|c|c|c|c|c|c|c|c|c|}
\hline $\begin{array}{l}\text { Frequency } \\
\text { [GHz] }\end{array}$ & Transition & AFGL 2591 & G24.78 & G75.78 & $\begin{array}{c}\text { Sources } \\
\text { NGC } 6334 \text { IRS1 }\end{array}$ & NGC 7538 IRS1 & $\mathrm{W} 3\left(\mathrm{H}_{2} \mathrm{O}\right)$ & W33A \\
\hline \multicolumn{9}{|c|}{$\mathrm{CH}_{3} \mathrm{OH}$ continued } \\
\hline 337.969 & $74,3,1,2-6_{4,3,1,2}$ & 0.48 & 3.2 & 0.76 & 14 & 1.3 & 3.6 & 0.77 \\
\hline 338.125 & $7_{4,4,0}-6_{3,3,0}$ & 2.9 & 20 & 4.7 & 56 & 5.9 & 24 & 5.8 \\
\hline 338.345 & $7_{3,4,0}-6_{3,4,0}$ & 3.9 & 35 & 7.7 & 71 & 8.1 & 30 & 11 \\
\hline 338.409 & $7_{4,4,0,1}-6_{3,3,0,1}$ & 3.9 & 39 & 7.9 & 59 & - & 66 & 11 \\
\hline 338.431 & $7_{1,7,0}-6_{0,6,0}$ & - & 4.0 & 0.84 & - & - & - & - \\
\hline 338.442 & $7_{7,1,0,1 / 2}-6_{6,0,0,1 / 2}$ & - & 4.7 & 1.4 & - & - & - & - \\
\hline 338.456 & $7_{1,6,0}-6_{1,6,0}$ & - & 5.6 & 1.5 & - & - & - & - \\
\hline 338.475 & $7_{6,1,0}-6_{6,1,0}$ & - & 5.9 & 1.8 & - & - & - & - \\
\hline 338.486 & $7_{6,1,0,1 / 2}-6_{6,1,0,1 / 2}$ & - & 6.9 & 1.6 & - & - & - & - \\
\hline 338.504 & $7_{2,6,0}-6_{1,5,0}$ & - & 6.8 & 1.9 & - & - & - & - \\
\hline 338.513 & $7_{5,3,0,2}-6_{4,2,0,2}^{a}$ & - & 14 & 3.3 & - & - & - & - \\
\hline 338.530 & $7_{6,2,0}-6_{5,1,0}$ & - & 7.2 & 1.8 & - & - & - & - \\
\hline 338.542 & $7_{5,2,0,1 / 2}-6_{5,2,0,1}$ & - & 17 & 4.7 & - & - & - & - \\
\hline 338.560 & $7_{2,5,0}-6_{2,5,0}$ & - & 8.6 & 2.1 & - & - & - & - \\
\hline 338.583 & $7_{5,2,0}-6_{5,2,0}$ & - & 10 & 2.5 & - & - & - & - \\
\hline 338.615 & $7_{4,3,0}-6_{4,3,0}$ & - & 20 & 8.0 & - & - & - & - \\
\hline 338.640 & $7_{5,3,0,1}-6_{4,2,0,1}$ & - & 13 & 3.1 & - & - & - & - \\
\hline 338.722 & $7_{3 / 5,5 / 3,0}-6_{2 / 4,4 / 2,0}$ & - & 27 & 6.5 & - & - & - & - \\
\hline 340.141 & $2_{2,0,0,1}-3_{2,1,0,1}$ & 0.89 & 5.6 & 1.6 & 27 & 3.2 & 4.1 & 1.7 \\
\hline 340.394 & $16_{11,5,0,1 / 2}-17_{11,6,0,1 / 2}$ & 0.65 & 2.2 & 0.58 & 19 & 1.6 & 1.1 & 0.78 \\
\hline 355.964 & $16_{10,7,1}-16_{9,7,1}$ & $<0.29$ & $<0.47$ & $<0.53$ & 5.6 & $<0.41$ & $<0.43$ & $<0.68$ \\
\hline 356.007 & $15_{8,7,0,2}-15_{8,8,0,1}$ & 2.4 & 9.5 & 3.9 & 29 & 6.8 & 13 & 3.4 \\
\hline \multicolumn{9}{|c|}{${ }^{13} \mathrm{CH}_{3} \mathrm{OH}$} \\
\hline 345.084 & $2_{2,0,0,1}-3_{2,1,0,1}$ & $<0.23$ & 0.26 & $<0.30$ & 4.1 & $<0.33$ & $<0.29$ & $<0.19$ \\
\hline 348.101 & $11_{6,6,0}-10_{6,5,0}$ & $<0.18$ & 2.0 & 0.27 & 10.0 & 0.61 & $<0.44$ & 0.19 \\
\hline
\end{tabular}

- means frequency not observed. ${ }^{a}$ Blend with $7_{6,2,0,1 / 2}-6_{5,1,0,1 / 2}$.

Table B.4. Observed line fluxes $\int T_{\mathrm{MB}} \mathrm{d} V\left(\mathrm{~K} \mathrm{~km} \mathrm{~s}^{-1}\right)$ for $\mathrm{CH}_{2} \mathrm{CO}$.

\begin{tabular}{|c|c|c|c|c|c|c|c|c|}
\hline \multirow{2}{*}{$\begin{array}{l}\text { Frequency } \\
{[\mathrm{GHz}]}\end{array}$} & \multirow{2}{*}{ Transition } & \multicolumn{7}{|c|}{ Sources } \\
\hline & & AFGL 2591 & $\mathrm{G} 24.78$ & G75.78 & NGC 6334 IRS1 & NGC 7538 IRS1 & $\mathrm{W} 3\left(\mathrm{H}_{2} \mathrm{O}\right)$ & W33A \\
\hline 81.586 & $4_{1,3}-3_{1,2}$ & 0.32 & - & $<0.75$ & - & 0.45 & 0.16 & - \\
\hline 140.127 & $7_{1,7}-6_{1,6}$ & - & - & - & - & 0.72 & 0.85 & - \\
\hline 244.712 & $12_{1,11}-11_{1,10}$ & $<0.39$ & - & $<0.78$ & - & 1.8 & 1.6 & - \\
\hline 262.619 & $13_{2,12}-12_{2,11}$ & $<0.33$ & - & $<0.47$ & - & $<1.7$ & 1.5 & - \\
\hline 220.178 & $11_{1,11}-10_{1,10}$ & $<0.19$ & 1.2 & 0.41 & 5.0 & 0.63 & 0.65 & 0.37 \\
\hline $222.199^{a}$ & $11_{0,11}-10_{0,10}$ & $<0.31$ & 1.3 & 0.38 & 5.9 & 0.51 & 0.87 & 0.37 \\
\hline 222.229 & $11_{2,10}-10_{2,9}$ & $<0.31$ & 0.38 & $<0.22$ & 2.7 & $<0.41$ & 0.20 & 0.11 \\
\hline 222.315 & $11_{2,9}-10_{2,8}$ & $<0.31$ & 0.20 & $<0.22$ & 1.5 & $<0.41$ & $<0.35$ & $<0.25$ \\
\hline 240.187 & $12_{1,12}-11_{1,11}$ & $<0.24$ & 1.5 & 0.50 & 4.5 & 0.46 & 1.4 & 0.51 \\
\hline 346.600 & $17_{1,16}-16_{1,15}$ & $<0.26$ & 1.4 & 0.52 & 8.4 & 0.81 & 1.4 & 0.60 \\
\hline
\end{tabular}

- means frequency not observed. ${ }^{a}$ Blend of lines $11_{011}-10_{010}, 11_{39}-10_{38}$, and $11_{38}-10_{37}$.

Table B.5. Observed line fluxes $\int T_{\mathrm{MB}} \mathrm{d} V\left(\mathrm{~K} \mathrm{~km} \mathrm{~s}^{-1}\right)$ for $\mathrm{CH}_{3} \mathrm{CHO}$.

\begin{tabular}{lcccccccc}
\hline $\begin{array}{l}\text { Frequency } \\
\text { [GHz] }\end{array}$ & Transition & & G24.78 & G75.78 & NGC 6334 IRS1 & NGC 7538 IRS1 & W3(H $\left.{ }_{2} \mathrm{O}\right)$ & W33A \\
\hline 98.901 & $5_{1,4}-4_{1,3}$ & 0.29 & - & $<0.14$ & - & 0.22 & 0.38 & - \\
112.249 & $6_{1,6}-5_{1,5}$ & - & - & - & - & 0.40 & 0.50 & - \\
149.507 & $8_{1,8}-7_{1,7}$ & $<0.15$ & - & $<0.36$ & - & 0.69 & 0.54 & - \\
168.093 & $9_{1,9}-8_{1,8}$ & $<0.21$ & - & $<0.30$ & - & 0.30 & 0.48 & - \\
\hline
\end{tabular}

- means frequency not observed. 
S. E. Bisschop et al.: Testing grain-surface chemistry in massive hot-core regions, Online Material p 16

Table B.6. Observed line fluxes $\int T_{\mathrm{MB}} \mathrm{d} V\left(\mathrm{~K} \mathrm{~km} \mathrm{~s}^{-1}\right)$ for $\mathrm{C}_{2} \mathrm{H}_{5} \mathrm{OH}$.

\begin{tabular}{|c|c|c|c|c|c|c|c|c|}
\hline $\begin{array}{l}\text { Frequency } \\
\text { [GHz] }\end{array}$ & Transition & AFGL 2591 & G24.78 & G75.78 & $\begin{array}{c}\text { Sources } \\
\text { NGC 6334 IRS1 }\end{array}$ & NGC 7538 IRS1 & $\mathrm{W} 3\left(\mathrm{H}_{2} \mathrm{O}\right)$ & W33A \\
\hline 220.155 & $24_{3,22,2}-24_{2,23,2}$ & $<0.24$ & $<0.38$ & $<0.36$ & 1.1 & 0.78 & $<0.39$ & $<0.24$ \\
\hline 222.138 & $19_{7,13 / 12,0}-18_{7,11 / 12,1}$ & $<0.39$ & $<0.43$ & $<0.32$ & 1.6 & $<0.32$ & $<0.27$ & $<0.32$ \\
\hline 225.279 & $13_{5,9,1}-12_{5,8,1}$ & $<0.41$ & $<0.43$ & $<0.24$ & 0.57 & $<0.26$ & $<0.21$ & $<0.29$ \\
\hline 225.283 & $13_{5,8,1}-12_{5,7,1}$ & $<0.41$ & $<0.43$ & $<0.24$ & 0.9 & $<0.26$ & $<0.21$ & $<0.29$ \\
\hline 225.457 & $13_{3,11,1}-12_{3,10,1}$ & $<0.41$ & 0.43 & $<0.24$ & 0.66 & $<0.26$ & $<0.21$ & $<0.29$ \\
\hline 225.546 & $13_{4,10,1}-12_{4,9,1}$ & $<0.41$ & $<0.43$ & $<0.24$ & 0.56 & $<0.26$ & $<0.21$ & $<0.29$ \\
\hline 225.560 & $13_{3,11,0}-12_{3,10,0}$ & $<0.41$ & $<0.43$ & $<0.24$ & 1.9 & $<0.26$ & $<0.21$ & $<0.29$ \\
\hline 225.660 & $13_{4,10,0}-12_{4,9,0}$ & $<0.41$ & $<0.43$ & $<0.24$ & 0.85 & $<0.26$ & $<0.21$ & $<0.29$ \\
\hline 226.581 & $26_{2,24,2}-26_{1,25,2}$ & $<0.30$ & $<0.48$ & $<0.21$ & 2.6 & $<0.26$ & $<0.35$ & $<0.30$ \\
\hline 230.954 & $16_{5,11,2}-16_{4,12,2}$ & $<0.32$ & 0.59 & $<0.21$ & 2.9 & $<0.29$ & $<0.32$ & $<0.42$ \\
\hline 230.991 & $14_{0,14,2}-13_{1,13,2}$ & $<0.32$ & 0.19 & $<0.21$ & 2.8 & 0.34 & 0.21 & $<0.42$ \\
\hline 232.035 & $18_{5,14,2}-18_{4,15,2}$ & $<0.30$ & $<0.43$ & $<0.26$ & 0.56 & $<0.30$ & - & $<0.41$ \\
\hline 232.319 & $23_{5,19,2}-23_{4,20,2}$ & $<0.30$ & $<0.43$ & $<0.26$ & 0.45 & $<0.30$ & - & $<0.41$ \\
\hline 232.405 & $17_{5,13,2}-17_{4,14,2}$ & $<0.30$ & $<0.43$ & $<0.26$ & 0.95 & $<0.30$ & - & $<0.41$ \\
\hline 232.491 & $14_{0,14,0}-13_{0,13,0}$ & $<0.30$ & 0.24 & $<0.26$ & 0.99 & $<0.30$ & - & $<0.41$ \\
\hline 232.809 & $16_{5,12,2}-16_{4,13,2}$ & - & - & $<0.30$ & 2.0 & - & - & - \\
\hline 232.929 & $14_{5,9,2}-14_{4,10,2}$ & - & - & $<0.30$ & 0.54 & - & - & - \\
\hline 233.571 & $13_{5,8,2}-13_{4,9,2}$ & $<0.41$ & $<0.43$ & $<0.24$ & 0.87 & $<0.25$ & $<0.21$ & $<0.29$ \\
\hline 234.524 & $25_{5,21,2}-25_{4,22,2}$ & $<0.30$ & $<0.48$ & $<0.21$ & 1.6 & 0.23 & $<0.35$ & $<0.30$ \\
\hline 234.666 & $10_{5,5,2}-10_{4,6,2}$ & $<0.30$ & $<0.48$ & $<0.21$ & $<0.62$ & 0.24 & $<0.35$ & $<0.30$ \\
\hline 234.715 & $10_{5,6,2}-10_{4,7,2}$ & $<0.30$ & $<0.48$ & $<0.21$ & 2.0 & 0.14 & $<0.35$ & $<0.30$ \\
\hline 234.853 & $9_{5,4,2}-9_{4,5,2}$ & $<0.30$ & $<0.48$ & $<0.21$ & 1.5 & $<0.25$ & $<0.35$ & $<0.30$ \\
\hline 234.984 & $8_{5,3,2}-8_{4,4,2}$ & $<0.30$ & $<0.48$ & $<0.21$ & 0.84 & $<0.25$ & $<0.35$ & $<0.30$ \\
\hline 234.992 & $8_{5,4,2}-8_{4,5,2}$ & $<0.30$ & 0.38 & $<0.21$ & 1.9 & $<0.25$ & $<0.35$ & $<0.30$ \\
\hline 240.110 & $27_{2,25,2}-27_{1,26,2}$ & $<0.30$ & $<0.36$ & $<0.26$ & $<0.72$ & $<0.30$ & 0.16 & $<0.41$ \\
\hline 240.782 & $15_{2,13,0}-14_{1,13,1}$ & $<0.32$ & $<0.53$ & $<0.30$ & 1.1 & $<0.28$ & $<0.45$ & $<0.26$ \\
\hline 240.839 & $14_{1,13,0}-13_{1,13,1}$ & $<0.32$ & $<0.53$ & $<0.30$ & 2.0 & $<0.28$ & $<0.45$ & $<0.26$ \\
\hline 338.099 & $18_{7,11,2}-18_{6,12,2}$ & $<0.30$ & 1.7 & $<0.20$ & 2.8 & $<0.25$ & $<0.30$ & 0.14 \\
\hline 338.110 & $18_{7,12,2}-18_{6,13,2}$ & $<0.30$ & $<0.29$ & $<0.20$ & 2.2 & $<0.25$ & $<0.30$ & 0.15 \\
\hline 338.163 & $10_{2,8,1}-9_{1,8,0}$ & $<0.30$ & 0.37 & $<0.20$ & 1.1 & $<0.25$ & $<0.30$ & $<0.29$ \\
\hline 339.511 & $9_{7,3 / 2,2}-9_{6,4 / 3,2}$ & $<0.30$ & 0.64 & $<0.21$ & 1.3 & $<0.28$ & $<0.39$ & $<0.21$ \\
\hline 339.544 & $8_{7,2 / 1,2}-8_{6,3 / 2,2}$ & $<0.30$ & $<0.26$ & $<0.21$ & 2.8 & 0.32 & $<0.39$ & $<0.21$ \\
\hline 339.566 & $7_{7,0 / 1,2}-7_{6,1 / 2,2}$ & $<0.30$ & $<0.26$ & $<0.21$ & 1.6 & $<0.28$ & $<0.39$ & $<0.21$ \\
\hline 339.979 & $9_{4,6,2}-8_{3,5,2}$ & $<0.30$ & 1.2 & $<0.21$ & 6.1 & 0.73 & $<0.39$ & $<0.21$ \\
\hline 340.189 & $6_{5,1 / 2,2}-5_{4,2 / 1,2}$ & $<0.36$ & 3.4 & 0.68 & 15 & 1.6 & 1.7 & 1.1 \\
\hline 340.420 & $9_{4,5,2}-8_{3,6,2}$ & $<0.36$ & $<0.55$ & $<0.26$ & 4.0 & 0.38 & $<0.36$ & 0.78 \\
\hline 345.173 & $7_{7,0 / 1,0}-6_{6,0 / 1,1}$ & $<0.29$ & $<0.43$ & $<0.30$ & 2.4 & $<0.26$ & $<0.21$ & $<0.24$ \\
\hline 345.295 & $21_{1,21,1}-20_{1,20,1}$ & $<0.29$ & 0.55 & $<0.30$ & 2.5 & $<0.26$ & $<0.21$ & $<0.24$ \\
\hline 345.408 & $21_{0,21,1}-20_{0,20,1}$ & $<0.29$ & 0.30 & $<0.30$ & 5.1 & $<0.26$ & 0.51 & $<0.24$ \\
\hline 346.620 & $20_{8,12 / 13,0}-19_{8,11 / 12,0}$ & $<0.26$ & 0.10 & $<0.36$ & 1.3 & 0.34 & $<0.32$ & $<0.23$ \\
\hline 346.817 & $20_{7,13 / 14,0}-19_{7,12 / 13,0}$ & $<0.26$ & 0.82 & $<0.36$ & 3.9 & 0.48 & 0.22 & 0.28 \\
\hline 346.929 & $20_{6,15,1}-19_{6,14,1}$ & $<0.26$ & 0.71 & $<0.36$ & 1.4 & $<0.19$ & $<0.32$ & $<0.23$ \\
\hline 346.963 & $21_{0,21,2}-20_{1,20,2}$ & $<0.26$ & 2.0 & $<0.36$ & $4.4^{a}$ & 0.80 & 0.89 & $<0.23$ \\
\hline 347.887 & $20_{5,15,0}-19_{5,14,0}$ & $<0.23$ & 0.38 & $<0.32$ & 2.4 & 0.23 & $<0.32$ & $<0.26$ \\
\hline 347.916 & $20_{4,17,0}-19_{4,16,0}$ & $<0.23$ & 2.1 & $<0.32$ & 8.1 & 1.4 & 0.74 & $<0.26$ \\
\hline 347.975 & $22_{2,20,2}-21_{3,19,2}$ & $<0.23$ & 0.57 & $<0.32$ & 2.7 & 0.36 & $<0.32$ & $<0.26$ \\
\hline 348.720 & $4_{4,0 / 1,1}-3_{3,0 / 1,0}$ & $<0.36$ & 0.65 & $<0.27$ & $<0.36$ & $<0.26$ & $<0.36$ & $<0.26$ \\
\hline 348.847 & $10_{6,5 / 4,0}-9_{5,5 / 4,1}$ & $<0.36$ & 0.97 & $<0.27$ & $<0.36$ & $<0.26$ & $<0.36$ & $<0.26$ \\
\hline 352.858 & $21_{1,20,2}-20_{2,19,2}$ & $<0.32$ & 1.2 & $<0.51$ & 4.9 & 0.49 & $<0.29$ & $<0.42$ \\
\hline 353.035 & $12_{3,9,2}-11_{2,10,2}$ & $<0.32$ & 0.97 & $<0.51$ & 5.2 & 0.64 & 0.58 & $<0.42$ \\
\hline 363.968 & $21_{7,15 / 14,1}-20_{7,14 / 13,1}$ & - & 0.50 & $<0.38$ & - & - & - & - \\
\hline 364.233 & $21_{7,15 / 14,0}-20_{7,14 / 13,0}$ & - & 0.57 & $<0.38$ & - & - & - & - \\
\hline
\end{tabular}

- means frequency not observed. ${ }^{a}$ Blend with $\mathrm{C}_{2} \mathrm{H}_{5} \mathrm{CN}$. 
S. E. Bisschop et al.: Testing grain-surface chemistry in massive hot-core regions, Online Material p 17

Table B.7. Observed line fluxes $\int T_{\mathrm{MB}} \mathrm{d} V\left(\mathrm{~K} \mathrm{~km} \mathrm{~s}^{-1}\right)$ for $\mathrm{HCOOH}$.

\begin{tabular}{|c|c|c|c|c|c|c|c|c|}
\hline $\begin{array}{l}\text { Frequency } \\
{[\mathrm{GHz}]}\end{array}$ & Transition & AFGL 2591 & $\mathrm{G} 24.78$ & G75.78 & $\begin{array}{c}c \text { Sources } \\
\text { NGC } 6334 \text { IRS1 }\end{array}$ & NGC 7538 IRS1 & $\mathrm{W} 3\left(\mathrm{H}_{2} \mathrm{O}\right)$ & W33A \\
\hline 223.916 & $10_{2,9}-9_{1,8}$ & $<0.21$ & - & $<0.17$ & - & 0.76 & 0.19 & - \\
\hline 247.514 & $11_{5,6 / 7}-10_{5,5 / 6}$ & - & - & - & - & 0.66 & 2.4 & - \\
\hline 257.975 & $12_{1,12}-11_{1,11}$ & $<0.38$ & - & $<1.9$ & - & $<0.89$ & $<0.95$ & - \\
\hline 262.103 & $12_{0,12}-11_{0,11}$ & - & - & - & - & $<0.36$ & $<1.3$ & - \\
\hline 220.038 & $10_{0,10}-9_{0,9}$ & $<0.19$ & $<0.29$ & $<0.29$ & 1.3 & 0.37 & $<0.46$ & $<0.19$ \\
\hline 225.513 & $10_{3,7}-9_{3,6}$ & $<0.32$ & 0.73 & $<0.19$ & 2.6 & $<0.25$ & 0.88 & 0.40 \\
\hline 338.144 & $15_{4,12}-14_{4,11}$ & $0.23^{a}$ & $2.1^{a}$ & $<0.16$ & 3.7 & $0.49^{a}$ & $1.2^{a}$ & 0.28 \\
\hline 338.202 & $15_{3,13}-14_{3,12}$ & $<0.24$ & 0.53 & 0.26 & 3.4 & 0.74 & 0.97 & 0.24 \\
\hline 338.249 & $15_{4,11}-14_{4,10}$ & $<0.24$ & 1.1 & $<0.16$ & 3.1 & 0.35 & 0.72 & 0.20 \\
\hline 345.031 & $16_{0,16}-15_{0,15}$ & $<0.23$ & $<0.32$ & $<0.20$ & 2.3 & 0.51 & 0.33 & $<0.19$ \\
\hline 346.719 & $15_{2,13}-14_{2,12}$ & 0.21 & 0.49 & 0.19 & 2.9 & 0.81 & 0.36 & 0.17 \\
\hline 356.137 & $16_{2,15}-15_{2,14}$ & 0.65 & 0.28 & 0.34 & 1.8 & 0.83 & 0.55 & $<0.54$ \\
\hline
\end{tabular}

- means frequency not observed. ${ }^{a}$ Blend with $\mathrm{C}_{2} \mathrm{H}_{5} \mathrm{CN}$.

Table B.8. Observed line fluxes $\int T_{\mathrm{MB}} \mathrm{d} V\left(\mathrm{~K} \mathrm{~km} \mathrm{~s}^{-1}\right)$ for HNCO.

\begin{tabular}{|c|c|c|c|c|c|c|c|c|}
\hline $\begin{array}{l}\text { Frequency } \\
{[\mathrm{GHz}]}\end{array}$ & Transition & AFGL 2591 & G24.78 & G75.78 & $\begin{array}{c}\text { Sources } \\
\text { NGC 6334 IRS1 }\end{array}$ & NGC 7538 IRS1 & $\mathrm{W} 3\left(\mathrm{H}_{2} \mathrm{O}\right)$ & W33A \\
\hline \multicolumn{9}{|c|}{$\mathrm{HNCO}$} \\
\hline 219.656 & $10_{3,7 / 8}-9,936 / 7$ & $<0.29$ & $<0.41$ & $<0.31$ & 1.2 & $<0.25$ & $<0.47$ & $<0.41$ \\
\hline 219.734 & $10_{2,9}-9_{2,8}$ & $<0.29$ & 0.59 & 0.77 & 3.2 & 0.72 & 0.90 & 0.78 \\
\hline 219.737 & $10_{2,8}-9_{2,7}$ & $<0.29$ & 1.1 & $a$ & $a$ & $a$ & $a$ & $a$ \\
\hline 219.798 & $10_{0,10}-9,9$ & 0.88 & 4.4 & 1.7 & 8.4 & 0.65 & 1.4 & 3.0 \\
\hline 240.876 & $11_{1,11}-10_{1,10}$ & $<0.25$ & 2.7 & 1.3 & 4.3 & 0.55 & 0.99 & 1.4 \\
\hline 352.898 & $16_{1,15}-15_{1,14}$ & 0.89 & 3.3 & 2.0 & 7.7 & 1.5 & 2.0 & 2.1 \\
\hline \multicolumn{9}{|c|}{$\mathrm{HN}^{13} \mathrm{CO}$} \\
\hline 219.803 & $10_{2,9}-9_{2,8}$ & $<0.36$ & $<0.41$ & $<0.26$ & $<0.98$ & $<0.32$ & $<0.39$ & $<0.41$ \\
\hline 240.881 & $11_{1,11}-10_{1,10}$ & $<0.25$ & $<0.46$ & $<0.36$ & $<0.41$ & $<0.28$ & $<0.54$ & $<0.26$ \\
\hline
\end{tabular}

- means frequency not observed. ${ }^{a}$ Blend with HNCO line at $219734 \mathrm{MHz}$.

Table B.9. Observed line fluxes $\int T_{\mathrm{MB}} \mathrm{d} V\left(\mathrm{~K} \mathrm{~km} \mathrm{~s}^{-1}\right)$ for $\mathrm{NH}_{2} \mathrm{CHO}$.

\begin{tabular}{|c|c|c|c|c|c|c|c|c|}
\hline $\begin{array}{l}\text { Frequency } \\
{[\mathrm{GHz}]}\end{array}$ & Transition & AFGL 2591 & G24.78 & G75.78 & $\begin{array}{c}\text { Sources } \\
\text { NGC } 6334 \text { IRS1 }\end{array}$ & NGC 7538 IRS1 & $\mathrm{W} 3\left(\mathrm{H}_{2} \mathrm{O}\right)$ & W33A \\
\hline 227.606 & $11_{0,11}-10_{0,10}$ & - & 0.90 & $<0.20$ & - & $a$ & $<0.39$ & - \\
\hline 232.274 & $11_{2,10}-10_{2,9}$ & $<0.5$ & $<0.27$ & 0.15 & 2.2 & 0.32 & - & $<0.60$ \\
\hline 233.529 & $11_{6,5 / 6}-10_{6,4 / 5}$ & $<0.15$ & $<0.32$ & $<0.19$ & 0.73 & 0.56 & $<0.21$ & $<0.42$ \\
\hline 233.595 & $11_{5,6 / 7}-10_{5,5 / 6}$ & $<0.15$ & 0.64 & $<0.19$ & $b$ & 0.93 & 1.4 & 0.56 \\
\hline 233.736 & $11_{4,8}-10_{4,7}$ & $<0.15$ & 0.56 & $<0.19$ & 1.3 & 0.23 & $<0.21$ & 0.30 \\
\hline 339.716 & $16_{8,8 / 9}-15_{8,7 / 8}$ & $<0.3$ & 1.3 & $<0.17$ & 3.8 & 1.2 & 0.22 & $<0.34$ \\
\hline 339.780 & $16_{7,9 / 10}-15_{7,8 / 9}$ & $<0.3$ & 0.93 & $<0.17$ & 2.2 & 0.95 & $<0.39$ & $<0.34$ \\
\hline 339.904 & $16_{6,10 / 11}-15_{6,9 / 10}$ & $<0.3$ & 1.2 & $<0.17$ & 4.1 & 0.81 & $<0.39$ & $<0.34$ \\
\hline 340.491 & $16_{3,14}-15_{3,13}$ & $<0.36$ & 1.3 & 0.18 & 3.0 & 0.70 & 0.45 & 0.75 \\
\hline 340.536 & $16_{4,13}-15_{4,12}$ & $<0.36$ & 0.55 & 0.31 & 2.3 & 0.49 & $<0.36$ & $<0.36$ \\
\hline 345.183 & $17_{0,17}-16_{0,16}$ & $<0.29$ & 1.2 & $<0.24$ & 2.1 & 0.66 & 0.44 & 0.34 \\
\hline 345.327 & $16_{1,15}-15_{1,14}$ & $<0.29$ & $<0.32$ & $<0.24$ & 3.8 & 2.2 & $<0.21$ & $<0.38$ \\
\hline
\end{tabular}

- means frequency not observed. ${ }^{a}$ Blend with $\mathrm{C}_{2} \mathrm{H}_{5} \mathrm{OH} .{ }^{b}$ Blend with $\mathrm{C}_{2} \mathrm{H}_{5} \mathrm{OH}$ at $225404 \mathrm{MHz}$ in other sideband. 
S. E. Bisschop et al.: Testing grain-surface chemistry in massive hot-core regions, Online Material p 18

Table B.10. Observed line fluxes $\int T_{\mathrm{MB}} \mathrm{d} V\left(\mathrm{~K} \mathrm{~km} \mathrm{~s}^{-1}\right)$ for $\mathrm{CH}_{3} \mathrm{CN}$.

\begin{tabular}{|c|c|c|c|c|c|c|c|c|}
\hline $\begin{array}{l}\text { Frequency } \\
\text { [GHz] }\end{array}$ & Transition & AFGL 2591 & G24.78 & G75.78 & $\begin{array}{c}\text { Sources } \\
\text { NGC } 6334 \text { IRS1 }\end{array}$ & NGC 7538 IRS1 & $\mathrm{W} 3\left(\mathrm{H}_{2} \mathrm{O}\right)$ & W33A \\
\hline \multicolumn{9}{|c|}{$\mathrm{CH}_{3} \mathrm{CN}$} \\
\hline 220.476 & $12_{8.0, \mathrm{~K}}-11_{8,0, \mathrm{~L}}$ & $<0.24$ & 0.45 & $<0.43$ & 1.0 & $<0.54$ & $<0.53$ & $<0.24$ \\
\hline 238.913 & $13_{7,0, \mathrm{~K}}-12_{7,0, \mathrm{~L}}$ & - & 1.4 & $<0.25$ & - & - & $<0.50$ & 0.38 \\
\hline 238.972 & $13_{6,0, \mathrm{~K}}-12_{6,0, \mathrm{~K}}$ & - & 2.8 & 0.47 & - & - & 1.8 & 0.73 \\
\hline 239.064 & $13_{4,0, \mathrm{~K}}-12_{4,0, \mathrm{~L}}$ & - & 3.8 & 0.83 & - & - & 1.9 & 0.97 \\
\hline 239.097 & $13_{3,0, \mathrm{~K}}-12_{3,0, \mathrm{~L}}$ & - & 5.9 & 1.2 & - & - & 3.8 & 1.5 \\
\hline 239.120 & $13_{2,0, \mathrm{~K}}-12_{2,0, \mathrm{~L}}$ & - & 5.0 & 1.1 & - & - & 3.4 & 1.5 \\
\hline 239.133 & $13_{1,0, \mathrm{~K}}-12_{0 / 1,0, \mathrm{~L}}$ & - & 5.7 & 1.8 & - & - & 8.1 & 1.4 \\
\hline 239.138 & $13_{0,0, \mathrm{~K}}-12_{0,0, \mathrm{~L}}$ & - & 5.2 & 0.98 & - & - & $<0.50$ & 0.69 \\
\hline 240.090 & $13_{1,2, \mathrm{~K}}-12_{1,2, \mathrm{~L}}$ & $<0.3$ & 0.94 & $<0.31$ & 3.0 & $a$ & 0.29 & $<0.32$ \\
\hline 348.645 & $19_{11,0, \mathrm{~K}}-18_{11,0, \mathrm{~L}}$ & $<0.36$ & $<0.36$ & $<0.43$ & 0.64 & $<0.59$ & $<0.58$ & $<0.24$ \\
\hline \multicolumn{9}{|c|}{$\mathrm{CH}_{3}^{13} \mathrm{CN}$} \\
\hline 220.485 & $12_{6,0, \mathrm{~K}}-11_{6,0, \mathrm{~L}}$ & $<0.24$ & 0.30 & $<0.43$ & 0.35 & $<0.54$ & $<0.53$ & $<0.24$ \\
\hline 238.905 & $13_{5,0, \mathrm{~K}}-12_{5,0, \mathrm{~L}}$ & - & 0.17 & $<0.25$ & - & - & $<0.50$ & $<0.34$ \\
\hline 238.946 & $13_{4,0, \mathrm{~K}}-12_{4,0, \mathrm{~L}}$ & - & 0.57 & $<0.25$ & - & - & $<0.50$ & $<0.34$ \\
\hline 238.978 & $13_{3,0, \mathrm{~K}}-12_{3,0, \mathrm{~L}}$ & - & 1.06 & $<0.25$ & - & - & $<0.50$ & 0.38 \\
\hline 239.001 & $13_{2,0, \mathrm{~K}}-12_{2,0, \mathrm{~L}}$ & - & 0.73 & $<0.25$ & - & - & $<0.50$ & $<0.34$ \\
\hline 348.853 & $19_{8,0, \mathrm{~K}}-18_{8,0, \mathrm{~L}}$ & $<0.36$ & 0.36 & $<0.43$ & $<0.36$ & $<0.59$ & $<0.58$ & $<0.24$ \\
\hline
\end{tabular}

- means frequency not observed. K refers to main transition of the upper level i.e. 12,13 , or $19+1,+0$, or $-1 \mathrm{~L}$ refers to the main transition of the lower level i.e. 11,12 , or $18+1,+0$, or $-1 .{ }^{a}$ Blend with $\mathrm{CH}_{3} \mathrm{OH}$.

Table B.11. Observed line fluxes $\int T_{\mathrm{MB}} \mathrm{d} V\left(\mathrm{~K} \mathrm{~km} \mathrm{~s}^{-1}\right)$ for $\mathrm{C}_{2} \mathrm{H}_{5} \mathrm{CN}$.

\begin{tabular}{|c|c|c|c|c|c|c|c|c|}
\hline $\begin{array}{l}\text { Frequency } \\
{[\mathrm{GHz}]}\end{array}$ & Transition & AFGL 2591 & $\mathrm{G} 24.78$ & G75.78 & $\begin{array}{c}\text { Sources } \\
\text { NGC } 6334 \text { IRS1 } \\
\end{array}$ & NGC 7538 IRS1 & $\mathrm{W} 3\left(\mathrm{H}_{2} \mathrm{O}\right)$ & W33A \\
\hline 218.390 & $24_{3,21}-23_{3,20}$ & - & 0.71 & $<0.41$ & - & - & - & - \\
\hline 219.506 & $24_{2,22}-23_{2,21}$ & $<0.36$ & 0.85 & $<0.26$ & 2.2 & $<0.32$ & $<0.39$ & $<0.41$ \\
\hline 222.918 & $25_{1,24}-24_{1,23}$ & $<0.32$ & - & - & 3.4 & $<0.36$ & - & - \\
\hline 223.385 & $26_{1,26}-25_{1,25}$ & $<0.32$ & - & - & 1.9 & $<0.36$ & - & - \\
\hline 227.781 & $25_{3,22}-24_{3,21}$ & - & 1.8 & $<0.26$ & - & $<0.32$ & $<0.39$ & - \\
\hline 228.483 & $25_{2,23}-24_{2,22}$ & $<0.24$ & 1.4 & $<0.36$ & 2.4 & $<0.30$ & $<0.33$ & $<0.24$ \\
\hline 231.310 & $26_{1,25}-25_{1,24}$ & $<0.32$ & 0.79 & $<0.21$ & 2.5 & $<0.36$ & 0.61 & $<0.42$ \\
\hline 233.443 & $26_{5,22}-25_{5,21}$ & $<0.15$ & 1.2 & $<0.24$ & 1.0 & $<0.41$ & 0.94 & $<0.29$ \\
\hline 233.498 & $26_{5,21}-25_{5,20}$ & $<0.15$ & 1.5 & $<0.24$ & $1.9^{a}$ & $<0.41$ & 0.63 & $<0.29$ \\
\hline 240.319 & $28_{1,28}-27_{1,27}$ & $<0.30$ & 1.4 & $<0.26$ & 3.2 & $<0.38$ & 0.66 & $<0.41$ \\
\hline 240.429 & $28_{0,28}-27_{0,27}$ & $<0.30$ & 1.1 & $<0.26$ & $<0.58$ & $<0.38$ & $<0.47$ & $<0.41$ \\
\hline 248.781 & $29_{1,29}-28_{1,28}$ & $<0.32$ & 1.1 & $<0.30$ & - & $<0.35$ & 0.60 & $<0.26$ \\
\hline 248.869 & $29_{0,29}-28_{0,28}$ & $<0.32$ & 1.2 & $<0.30$ & - & $<0.35$ & 1.1 & $<0.26$ \\
\hline 339.895 & $39_{2,38}-38_{2,37}$ & $<0.30$ & 1.2 & $<0.21$ & 2.8 & $<0.36$ & $<0.39$ & $<0.21$ \\
\hline 339.968 & $38_{2,36}-37_{2,35}$ & $<0.30$ & 1.4 & $<0.21$ & 2.9 & $<0.36$ & $<0.39$ & $<0.21$ \\
\hline 340.149 & $39_{1,38}-38_{1,37}$ & $<0.36$ & 1.0 & $<0.26$ & $<0.62$ & $<0.41$ & $<0.36$ & $<0.23$ \\
\hline 340.433 & $38_{12,26 / 27}-37_{12,25 / 26}$ & $<0.36$ & 0.63 & $<0.26$ & 1.1 & $<0.41$ & $<0.36$ & $<0.23$ \\
\hline 340.483 & $38_{10,28 / 29}-37_{10,27 / 28}$ & $<0.36$ & 0.83 & $<0.26$ & 1.4 & $<0.41$ & $<0.36$ & $<0.23$ \\
\hline 340.551 & $38_{15,23 / 24}-37_{15,22 / 23}$ & $<0.36$ & $<0.35$ & $<0.26$ & 0.63 & $<0.41$ & $<0.36$ & $<0.23$ \\
\hline 340.576 & $38_{9,29 / 30}-37_{9,28 / 29}$ & $<0.36$ & 0.85 & $<0.26$ & $<0.62$ & $<0.41$ & $<0.36$ & $<0.23$ \\
\hline 346.712 & $25_{8,17 / 18}-25_{7,18 / 19}$ & $<0.26$ & $<0.47$ & $<0.36$ & 1.9 & $<0.24$ & $<0.32$ & $<0.23$ \\
\hline 346.864 & $22_{8,14 / 15}-22_{7,15 / 16}$ & $<0.26$ & $<0.47$ & $<0.36$ & 0.96 & $<0.24$ & $<0.32$ & $<0.23$ \\
\hline 346.874 & $38_{4,34}-37_{4,33}$ & $<0.26$ & 0.82 & $<0.36$ & 2.4 & $<0.24$ & $<0.32$ & $<0.23$ \\
\hline 346.898 & $21_{8,13 / 14}-21_{7,14 / 15}$ & $<0.26$ & 0.49 & $<0.36$ & 1.8 & $<0.24$ & $<0.32$ & $<0.23$ \\
\hline 346.925 & $20_{8,12 / 13}-20_{7,13 / 14}$ & $<0.26$ & $<0.47$ & $<0.36$ & 0.93 & $<0.24$ & $<0.32$ & $<0.23$ \\
\hline 348.261 & $39_{2,37}-38_{2,36}$ & $<0.23$ & 1.8 & $<0.21$ & 3.6 & $<0.27$ & $<0.32$ & $<0.26$ \\
\hline 348.345 & $40_{1,39}-39_{1,38}$ & $<0.23$ & 1.2 & $<0.21$ & 3.5 & $<0.27$ & $<0.32$ & $<0.26$ \\
\hline 353.089 & $23_{3,20}-22_{2,21}$ & $<0.32$ & 0.27 & $<0.51$ & 0.58 & $<0.30$ & $<0.29$ & $<0.42$ \\
\hline 353.235 & $11_{6,5 / 6}-10_{5,6 / 5}$ & $<0.32$ & $<0.23$ & $<0.51$ & 2.9 & $<0.30$ & $<0.29$ & $<0.42$ \\
\hline
\end{tabular}

- means frequency not observed. ${ }^{a}$ Blend with $\mathrm{NH}_{2} \mathrm{CHO}$. 
S. E. Bisschop et al.: Testing grain-surface chemistry in massive hot-core regions, Online Material p 19

Table B.12. Observed line fluxes $\int T_{\mathrm{MB}} \mathrm{d} V\left(\mathrm{~K} \mathrm{~km} \mathrm{~s}^{-1}\right)$ for $\mathrm{CH}_{3} \mathrm{CCH}$.

\begin{tabular}{|c|c|c|c|c|c|c|c|c|}
\hline $\begin{array}{l}\text { Frequency } \\
{[\mathrm{GHz}]}\end{array}$ & Transition & AFGL 2591 & $\mathrm{G} 24.78$ & G75.78 & $\begin{array}{c}\text { Sources } \\
\text { NGC } 6334 \text { IRS1 }\end{array}$ & NGC 7538 IRS1 & $\mathrm{W} 3\left(\mathrm{H}_{2} \mathrm{O}\right)$ & W33A \\
\hline 222.014 & $13_{6}-12_{6}$ & $<0.23$ & $<0.27$ & $<0.25$ & 0.51 & $<0.41$ & $<0.27$ & $<0.25$ \\
\hline 222.061 & $13_{5}-12_{5}$ & $<0.23$ & 0.18 & $<0.25$ & $<0.59$ & $<0.41$ & $<0.27$ & $<0.25$ \\
\hline 222.099 & $13_{4}-12_{4}$ & $<0.23$ & 0.44 & $<0.25$ & 1.2 & 0.19 & 0.49 & $<0.25$ \\
\hline 222.129 & $13_{3}-12_{3}$ & 0.63 & 2.5 & 0.54 & 7.6 & 0.92 & 2.0 & 0.58 \\
\hline 222.150 & $13_{2}-12_{2}$ & 0.87 & 2.2 & 0.81 & 7.2 & 1.2 & 2.1 & 0.89 \\
\hline 222.163 & $13_{1}-12_{1}$ & 1.2 & 4.3 & 1.0 & 8.1 & 1.7 & 1.7 & 1.9 \\
\hline 222.167 & $13_{0}-12_{0}$ & 1.5 & 3.4 & 1.5 & 8.1 & 1.2 & 3.2 & 2.0 \\
\hline 239.088 & $14_{6}-13_{6}$ & - & 0.46 & $<0.17$ & - & - & $<0.32$ & $<0.34$ \\
\hline $239.138^{a}$ & $14_{5}-13_{5}$ & - & 0.69 & 0.98 & - & - & $<0.32$ & $<0.34$ \\
\hline 239.179 & $14_{4}-13_{4}$ & - & 0.62 & $<0.17$ & - & - & 0.70 & $<0.34$ \\
\hline 239.211 & $14_{3}-13_{3}$ & - & 2.6 & 1.4 & - & - & 1.9 & 0.86 \\
\hline 239.234 & $14_{2}-13_{2}$ & - & 3.2 & 1.4 & - & - & $8.0^{b}$ & 1.3 \\
\hline 239.248 & $14_{1}-13_{1}$ & - & 4.0 & 1.6 & - & - & 1.5 & 1.9 \\
\hline 239.252 & $14_{0}-13_{0}$ & - & 4.4 & 2.1 & - & - & 3.4 & 2.0 \\
\hline
\end{tabular}

- means frequency not observed. ${ }^{a}$ Blend with $\mathrm{CH}_{3} \mathrm{CN} .{ }^{b}$ Blend with OCS at $231062 \mathrm{MHz}$ in the main sideband. 
S. E. Bisschop et al.: Testing grain-surface chemistry in massive hot-core regions, Online Material p 20

Table B.13. Observed line fluxes $\int T_{\mathrm{MB}} \mathrm{d} V\left(\mathrm{~K} \mathrm{~km} \mathrm{~s}^{-1}\right)$ for $\mathrm{HCOOCH}_{3}$ for the $230 \mathrm{GHz}$ band.

\begin{tabular}{|c|c|c|c|c|c|c|c|c|}
\hline $\begin{array}{l}\text { Frequency } \\
{[\mathrm{GHz}]}\end{array}$ & Transition & AFGL 2591 & $\mathrm{G} 24.78$ & G75.78 & $\begin{array}{c}\text { Sources } \\
\text { NGC 6334 IRS1 }\end{array}$ & NGC 7538 IRS1 & $\mathrm{W} 3\left(\mathrm{H}_{2} \mathrm{O}\right)$ & W33A \\
\hline 211.537 & $17_{6,11}-16_{6,10} \mathrm{E}$ & $<0.36$ & - & - & 8.6 & - & - & $<0.14$ \\
\hline 211.575 & $17_{6,11}-16_{6,10} \mathrm{~A}$ & $<0.36$ & - & - & 6.3 & - & - & 0.19 \\
\hline 211.771 & $17_{5,13}-16_{5,12} E$ & $<0.36$ & - & - & 6.2 & - & - & $<0.14$ \\
\hline 211.785 & $17_{5,13}-16_{5,12} \mathrm{~A}$ & $<0.36$ & - & - & 6.2 & - & - & $<0.14$ \\
\hline 218.281 & $17_{1,16}-16_{1,15} \mathrm{E}$ & - & 0.48 & $<0.41$ & - & - & - & - \\
\hline 218.297 & $17_{3,14}-16_{3,13} \mathrm{~A}$ & - & 0.46 & $<0.41$ & - & - & - & - \\
\hline 220.167 & $17_{2,15}-16_{4,12} \mathrm{E}$ & $<0.24$ & 0.82 & $<0.36$ & 7.1 & 0.42 & 0.98 & $<0.24$ \\
\hline 220.190 & $17_{4,13}-16_{4,12} \mathrm{~A}$ & $<0.24$ & 0.67 & $<0.36$ & 6.4 & 0.66 & $<0.33$ & $<0.24$ \\
\hline 221.979 & $18_{9,9 / 10}-17_{9,8 / 9} \mathrm{~A}$ & $<0.39$ & 0.71 & $<0.32$ & 5.7 & 0.84 & 1.1 & $<0.32$ \\
\hline 223.125 & $18_{7,11}-17_{7,10} \mathrm{E}$ & $<0.32$ & - & - & 7.2 & 0.30 & - & - \\
\hline 223.135 & $18_{7,12}-17_{7,11}$ & $<0.32$ & - & - & 8.9 & $<0.43$ & - & - \\
\hline 223.163 & $18_{7,11}-17_{7,10} \mathrm{~A}$ & $<0.32$ & - & - & $<1.3$ & 0.14 & - & - \\
\hline 225.609 & $19_{3,16}-18_{3,15} \mathrm{E}$ & $<0.41$ & $<0.27$ & $<0.24$ & 4.9 & $<0.32$ & 1.2 & 0.39 \\
\hline 225.619 & $19_{3,17}-18_{3,16} \mathrm{~A}$ & $<0.41$ & 1.0 & $<0.24$ & 5.7 & $<0.32$ & 1.9 & 0.18 \\
\hline 226.713 & $20_{2,18}-19_{2,18} E$ & $<0.30$ & 0.65 & $<0.21$ & 9.1 & 0.56 & 0.60 & $<0.30$ \\
\hline 226.719 & $20_{2,19}-19_{2,18} \mathrm{~A}$ & $<0.30$ & 1.3 & $<0.21$ & 14 & 0.66 & 0.73 & 0.52 \\
\hline 226.773 & $20_{3,18}-19_{3,17} \mathrm{E}$ & $<0.30$ & $<0.30$ & $<0.21$ & $<1.4$ & 0.44 & $<0.35$ & $<0.30$ \\
\hline 226.779 & $20_{1,19}-19_{1,18} \mathrm{~A}$ & $<0.30$ & $<0.30$ & $<0.21$ & $<1.4$ & 0.53 & $<0.35$ & $<0.30$ \\
\hline 227.561 & $21_{1,21}-20_{1,20} \mathrm{E}^{a}$ & - & 5.3 & 0.73 & - & 1.4 & 6.1 & 0.34 \\
\hline 233.247 & $19_{16,3 / 4}-18_{16,2 / 3} \mathrm{~A}$ & $<0.41$ & $<0.27$ & $<0.24$ & 1.5 & $<0.32$ & $<0.21$ & $<0.29$ \\
\hline 233.256 & $19_{16,3}-18_{16,2} \mathrm{E}$ & $<0.41$ & $<0.27$ & $<0.24$ & 3.0 & $<0.32$ & $<0.21$ & $<0.29$ \\
\hline 233.269 & $19_{16,4}-18_{16,3} \mathrm{E}$ & $<0.41$ & $<0.27$ & $<0.24$ & 1.3 & $<0.32$ & $<0.21$ & $<0.29$ \\
\hline 233.310 & $19_{15,4 / 5}-18_{15,3 / 4} \mathrm{~A}$ & $<0.41$ & $<0.27$ & $<0.24$ & 3.1 & $<0.32$ & $<0.21$ & $<0.29$ \\
\hline 233.316 & $19_{15,4}-18_{15,3} \mathrm{E}$ & $<0.41$ & $<0.27$ & $<0.24$ & 2.0 & $<0.32$ & $<0.21$ & $<0.29$ \\
\hline 233.331 & $19_{15,5}-18_{15,4} \mathrm{E}$ & $<0.41$ & $<0.27$ & $<0.24$ & 2.3 & $<0.32$ & $<0.21$ & $<0.29$ \\
\hline 233.395 & $19_{14,5 / 6}-18_{14,4 / 5} \mathrm{~A}^{b}$ & $<0.41$ & $<0.27$ & $<0.24$ & 4.0 & $<0.32$ & $<0.21$ & $<0.29$ \\
\hline 233.414 & $19_{14,6}-18_{14,5} \mathrm{E}$ & $<0.41$ & $<0.27$ & $<0.24$ & 2.1 & $<0.32$ & $<0.21$ & $<0.29$ \\
\hline 233.505 & $19_{13,6}-18_{13,5} \mathrm{E}^{c}$ & $<0.41$ & 1.4 & $<0.24$ & 6.1 & $<0.32$ & 1.6 & $<0.29$ \\
\hline 233.525 & $19_{13,7}-18_{13,6} E$ & $<0.41$ & 0.72 & $<0.24$ & 2.8 & $<0.32$ & $<0.21$ & 0.40 \\
\hline 233.649 & $19_{12,7}-18_{12,6} \mathrm{E}$ & $<0.41$ & 0.22 & $<0.24$ & $<0.74$ & $<0.32$ & $<0.21$ & $<0.29$ \\
\hline 233.655 & $19_{12,7 / 8}-18_{12,6 / 7} \mathrm{~A}$ & $<0.41$ & $1.5^{d}$ & $<0.24$ & 4.4 & $<0.32$ & $<0.21$ & $<0.29$ \\
\hline 233.671 & $19_{12,8}-18_{12,7} \mathrm{E}$ & $<0.41$ & 0.18 & $<0.24$ & 2.3 & $<0.32$ & $<0.21$ & 0.17 \\
\hline 233.754 & $18_{2,16}-17_{2,15} \mathrm{E}$ & $<0.41$ & 1.1 & $<0.24$ & 7.5 & $<0.32$ & $<0.21$ & $<0.29$ \\
\hline 234.502 & $19_{9,10 / 11}-18_{9,9 / 10} \mathrm{~A}$ & $<0.30$ & 0.94 & $<0.21$ & 7.3 & 0.41 & $<0.35$ & $<0.30$ \\
\hline 240.021 & $19_{1,18}-18_{1,17} \mathrm{E}$ & $<0.30$ & 1.1 & $<0.26$ & 6.8 & 0.72 & $<0.42$ & $<0.41$ \\
\hline 240.035 & $19_{3,16}-18_{3,15} \mathrm{~A}$ & $<0.30$ & 1.1 & $<0.26$ & 7.0 & 0.68 & 1.1 & 0.29 \\
\hline 248.617 & $20_{7,14}-19_{7,13} \mathrm{~A}$ & $<0.32$ & 0.69 & $<0.30$ & - & $<0.35$ & 0.91 & $<0.26$ \\
\hline 248.634 & $20_{7,14}-19_{7,13} \mathrm{E}$ & $<0.32$ & 0.94 & $<0.30$ & - & $<0.35$ & 0.96 & $<0.26$ \\
\hline 248.744 & $20_{7,13}-19_{7,12} \mathrm{E}$ & $<0.32$ & $<0.33$ & $<0.30$ & - & 0.69 & $<0.45$ & $<0.26$ \\
\hline 248.750 & $23_{2,22}-22_{1,22} \mathrm{E}^{e}$ & $<0.32$ & 3.8 & $<0.30$ & - & 1.3 & 2.0 & $<0.26$ \\
\hline 248.787 & $20_{7,13}-19_{7,12} \mathrm{~A}$ & $<0.32$ & $<0.33$ & $<0.30$ & - & 0.24 & $<0.45$ & $<0.26$ \\
\hline 249.031 & $20_{5,16}-19_{5,15} \mathrm{E}$ & $<0.32$ & 0.51 & $<0.30$ & - & $<0.35$ & 0.33 & $<0.26$ \\
\hline 249.047 & $20_{5,16}-19_{5,15} \mathrm{~A}$ & $<0.32$ & 0.77 & $<0.30$ & - & $<0.35$ & 0.59 & $<0.26$ \\
\hline
\end{tabular}

- means frequency not observed. ${ }^{a}$ Blend with $21_{2,20}-20_{2,19}$ E, $21_{1,21}-20_{1,20}$ A, and $21_{0,21}-20_{0,20}$ A. ${ }^{b}$ Blend with line at $23339719_{14,5}-18_{14,4}$ E. ${ }^{c}$ Blend with $19_{13,6}-18_{13,5}$ A, and $19_{13,7}-18_{13,6}$ A. ${ }^{d}$ Blend with $\mathrm{C}_{2} \mathrm{H}_{5} \mathrm{CN}$. ${ }^{e}$ Blend with $23_{1,23}-22_{122}$ E, $23_{2,22}-22_{2,21}$ E, $23_{1,23}-22_{2,21}$ E. 
S. E. Bisschop et al.: Testing grain-surface chemistry in massive hot-core regions, Online Material p 21

Table B.14. Observed line fluxes $\int T_{\mathrm{MB}} \mathrm{d} V\left(\mathrm{~K} \mathrm{~km} \mathrm{~s}^{-1}\right)$ for $\mathrm{HCOOCH}_{3}$ in the $345 \mathrm{GHz}$ band.

\begin{tabular}{|c|c|c|c|c|c|c|c|c|}
\hline \multirow{2}{*}{$\begin{array}{l}\text { Frequency } \\
{[\mathrm{GHz}]}\end{array}$} & \multirow{2}{*}{ Transition } & \multicolumn{7}{|c|}{ Sources } \\
\hline & & AFGL 2591 & $\mathrm{G} 24.78$ & G75.78 & NGC 6334 IRS1 & NGC 7538 IRS1 & $\mathrm{W} 3\left(\mathrm{H}_{2} \mathrm{O}\right)$ & W33A \\
\hline 338.356 & $27_{8,19}-26_{8,18} E$ & $<0.30$ & $<0.30$ & $<0.20$ & 8.8 & 0.23 & 1.6 & $<0.29$ \\
\hline 338.397 & $27_{7,21}-26_{7,20} \mathrm{E}$ & $<0.30$ & $<0.30$ & 0.13 & 11 & 0.85 & $<0.30$ & $<0.29$ \\
\hline 340.221 & $31_{13,19}-31_{12,19} \mathrm{E}^{a}$ & $<0.36$ & $<0.35$ & $<0.26$ & 2.7 & $<0.41$ & $<0.36$ & $<0.23$ \\
\hline 345.069 & $28_{14,14}-27_{14,13} E^{b}$ & $<0.29$ & 1.7 & $<0.30$ & 14 & $<0.33$ & 1.5 & $<0.24$ \\
\hline 345.090 & $28_{14,15}-27_{14,14} E$ & $<0.29$ & 0.69 & $<0.30$ & 8.2 & $<0.33$ & 0.78 & $<0.24$ \\
\hline 345.281 & $18_{13,5 / 6}-18_{12,6 / 7} \mathrm{~A}$ & $<0.29$ & $<0.27$ & $<0.30$ & 3.5 & $<0.33$ & $<0.21$ & $<0.24$ \\
\hline 345.462 & $28_{13,15}-27_{13,14} \mathrm{E}$ & $<0.29$ & $<0.27$ & $<0.30$ & 4.8 & $<0.33$ & $<0.21$ & $<0.24$ \\
\hline 345.467 & $28_{13,15 / 16}-27_{13,14 / 15} \mathrm{~A}$ & $<0.29$ & 1.1 & $<0.30$ & 8.9 & $<0.33$ & 0.32 & $<0.24$ \\
\hline 345.486 & $28_{13,16}-27_{13,15} \mathrm{E}$ & $<0.29$ & 0.16 & $<0.30$ & 5.7 & $<0.33$ & $<0.21$ & $<0.24$ \\
\hline 345.975 & $28_{12,16}-27_{12,15} \mathrm{E}$ & - & - & - & - & 0.68 & $<0.29$ & - \\
\hline 345.985 & $28_{12,16 / 17}-27_{12,15 / 16} \mathrm{~A}$ & - & - & - & - & 0.78 & 2.0 & - \\
\hline 346.001 & $28_{12,17}-27_{12,16} \mathrm{E}$ & - & - & - & - & 0.39 & 0.64 & - \\
\hline 346.660 & $28_{11,17}-27_{11,16} \mathrm{E}$ & $<0.26$ & $<0.47$ & $<0.36$ & 7.5 & 0.67 & $<0.32$ & $<0.23$ \\
\hline 346.675 & $28_{11,17 / 18}-27_{11,16 / 17} \mathrm{~A}$ & $<0.26$ & 1.1 & $<0.36$ & 11 & 0.67 & $<0.32$ & $<0.23$ \\
\hline 346.687 & $28_{11,18}-27_{11,17} \mathrm{E}$ & $<0.26$ & 0.27 & $<0.36$ & 6.7 & 0.31 & $<0.32$ & $<0.23$ \\
\hline 348.050 & $28_{4,24}-27_{4,23} \mathrm{E}$ & $<0.23$ & 1.8 & 0.11 & 12 & 0.73 & 1.5 & $<0.26$ \\
\hline 348.066 & $28_{6,23}-27_{6,22} \mathrm{~A}$ & $<0.23$ & 1.6 & $<0.32$ & 11 & 0.60 & 1.3 & $<0.26$ \\
\hline 348.909 & $28_{9,20}-27_{9,19} \mathrm{E}$ & $<0.23$ & 1.2 & $<0.32$ & $<0.43$ & $<0.33$ & $<0.36$ & $<0.30$ \\
\hline 348.915 & $28_{9,20}-27_{9,19} \mathrm{~A}$ & $<0.23$ & 1.5 & $<0.32$ & 7.7 & $<0.33$ & $<0.36$ & $<0.30$ \\
\hline 356.215 & $29_{21,8 / 9}-28_{21,7 / 8} \mathrm{~A}$ & $<0.36$ & $<0.47$ & $<0.53$ & 2.6 & $<0.41$ & $<0.36$ & $<0.68$ \\
\hline 356.297 & $29_{20,9 / 10}-28_{20,8 / 9} \mathrm{~A}$ & $<0.36$ & 0.49 & $<0.53$ & 6.3 & 0.30 & $<0.36$ & $<0.68$ \\
\hline 356.404 & $29_{19,10 / 11}-28_{19,9 / 10} \mathrm{~A}$ & $<0.36$ & $<0.47$ & $<0.53$ & 4.2 & $<0.41$ & $<0.36$ & $<0.68$ \\
\hline
\end{tabular}

- means frequency not observed. ${ }^{a}$ Blend with $31_{13,18}-31_{12,19}$ A, and $31_{13,19}-31_{12,20}$ A. ${ }^{b}$ Blend with $28_{14,14}-27_{14,13}$ A, and $28_{14,15}-27_{14,14}$ A.

Table B.15. Observed line fluxes $\int T_{\mathrm{mb}} \mathrm{d} V\left(\mathrm{~K} \mathrm{~km} \mathrm{~s}^{-1}\right)$ for $\mathrm{CH}_{3} \mathrm{OCH}_{3}$.

\begin{tabular}{|c|c|c|c|c|c|c|c|c|}
\hline $\begin{array}{l}\text { Frequency } \\
\text { [GHz] }\end{array}$ & Transition & AFGL 2591 & G24.78 & G75.78 & $\begin{array}{c}\text { Sources } \\
\text { NGC 6334 IRS1 }\end{array}$ & NGC 7538 IRS1 & $\mathrm{W} 3\left(\mathrm{H}_{2} \mathrm{O}\right)$ & W33A \\
\hline 222.029 & $21_{2,20,2 / 3}-21_{1,21,2 / 3}$ & $<0.39$ & 0.26 & $<0.32$ & 3.1 & $<0.41$ & 0.42 & $<0.25$ \\
\hline 222.035 & $21_{2,20,0 / 1}-21_{1,21,0 / 1}$ & $<0.39$ & 0.72 & $<0.32$ & 2.5 & $<0.41$ & 0.37 & $<0.25$ \\
\hline 222.239 & $4_{3,2,2}-3_{2,1,2}$ & $<0.39$ & 0.16 & $<0.32$ & 1.6 & $<0.41$ & $<0.27$ & $<0.25$ \\
\hline 222.248 & $4_{3,2,1 / 3}-3_{2,1,1 / 3}$ & $<0.39$ & 0.86 & $<0.32$ & 5.3 & $<0.41$ & 0.37 & 0.37 \\
\hline 222.255 & $4_{3,2,0}-3_{2,1,0}$ & $<0.39$ & 0.53 & $<0.32$ & 4.7 & $<0.41$ & 0.50 & 0.18 \\
\hline 222.259 & $4_{3,1,1 / 2}-3_{2,1,1 / 2}$ & $<0.39$ & 0.60 & $<0.32$ & 2.6 & $<0.41$ & 0.48 & 0.18 \\
\hline 222.326 & $25_{3,23, K}-24_{4,20,0}$ & $<0.39$ & 0.15 & $<0.32$ & 2.3 & $<0.41$ & $<0.27$ & $<0.25$ \\
\hline 225.599 & $12_{1,12, K}-11_{0,11, K}$ & $<0.41$ & 3.1 & 0.73 & 11.8 & 0.83 & 4.0 & 1.0 \\
\hline 226.347 & $14_{1,13, K}-13_{2,12, K}$ & - & 1.5 & $<0.41$ & - & - & - & - \\
\hline 227.648 & $26_{5,21, K}-26_{4,22, K}$ & - & 0.40 & $<0.26$ & - & $<0.32$ & $<0.39$ & - \\
\hline 227.658 & $24_{3,22,0 / 1}-24_{2,23,0 / 1}$ & - & 0.81 & $<0.26$ & - & $<0.32$ & $<0.39$ & - \\
\hline 230.140 & $17_{2,15, K}-16_{3,14, K}$ & $<0.39$ & 1.7 & $<0.32$ & 3.3 & $<0.41$ & 1.4 & $<0.25$ \\
\hline 233.633 & $25_{5,20, K}-25_{4,21, K}$ & $<0.15$ & 1.1 &, 0.24 & 2.6 & $<0.32$ & 0.46 & $<0.23$ \\
\hline 240.978 & $5_{3,3,2}-4_{2,2,2}$ & $<0.32$ & $a$ & $<0.30$ & 2.6 & $<0.35$ & $<0.45$ & $<0.26$ \\
\hline 240.985 & $5_{3,3,1}-4_{2,2,1}$ & $<0.32$ & $3.4^{a}$ & $<0.30$ & 8.3 & 0.41 & 2.8 & 0.56 \\
\hline 240.990 & $5_{3,3,0}-4_{2,2,0}$ & $<0.32$ & $a$ & $<0.30$ & 3.3 & $<0.35$ & $<0.45$ & 0.19 \\
\hline
\end{tabular}

- means frequency not observed. $\mathrm{K}$ is either $0,1,2$, or $3 .{ }^{a} 5_{3,3,1}-4_{2,2,1}$ transition is blended with $5_{3,3,2}-4_{2,2,2}$ and $5_{3,3,0}-4_{2,2,0}$. 